\title{
Environmental Assessment for the Satellite Power System Concept Development and Evaluation Program-Electromagnetic Systems Compatibility
}

January 1981

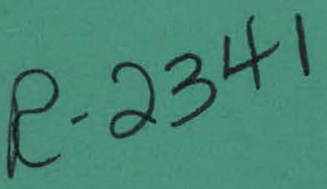

Prepared for:

U.S. Department of Energy

Office of Energy Research

Solar Power Satellite Proiects Division

Under Contract No. KD-03-82029

DOE/NASA

Satellite Power System

Concept Development

and

Evaluation Program 


\section{DISCLAIMER}

This report was prepared as an account of work sponsored by an agency of the United States Government. Neither the United States Government nor any agency Thereof, nor any of their employees, makes any warranty, express or implied, or assumes any legal liability or responsibility for the accuracy, completeness, or usefulness of any information, apparatus, product, or process disclosed, or represents that its use would not infringe privately owned rights. Reference herein to any specific commercial product, process, or service by trade name, trademark, manufacturer, or otherwise does not necessarily constitute or imply its endorsement, recommendation, or favoring by the United States Government or any agency thereof. The views and opinions of authors expressed herein do not necessarily state or reflect those of the United States Government or any agency thereof. 


\section{DISCLAIMER}

Portions of this document may be illegible in electronic image products. Images are produced from the best available original document. 
NOTICE

This report was prepared as an account of work sponsored by the United States Government. Neither the United States nor the United States Department of Energy, nor any of their employees, makes any warranty, express or implied, or assumes any legal liability or responsibility for the accuracy, completeness, or usefulness of any information, apparatus, product, or process disclosed, or represents that its use would not infringe privately owned rights. Reference herein to any specific commercial product, process, or service by trade name, mark, manufacturer, or otherwise, does not necessarily constitute or imply its endorsement, recommendation, or favoring by the United States Government or any agency thereof. The views and opinions of authors expressed herein do not necessarily state or reflect those of the United States Government or any agency thereof.

Avallable from:

National Technical Information Service (NIIS)

U.S. Department of Commerce

5285 Port Royal Road

Price: Printed Copy: $\$ 9.50$

$$
\begin{aligned}
& \text { Printed Copy: } \\
& \text { Microfiche: }
\end{aligned}
$$


DOE/ER-0096

Dist. Category UC-97

\section{Environmental Assessment for the Satellite Power System Concept Development and Evaluation Program-Electromagnetic Systems Compatibility}

January 1981

Prepared by:

K.A. Davis

Pacific Northwest Laboratory

Richland, WA 99353

and

W.B. Grant, E. L. Morrison and J. R. Juroshek

Institute for Telecommunications Sciences

Boulder, $\mathrm{CO} 80303$

Under Contract No. KD-03-82029

Prepared for:

U.S. Department of Energy .

Office of Energy Research

Solar Power Satellite Projects Division

Washington, D.C. 20585

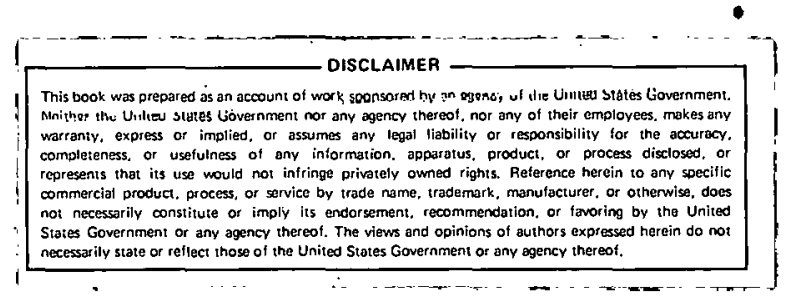

DOE/NASA

Satellite Power System

Concept Development

and

Evaluation Program 


\section{EXECUTIVE SUMMARY}

1.0 INTRODUCTION

2.0 METHODOLOGY

2.1 EQUIPMENT CATEGORIES

2.2 RECTENNA SITES

2.3 MITIGATION

3.0 SPS EMISSIONS AND MEDIA EFFECTS

3.1 ELECTROMAGNETIC FIELDS DUE TO THE MICROWAVE POWER TRANSMISSION SYSTEM

3.2 MEDIA EFFECTS

3.3 MICROWAVE FIELDS IN STTRUCTURES

3.4 THERMAL BLACKBODY RADIATION

3.5 SCATTERED SUNLIGHT

4.0 EFFECTS ON MAJOR EQUIPMENT CATEGORIES

4.1 COMMUNICATION RECEIVERS

4.2 RADAR SYSTEMS

4.3 COMPUTERS AND PROCESSORS

4.4 INTEGRATED CIRCUITS

4.5 OPTICAL SENSORS

4.6 MEDICAL ELECTRONIC DEVICES

4.6.1 Caradic Pacemakers

4.6.2 EMC Standards for Medical Electronfc Devices

4.6.3 Conclusions

6.1 COMMUNICATIONS RECEIVERS

6.2 MINICOMPUTERS AND MICROPROCESSORS

6.3 OPTICAL SENSORS

6.4 RADAR RECEI'ERS

6.5 GEOGRAPHIC SEPARATION

7.0 ALTERNATE FREQUENCY ANALYSIS

8.0 MOJAVE SITF. ANALYSIE

8.1 APPROACH

8.2 RECEIVERS

8.3 MILITARY SIGNAL MONITORS

8.4 SENSOR EVALUATION

8.5 COMPUTER AND PROCESSOR EVALUATION

8.6. RANGE INSTRUMENTATION

8.7 OPERATIONAL SYSTEMS

8.8 EFFECTS AND IMPACTS

8.9 CONCLUSIONS AND RECOMMENDATIONS 
9.1.1 GPS Navigation Terminal

9.1.2 MARISAT Ship Terminals

9.2 GEOSTATIONARY SATELLITES

9.2.1 INTELSAT Satellite

9.2.2 TDRSS Satellite

9.3 SATELLITES IN LOW EARTH ORBIT

9.3.1 LANDSAT Satellite

9.3.2 GPS Satell,ite

9.3.3 Space Telescope

9.3.4 Summary of LEO Effects and Mitigation.

9.4 OTHER POTENTIAL INTERFERENCE CONSIDERATIONS FOR

0.5 . EITTIRF, SATELLITE SYSTEMS

9.6 CONCLUSIONS AND RECȮMENDA'ILUNS

10.0 EFFECTS ON · ASTRONOMY AND RELATED RESEARCH • 71

10.1 RADTO ASTRONOMY AND DEEP SPACE RESEARCH 72

10.2 OPTICAL ASTRONOMY

10.2.1 Major Research Areas •

10.2.1.1 Cosmology and Extragalactic Astronomy

10.2.1.2 The Milky Way .

$\begin{array}{lll}10.2 .1 .3 & \text { Solar System } & 77\end{array}$

10.2.2 Effects of SPS on Optical Observations 77

LU. 3 AEROHOHY

$\begin{array}{lll}10.4 \text { MIIIGATION } & 81\end{array}$

11.0 CONGI.USIONS AND RECOMMNDATIONS

11.1 CONCLUSIONS $\quad .02$

11.2 RECOMMENDATIONS $\quad \cdot 23$

$\triangle$ ARBREVIATIONS $\quad \cdot \quad . \quad . \quad 85$

REFERENCES

87 
'he effects of the Satellite Power System (SPS) and its microwave power transmission system (MPTS) on ther electromagnetic and electronic systems were analyzed as one of the flve tasks of the Environmental Assessment part of the SPS Concept Development and Evaluation Program. The very large quantities of electromagnetic power that would be transmitted by SPS prompt important questions as to its compatibility with electronic systems on which our modern soclety is heavily dependent. Electromagnetic compatibility (EMC) analysis is a well-developed discipline and existing techniques are adequate for an accurate prediction of SPS effects. The SPS EMC Assessment is limited at this time by two major factors: incomplete data on some important aspects of the MPTS performance and the unusually wide scope of potential effects, which has precluded an exhaustive analysis.

There were two major phases in the EMC Assessment: computations of the changes that SPS would produce in the electromagnetic environment and evaluation of the effects of these changes on other electromagnetic and electronic systems. The electromagnetic environment would be changed both by direct emissions from SPS and by modification of these emissions by other factors such as scattering in the atmosphere. Computation of emissions has been based as far as possible on the system described in the Reference System Report of October 1978 (DOE/ER-0023), with some additional information from later NASA concept development efforts. In some important areas, it has been necessary to extrapolate SPS performance from that. of existing systems that use similar technology. Although some of the quantitative conclusions such as geographic ranges of particular effects are specific to the Reference System, the assessment was done parametrically so that conclusions can easily be re-evaluated as SPS concepts evolve or new data become available.

Satellite power system EMC emissions can be grouped-into four categories: those at the intended power transmission frequency, spurlous microwave emissions at frequencles outside the intended bandwidth, emissions from warm space structures, and sunlight scattered from those structures. Some microwave power will unavoldably escape from the power transmission system. The amount and spatial distribution of this lost power have been analyzed in detall because of their importance to sps performance. Th1s lost power Is also the basls for most of the EMC concerns that are pecullar to the SPS concept. The assessment focused on the effects of emissions at the power transfer frequency both because of their unique relation to the SPS and because they are relatively well defined at the present stage of SPS concept development. The high total power transmitted by SPS means that the escape of even a small percentage can be a source of significant interference to other systems. The density of escaping microwave power is highest near rectenna sites, falling off rapidly with distances from the rectenna.

Emissions outside a bandwidth assigned to power transmission are of concern because of the unprecedented power levels of an SPS which could cause potentlal interference to other spectrum isers over a hemisphere. Most spectrum use is controlied and protected by detalled international agreements which include limits on Interference (International Telecommunication Union Radio Regulations). There 1s, at present, no provision in these agreements for space-to-earth microwave power transmission. The EMC assessment has assumed that a frequency band from 2.40 to $2.50 \mathrm{GHz}$ would be assigned to SPS. The strength and spat lal distribution of SPS emissions outside this assumed band is not now known and could only be determined with confidence by building and testing representative SPS components. Because firm data are lacking and because potent lal problems from SPS spurious emissions are similar to those.from other systems, the assessment in this area has been confined to 1dentifying major potential problems and recommending that limitation of spurious emission to noninterfering levels be an SPS design goal. A further assessment of this area would be needed if the SPS concept is to be pursued.

The large photovoltaic arrays and other components of SPS strurturee would emit broad-band thermal and microwave radiation, This radintion cuuld, according to present estimates, be a significant source of incerference to sensitive receiving systems such $a s$ are used in radio astronomy, deep space research,' and some satellite communications when the directional antennas of these systems are pointed near an SPS.

Sunlight scattered from the very large areas of the SPS solar collectors can cause the structures to appear as very bright objects in the night sky. For the Reference System, with an est1mated. $4 \%$ diffuse reflectivity for the photovoltaic cells, each structure would be as bright as the planet Venus ever appears, brighter than any object in the sky except the sun or moon. This amount of scattered $11 \mathrm{ght}$ would have a severe impact on scientific observations requiring dark night skies.

The effects of SP3-produced changes in the electromagnetic environment on other systems were evaluated in two closely related studies. Electromagnetic compatibility problems at five hypothet ical rectenna locations were analyzed to illustrate site-specific problems, and effects on representative items in important categories of electronic systems were determined to ascertain the overall extent of SPS EMC problems. At the first hypothetical rectenna site considered in California's Mojave Desert, unacceptable impacts on military test facilities were identifled which could only be mitigated by changing the rectenna location. 
Electromagnetic compatibility was thus demonstrated to be an important factor in rectenna site selection. Specific recommended separation distances of from 50 to $150 \mathrm{~km}$ between rectennas and sensitive faciliti such as nuclear reactors and radio astronomy observations have been provided for rectenna siting studie

Tests and analyses of the interference susceptibility of Important categorles of electronic systems and equipment including radar, communications, computers, and sensors were performed to obtain a general assessment of EMC problems. Systems include current designs and to the extent practical, evaluation of the impacts on advanced electronic technologies. Techniques for mitigating potentfal effects were also evaluated. It was found that many items would be affected at ranges up to about $50 \mathrm{~km}$ from rectenna sites, and some particularly sensitive equipment would experience interference at greater ranges. In many cases, straightforward modifications such as improved shielding or minor circult changes could substantially eliminate interference. Some sensitive microwave recelvers would require more extensive changes such as additional filters to reject SPS inputs.

Many of the satellites in orbits lower than SPS position would occaslonally pass through an SPS power beam and thus encounter intense microwave flelds for perlods of a few seconds. Some of the electronic systems on these satellites would experfence interference and a temporary degradation in performance during this period. Improved electromagnetic shielding and other minor modifications would be expected to eliminate or substantially reduce effects to allow normal performance.

Satellites in geosynchronous earth orbit (GEO), If sufficlently separated from a sular power batellite, should not be affected. The allowable spacing between an SPS and other sateli1tes in GEO would probably not be less than $1^{*}$, but $t h 1 s$ la based on approximate analyses that will require refinement as the sPS technology develops. Scientific observations of very low levels of electromagnet.f. radiation, such as are made in optical and radio astronomy, would be particularly sensitive to sPS additions to the electromagnetic environment. In many cases, these observations are already limfted by ex1sting sources of radiation, and any additions would further limit capabilities. The only clearly effective mitigating technique would be to conduct the observations from unaffected regions, 1.e., the far side of the earth if SPS satellites are deployed over a hemlsphere or less, or from space. The added expense and difficulty, especially for the space option, might have an undestrable Impact on the scope of observations.

The SPS concept was thus found to have a wide range of potential EMC effects. Microwave power unavoidably escaping from the power transmission system could affect a.wide range of electronic equipment within about $50 \mathrm{~km}$ of rectenna sites. Effective mitigation is avallable in most cases, but it is recommenided that rectennas be separated by distances of $50 \mathrm{~km}$ to $150 \mathrm{~km}$ for various sensitive facilities, such as military operational and test/evaluation areas; radio and optical astronomy sites, and nuclear research and power generation operations. For military equipments, separation is mandated because mitigation methods would modify the normal performance characteristics of m1litary equipments when operated outside SPS environments. Astronomy and nuclear facility separation is considered necessary because of the extreme sensitivity of astronomy recelvers and sensors, and the safety risks inherent with complex nuclear instrumentation systems operating in any additionul environment. Microwave emissions from SPS outside a presumed assigned bandwidth have the potential for interfering with uses of the radio spectrum over a homisphere, Whether, or to what degree, such interference would occur cannot be determined without construction and tcoto of romponents of SPS mfcrowave syslems. Finally, large sunlit sPS structures would, unless much darker than the present reference design, brighten the night sky significantly, impairing astronomical and other scientific observations.

If the SPS concept is to be pursued further, more detalled consideration of EMC w111 be required. The following areas will be of particular importance:

a) development of complete and accurate data on all SPS electromagnetic emissions; and

b) Specific SPS design studies of means for contrulling offonding emissions. 


\subsection{INTRODUCTION}

The SPS concept has been suggested as a possible new energy source which, if fully developed, could provide a source of power equal to all the electrical energy generated in the United States in 1975. The energy would be collected by building and operating satellites equipped with large solar arrays in geostationary orbits around the earth. In the present version, solar energy would be converted to microwaves and transmitted from space to earth. Earth receiving stations would convert the microwave energy to electricity, which could be fed directly into utility networks. Each satellite/recelving station combination would provide approximately 5 GW of electric power. Other transmission systems, such as lasers, also are being considered, but the current evaluation considered only the microwave version.

The SPS design concept considered in the Concept Development and Evaluation Program is described in the "Reference System Report" of October 1978 (DOE/ER-0023). The Reference System's purpose is to serve as a common basis for further technological development (systems definition and critical supporting investigations), environmental and societal assessments, and comparative analyses of the SPS concept and other national energy ventures. For the most part, the Reference System is based on fully-matured engineering precepts (methods, materials, practices, etc.) and realizable projections of future improvements. However, it is by no means an optimized engineering design, and does not account for newly emerging technologies which might become standard practices in the post-2000 era. Continuing systems definition undoubtedly will change many of the current characteristics of the Reference System. Some of those changes can already be reasonably perceived, but others most likely will occur that cannot yet be appreciated. Thus some potential problems associated with the present Reference System may subsequently become moot, and new ones will be recognized as developed continues. Despite its current limitations, the Reference System is an important tool for identifying and evaluating significant side effects which conceivably could accompany SPS.

The current satellite power system (SPS) concept proposes the transmission of approximately 400 GW of microwave power to the earth from 60 stations in geostationary orbit. Most of this power would be captured by rectifying antenna arrays ("rectennas") on the ground, delivering a total of approximately $300 \mathrm{GW}$ to the electrical utility grid. The unavoidable escape of energy from the microwave power transmission system provides the potentlal for a wide range of effects to electronic and electromagnetic communications, control, and measurement systems.

The electromagnetic compatibility (EMC) of the proposed concept with present and anticipated electronic systems has been assessed as part of the SPS Concept Development and Evaluation Program (CDEP) carried out by DOE and NASA. This report is a summary of that work, the technical details of which will be presented in a number of separate topical reports.

The EMC analysis was the fifth of five tasks of the Environmental Assessment area of the CDEP. The other tasks were:

1) Microwave Health and Ecological Effects,

2) Non-Microwave Health and Ecological Effects,

3) Atmospheric Effects (extending up to the spacecraft orbit), and

4) Effects of Ionospheric Heating on Telecommunications (which considered the possible effects of the microwave power beam on the ionosphere).

The EMC analysis addressed only the direct effects of electromagnetic emissions from the SPS on other technological systems. Emissions were defined quite broadly, including not only those from the microwave system, but also thermal blackbody emission and scattered sunlight from Llie satellite. Figure 1 shows the SPS from dII EMC perspective and schematically identifies the major emissions. The analysis is based on the design for an SPS as described in the Reference System Report and some quantitative conclusions, e.g., ranges from rectenna sites at which effects are expected are specific to that design. The methodology and qualitative conclusions, however, app1y to any SPS concept using microwave power transmission. Quantitative conclusions have been obtained parametrically and can be adjusted as SPS designs change.

The balance of this summary report presents an overview of the assessment. Section 2, Methodology, explains the organization of work, procedures followed, and the constraints and limitations of the assessment. The electromagnetic environment that the Reference System would produce, and in which other systems would have to function, is described in section 3. As an early part of the EMC Assessment, the problems expected for a hypothetical rectenna site, in the Mojave Desert of southern California, mere analyzed in detail. This effort provider an initial yualliative indication of the scope of potential EVIC problems and indicated the importance of EMC considerations in rectenna site selection. The results of this analysis are presented in Section 8. The effects of SPS microwave emissions on important categories of electronic systems and equipment are summarized in Section 4, with many examples of test results and demonstrated techniques for mitigation of problems encountered. SPS effects on other satellite systems are presented in Section 9. Astronomical research frequently involves measurement of 


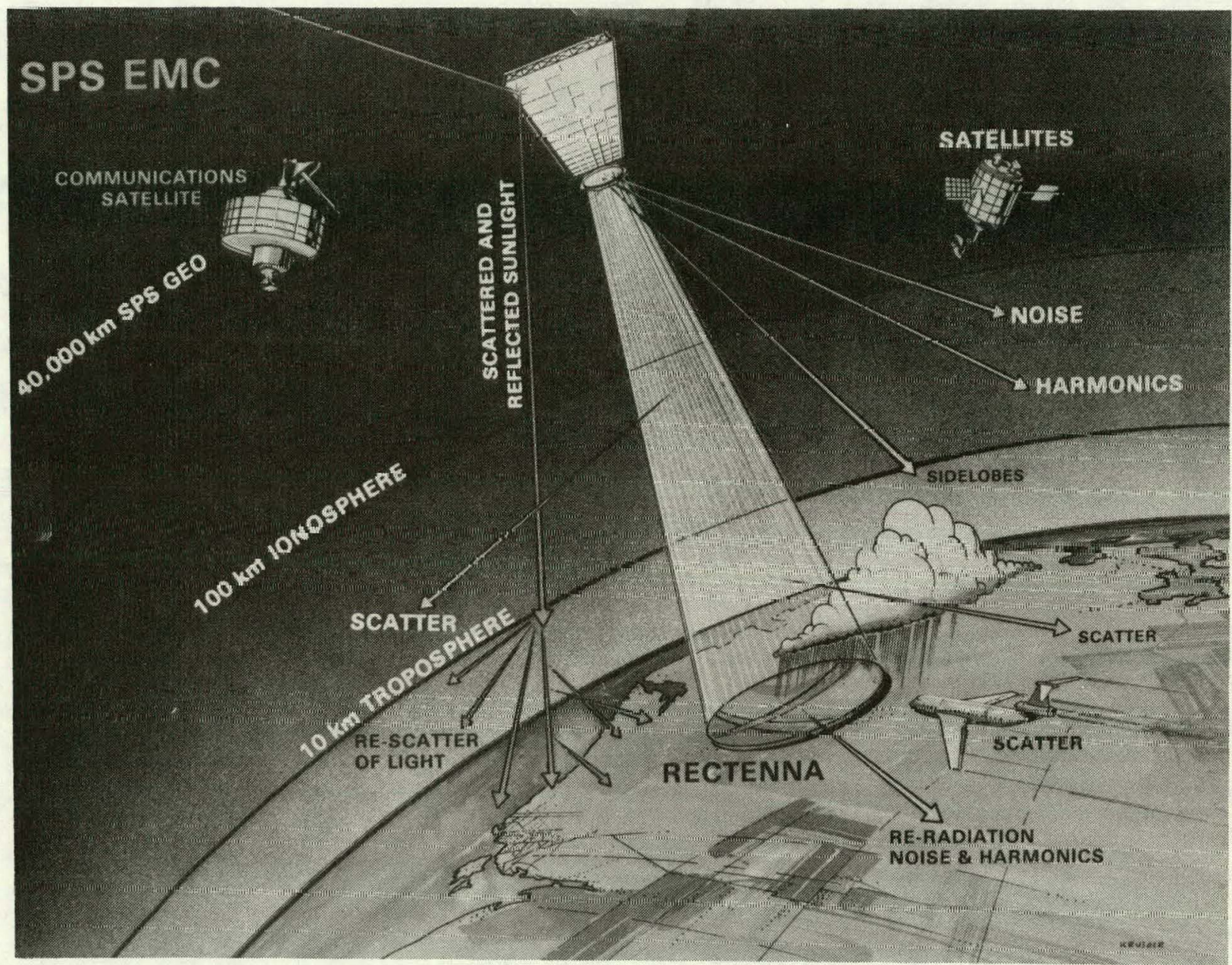

Figure 1. Flertromagnet1c EmLssluns from the Sate11ite Power System.

extremely low levels of electromagnetic radiation and is thus very susceptible to interference. The concerns of both radio astronomy with microwave emissions from SPS and optical astronomy with sunlight scattered from SPS spacecraft are discussed in Section 10. Brief summaries of mitigation techniques, cost estimates, and conclusions complete the report.

In addition to this summary document, the EMC Assessment Task is documented by the following ITS-published reports: 


\subsection{METHODOLOGY}

Electromagnetic compatibility analysis is a well developed field having become of increasing importance as the number, complexity, and transmitted power levels of electronic systems have increased dramatically In the last 30 years. The SPS EMC Assessment requires no major new developments in technique or understanding, but is a problem of unusually wide scope. Because of the large area potentially covered by sps microwave emissions and high total power involved, a very large number of systems and pleces of electronic equipment of a wide variety of types are potentially affected. It has thus been necessary to select representative items in important categories for analysis.

Assessment of the electromagnet1c effects of SPS required two distinct types of data: the changes in the electromagnetic environment that SPS would produce and the response of existing or anticipated systems and equipment to the new environment. The environmental changes result from electromagnetic emissions from the SPS and the effects of other phenomena, such as weather, that could modify the emisstons or at least their geographic distribution. In considering the response of equipment to SPS, it was necessary to consider the potential, which is substantial in many cases, for mitigating anticipated problems. Finally, the actual signfficance of changes in equipment performance to the user must be evaluated. Figure 2 shows the relations between the mafor elements of the assessment.

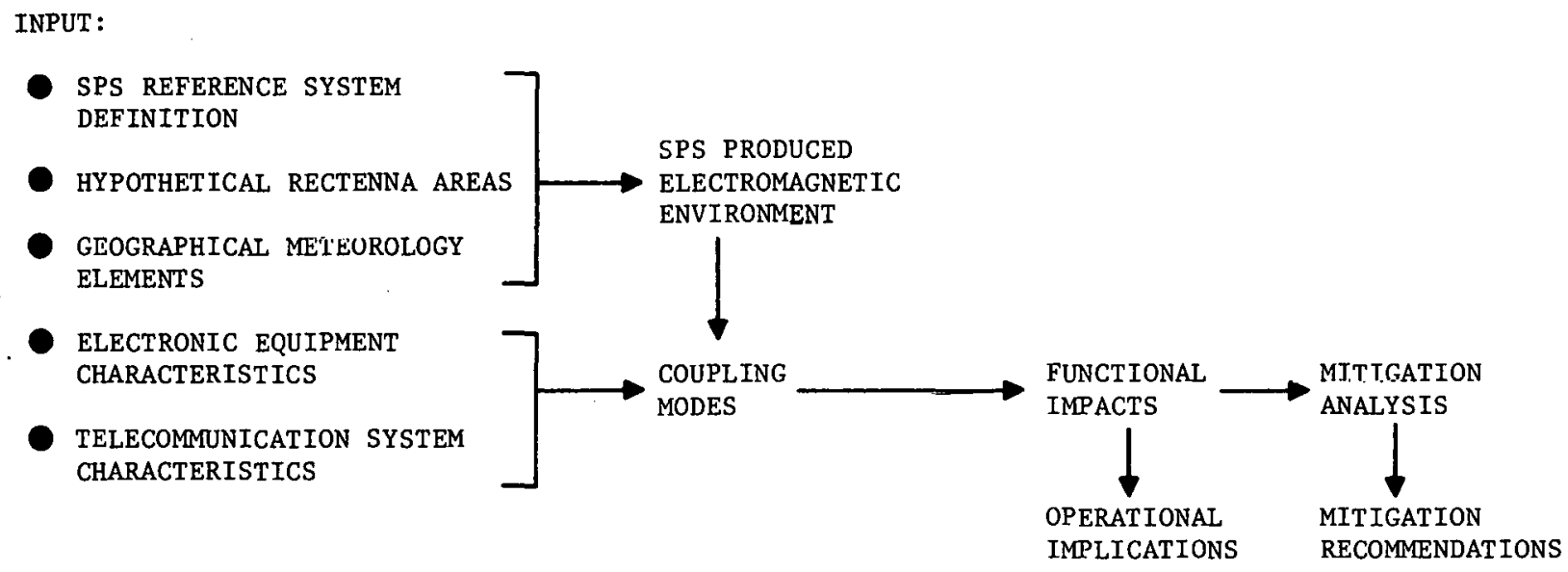

Figure 2. SPS EMC Analysis Evaluation

The major limitation on the present assessment is the limited knowledge of some of the electromagnetic emissions from SPS. More accurate data on these emissions will not be known without further examination. As noted above, much of the electromagnetic compatibility assessment completed during the Concept Development and Evaluation Program is parametric, and conclusions could easily be adjusted if new data on SPS preferred systems become available in the future.

Prosent lnowledge of the èlectromagnetic environment that SPS would produce 1s based on the Reference System. The Reference System is, however, only a conceptual design, as mentioned earlier, and 1s incomplete in some areas important for an EMC Assessment; for example, the details of the performance of the devices used for conversion of direct current (DC) power to microwaves on the satellite are unknown. The Reference System uses klystrons for DC to microwave conversion, but several other devices, including solid state components, are being considered. The basic performance of the Microwave Power Transmission System (MPTS) has been studied, since it is critical to total SPS performance; as a result, the spatial distribution of microwave power at the intended transmission frequency can be computed with good assurance of accuracy for the far field. The etrongth and spatial distribution of emisstons at other frequencies can now only be estimated by using data on the performance of existing systems.

Effects of the media (atmospheric attenuation, ccatter, refiduliun, rain and hail scatter, etc) on the SPS mäin beam at $2.45 \mathrm{GHz}$ have been estimated and have not proven to be a major problem (Grant et al., 1980). However, the effects of the media on the complete spacetenna control loop, which would include the pilot beam interactions, are not well known as yet and may present control loop stability problems that will need further study. For the SPS, system control includes beam aiming at the rectenna center, spacetenna sidelobe minimization, and safety actions.

This EMC assessment has concentrated on determining the microwave power levels outside of the rectenna :xclusion area due to sidelobes and scattering of energy from the main beall alld the impact on electronic Ind clcctromayutic systems operating within $150 \mathrm{~km}$ of a rectenna site. These levels were estimated 
given the conceptual design of the Reference System. The EMC effort has been directed at establishing the threshold where unacceptable performance begins for a wide variety of electronic and EM systems wher subjected to various levels of $2.45 \mathrm{GHz}$ energy. Knowing the estimated EM field outside the rectenna art and the threshold of unacceptable performance, one can determine how far a given system must be from the rectenna to allow acceptable performance or what mitigation techniques must be applied to allow the system to perform satisfactorily when in fields that surpass the threshold level. Solar power satelite concept design changes that will most likely come about as the total systems are studied may alter the spatial distribution of microwave energy, but this would only alter the distance that a system would have to be from the rectenna to perform satisfactorily, or determine the mitigation involved for acceptable performance.

Solar power satellite emissions at frequencies outside the ISM band assumed for the reference system design would present "in-band" interference to users of those frequencles for .communications, allocated only in East Europe. For SPS operation in the western hemisphere, western Europe, or most of As1a, this interference mode will not exist. The dominant interference mode for radio recelvers will be "out-ofband." The effects of such interference and allowable limits are established and incorporated in the Radio Regulations of the International Telecommunfation Union and the Federal Communications Commission Rules and Regulations. I'his scudy has alupted the approach of examinting possible emisston ranges and recommending threshold levels for system design.

The current EMC analysis is dependent on the assiutheriun LlaL Llie MTTS vould eperate in the $2.40-$ to 2.50-GHz industrial, scientific and medical (ISM) liequency band. Althnigh this is a logical chotce of frequency, it is not the only possibility and has not yet been allocated for space-to-earth power transmission. Some of the constdcrations in SPS. flequency gelcction are dismissed in Section 7 . A substantial change in SPS operating frequency would alter the coupling with other systems, requiring reassessment of many EMC concerns.

In many cases, the response of electronic systems and equipment to the SPS environment could be predicted from existing EMC data. Tests spectfic to SPS were conductcd on important, representative systems and Items and, where needed, were run to f 111 gaps in available data. A total of 57 major systems were tested. The tests concentrated on advanced systems to provide maximum relevance to the $1990-2000$ time frame appropriate for sps startup. Complete system configurations were tested in many cases to determine overall functional impact.

\subsection{EQUIPMENT CATEGORIES}

The major categories of equipment tested are summarized in Table 1 . These cover the princlpal military, government, and commercial equipment and systems in use in the continental United States (CoNus) and are representative of those used by other industrial nations.

TABLE 1. Major Equipment Categories for SPS EMC Assessment

COMMUNICAIILUNS

Terrestrial Links Satellite Links

MEDICAL ELECTRONICS

Diagnostic Systems Implanted Devices

Pacleul Teleuetry

$$
\text { COPTUTERS/PBOCESSORS }
$$

Centralized Mini-Computers/ M1croprocessors

Distributed Mini-Computers/ Microprocessors

\section{RESEAKCH SUPFORT}

Radio Astronomy
Optical Astronomy
Space Tel psconpe

RADAR3

Area Monitor

Target Track

Command/Control

\section{SENSORS}

Slal luy Detector Syctams

Scanning Detector Systems

EM Field Detection Systems

Evaluation of communications systems enphasized command aul ciontrol opcratione in applirations including mass transportation, utility and pipeline control, and alr traffic control. Long-distance, multinode data networks were evaluated for node or switching center input-output delay and lost messages caused by errors resulting from interference and increased nolse levels.

Computers in the mini- and microprocessor classes were evaluated including both military and commercial systems and those implemented with both medium and large scale integrated circuits (MSI and LSI). Complete functional configurations were tested under simulated SPS exposure conditions to determine effects on system interconnections and overall performance. The sensitivity of individual digital integrated circuits to the SPS environment was analyzed separately. 
Radar systems for air traffic monitor, military test range instrumentation, and military operational monitor and control systems were evaluated. Effects on detection range, 1dentification delay, tracking error, and tracking lock uncertainty were consldered for both passive (skin) and cooperative (transponder) targets.

Pacemakers, and general medical electronics were investigated to find if there were current standards used for EMI susceptibility. Manufacturers were contacted and data obtained where possible. Actual testing was not accomplished, and further study would be warranted.

Scientific research equipment used in studies of extremely weak electromagnetic radiation, at both radio and optical wavelengths, was identified early in the program as a category particularly sensitive to interference from SPS. A workshop was convened in May 1979 to consider potential SPS impacts on optical and radio astronomy, deep space research, and related scientific programs. Proceedings of this workshop have been published as "Workshop on Satellite Power Systems (SPS) Effects on OptIcal and Radio Astronomy," CONF-7905143 (1980), and a summary of our current understanding of these problems is included in this report.

A wide range of electro-optical sensor systems was evaluated covering both the infrared and visible wavelengths. Staring and imaging sensors using solid state and vacuum tube detectors were 1ncluded. Effects on video and control electronics were considered as well as primary effects on the sensors. Target detection and feature extraction processes for identification in security and intrusion detection applications were considered, as were track nolse or prediction filter coefficient uncertainties in star and aircraft tracking systems. Tested performance scoring points included video noise, scan jitter, dynamic range compression, and alterations in modulation transfer function.

\subsection{RECTENNA SITES}

As one part of the assessment, the EMC problems associated with hypothetical rectenna sites in reglons representing different climates and degrees of urbanization were evaluated in detail to indicate the extent of anticipated effects. The results for the first hypothetical site considered, in the Mojave Desert of southern California, are summarized in Section 8. This first site analysis demonstrated that EMC considerations would be important in rectenna site selection.

\subsection{MITIGATION}

Consideration of mitigation of anticipated EMC problems was an integral part of the assessment. Many potent lal problems arise simply because most current electronic equipment, was not designed to operate in the electromagnetic environment anticipated near SPS rectennas (or that experienced by satellites transmiting the microwave power beam). Testing to date has indicated that relatively simple modifications of existing equipment can, in many cases, substantially eliminate expected SPS interference. Where safety or similar concerns dictate an extremely low probability of interference, or where state of the art performance of electronic systems is required and would be impaired by modification, geographic separation between rectennas and sensitive systems is recommended.

Specific means of mitigating anticipated SPS problems were evaluated wherever such problems were found. Many of the tests included measurements of the effectiveness of varlous mitigating techniques. Figure 3 indicates the relationships between 1dentified effects on equipment, evaluation of mitigation methods, and development of design and modification recommendations. The EMC Assessment has provided recommendations, and estimates of the cost of modifications and incremental cost of design changes have been provided.

Mitigation methods considered include shielding improvements, circult modifications, and changes in the functional use of equipment. Geographic separation between rectennas and some systems may, as noted above, be a required mitigation technique in some cases. Constraints on the rectenna siting to provide this separation have been provided to rectenna site evaluation studies. Redeployment of existing facilities could also be considered if necessary.

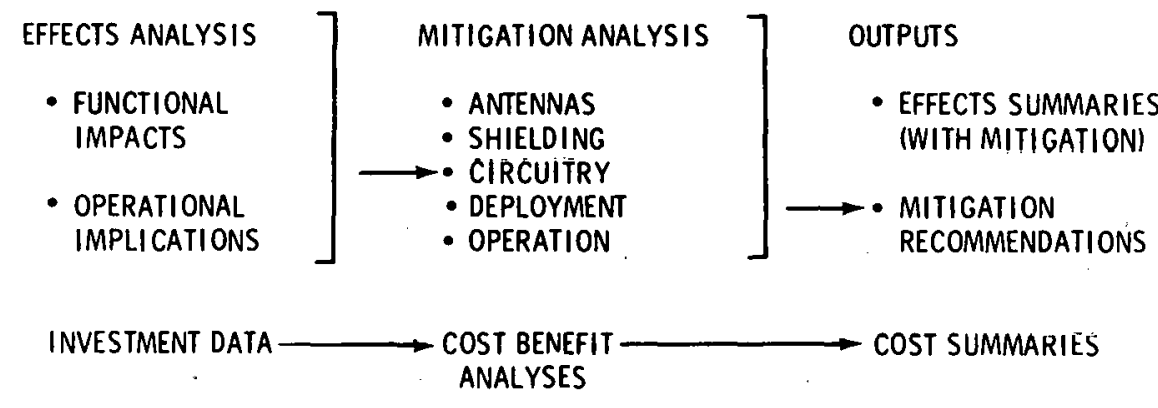

Figure 3. Data Flow in Mitigation Anaysis Area of SPS EMC $\Lambda$ ssessment 


\subsection{SPS EMISSIONS AND MEDIA EFFECTS}

An EMC assessment $1 \mathrm{~s}$ based on measured or a range of assumed emissions from a proposed system or concept of operation. The SPS concept presently includes the GEO solar collection -- microwave conversion and transmission platform -- and terrestrial microweve power collector and utility conversion facility. Emission sources include direct and induced components from the GEO platform and reradiation and induced components from the rectenna circultry and structures.

The SPS emission categories important in the EMC evaluation are 1isted.

1. Primary frequency (2.4-2.5 GHz band) and the second, third, and fourth harmonic power amplitudes, and spatial distributions from the spacetenna.

2. Nolse sidebands generated. by multiplying and amplifying devices, and radiated from the spaceterma.

3. Intermudilalion products from the GEO platform (1,e., sourcco represented by multiple frequency lllumination of structure composite material junction areas and the solar cells and control/ conversion circuitry).

4. Fundamental frequency and harmonic reradiation from the rectenna dipoles.

5. Intermodulation products from the rectenna site structures (e.g., dipole group framework and other metal structures within the rectenna site). Illumination sources include the SPS fundamental and harmonic components and other signals in the locale (e.g., alrborne and surface radars, satellite communications, commercial communications).

6. Thermal black body radiation from the SPS GEO platform.

7. Scattered sunlight and moonlight from the SPS GEO platform.

\subsection{ELECTROMAGNETIC. FIELDS DUE TO THE MICROWAVE POWER TRANSMISSION SYSTEM}

In the current Reference System design, the microwave power transmission beam is formed by a $1-k m$ dlameter phased-array antenna (spacetenna). The array consists of 7220 subarrays, each approximately 10 meters square, of slotted waveguide radiators. The DC power from photovoltalc collectors is converted to the $2.45 \mathrm{GHz}$ frequency and amplified by more than 100,000-70. kW klystrons. An active phase control system would accommodate mechanical flexing and subarray positioning errors, and maintaln beam shape and pointing. This control system will also accommodate beam perturbations and distortions imposed by atmoopheric anomalles. Several different phase control schemen are under consideration. The array illumination has a $10 \mathrm{~dB}$ Gaussian taper accomplished in ten discrete steps.

Gain patterns for the transmitting array at the fundamental frequency. have been computed separately by ITS and NASA. The ITS pattern, shown In Flgures 4 and 5, does not include the effects of mechanical tolerances or component fallures. [Derivation of this pattern is given in 0tt (1979)]. The NASAcomputed patterns are shown in FIgures 6 and 7 (from DOE/ER-0023). The independent computations are in close agreement (differences of about 6-8 dB in the $60^{\circ}-90^{\circ}$ angles from borestght). The grating lobe shown in Figure 6 results from subarray spacings, and would repeat on the earth in a rectangular pattern at intervals of $440 \mathrm{~km}$.

A smoothed, fundamental power-density pattern on the ground for a single SPS is shown in F1gure 8 . Figure 9 shows power densities in the continental United States for $\dot{a}$ 60-SPS configuration assuming 


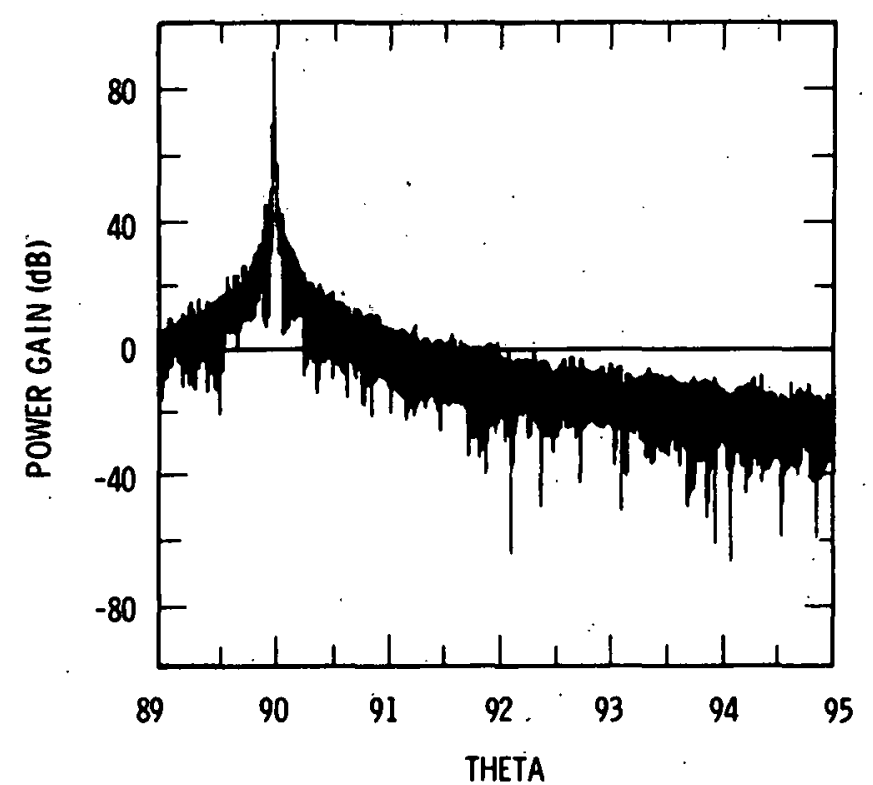

F1gure 4. SPS Transmitting Antenna Galn Versus Angle from Antenna Plane. On-ax1s gain 18 approximately $87.7 \mathrm{~dB} 1$.

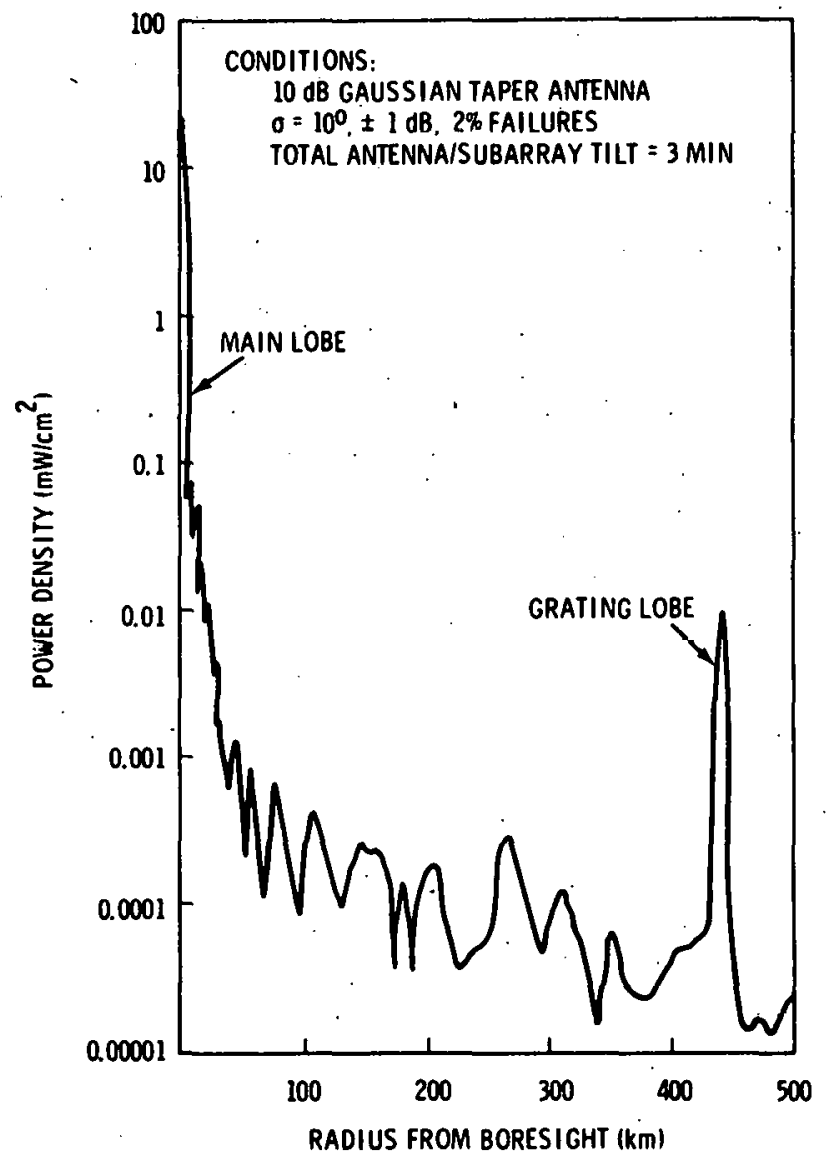

F1gure 6. Peak Power Density for SPS Side Lobes and Grating Lobe as a Function of Radial Distance from Rectenna.

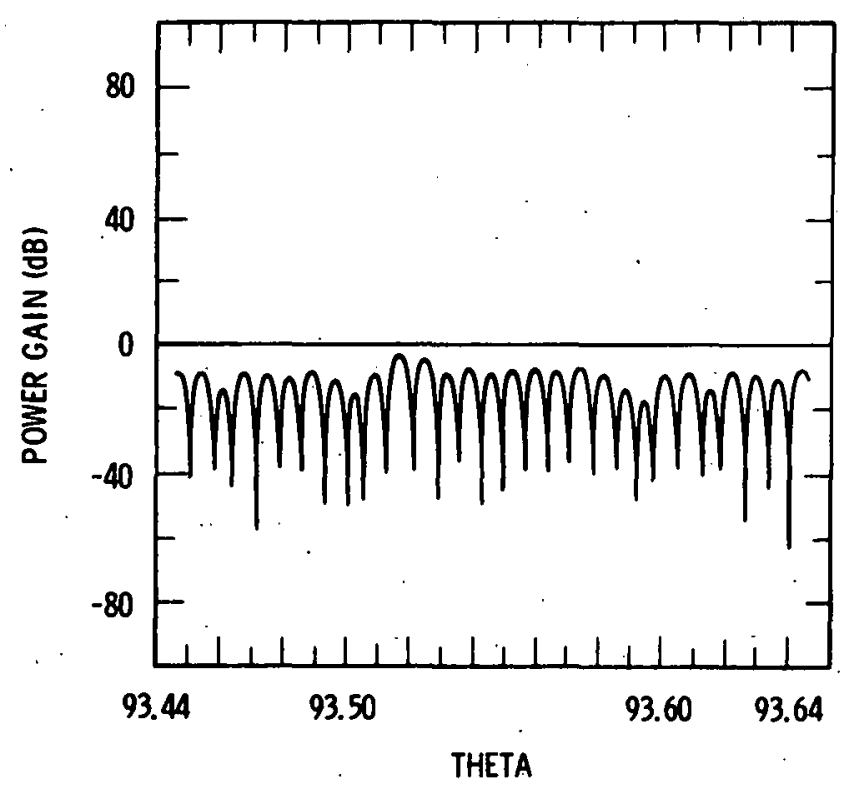

F1gure 5. SPS Transmitting Antenna Gain S1de Lobe Deta11.

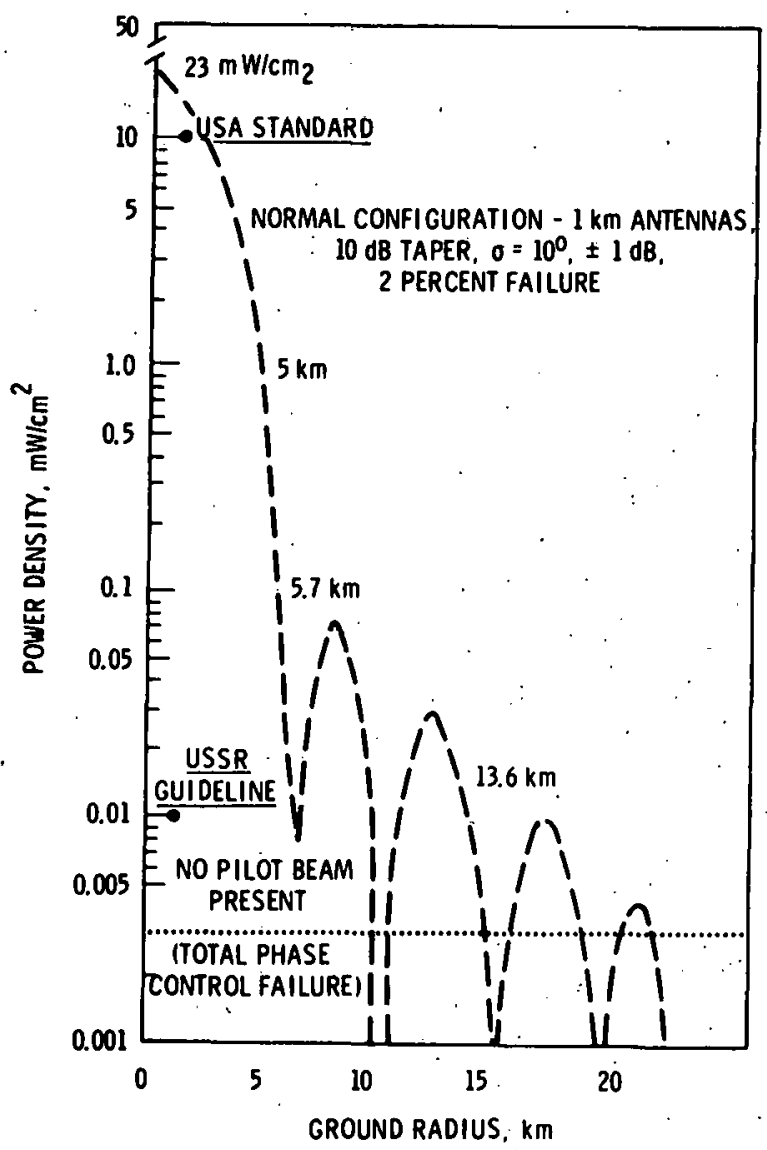

Figure 7. Power Density near Rectenna as a Function of Distance from Center. 


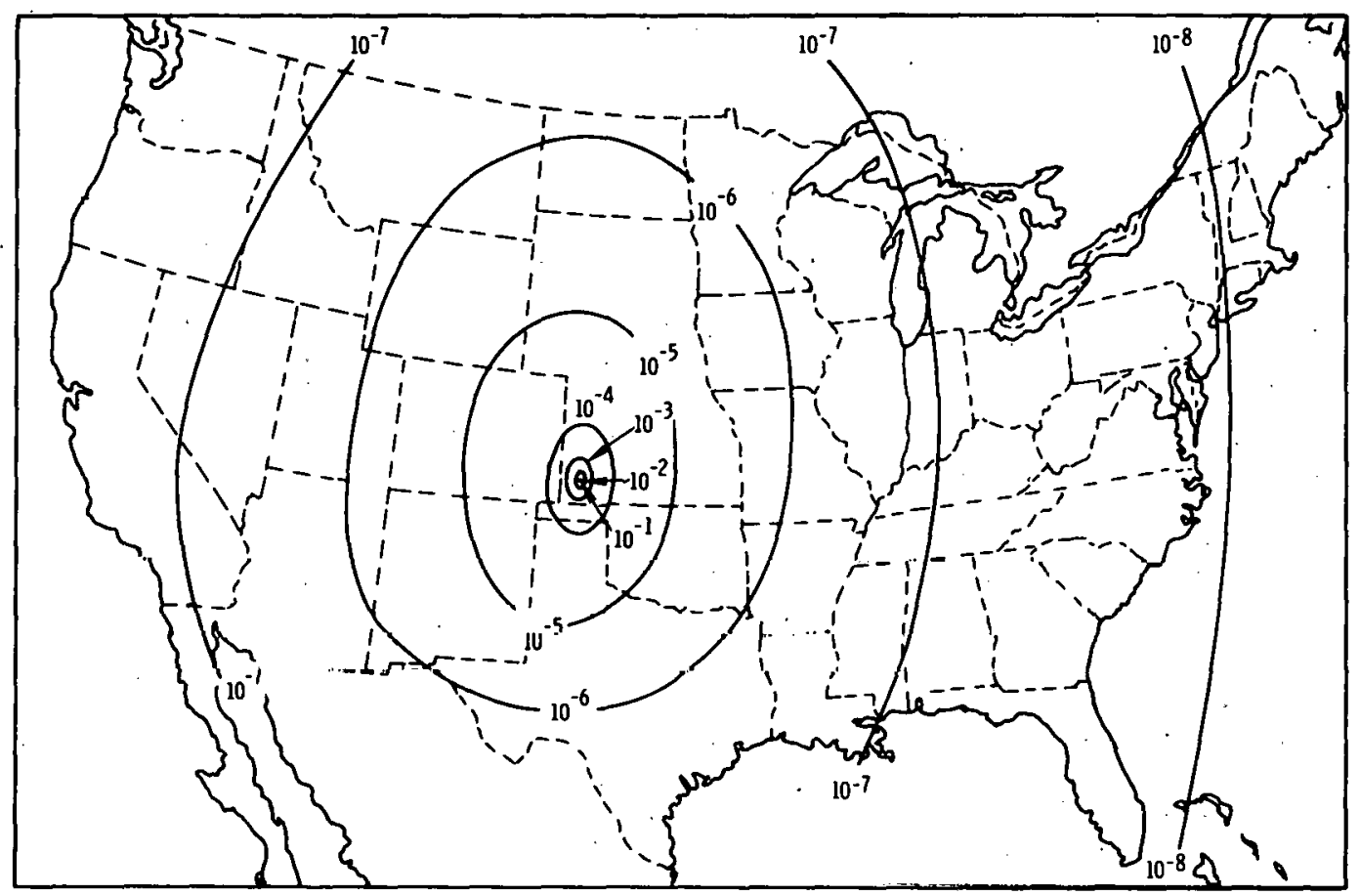

Figure 8. Microwave Power Density $\left(\mathrm{W} / \mathrm{m}^{2}\right)$ from a Single SPS with Rectenna in Kansas

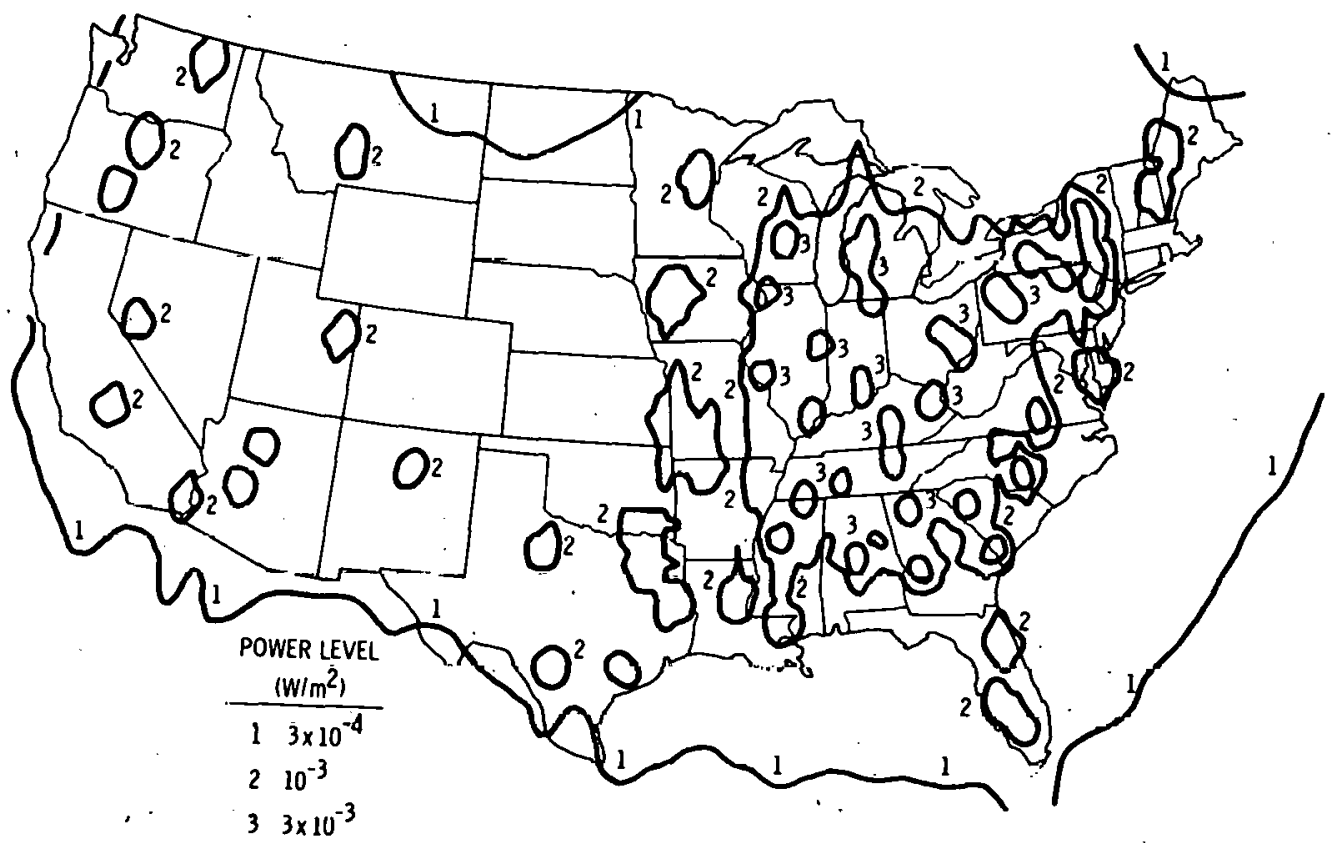

Figure 9. Microwave Power Densities $\left(\mathrm{W} / \mathrm{m}^{2}\right)$ in the Western Hemisphere for a configuration of 60 spss with Rectennas in conUs (from Boeing D180-26019-1). 
rectenna siting consistent with satellites positioned every $1^{\circ}$ from $60^{\circ}$ to $120^{\circ}$ West longitude. The rectenna sites were Identified by the Rice University siting criteria study (Blackburn, 1980).

The estimate of amplifier chain harmonic source amplitudes is presented in Figure 10 . Amplifier harmonic emissions plotted represent spectrum signature data for a wide range of klystron amplifiers used for power amplifiers in $S, C$, and $X$ band communications and radar equipment. The notse sideband plot in Figure 11 is representative of high-power klystron amplifier chains, where the power output is in the $10 \mathrm{~kW}-50 \mathrm{~kW}$ range. These modulation components are important in evaluating potential in-channel interference for communications channels adjacent to the $2.4-2.5 \mathrm{GHz}$ ISM band. One operation constraint imposed by these sidebands is the minimum separation between an SPS frequency assignment and the edge of the ISM band. For the sidebands plotted, the minimum SPS frequency separation from the ISM band edge must be $10 \mathrm{MHz}$. Normal life parameter variations for high power TWT or klystron amplifiers would Indicate a 15-20 MHz separation from the band edge.

No1se sidebands from SPS, if held to the levels computed by Annt and Leopold (1978), would exceed interference limits only for the adjacent satellite broadcast band, which is not now used. If these noise sideband levels are realized, problems in the nearby deep space research and radio astronomy bands would probably be due largely to the effects of high power levels at $2.45 \mathrm{GHz}$.

Estimates of the spatial distribution of harmonic power from the spacetenna are plotted in Figures 12 and 13. These patterns were derived by relating fundamental and harmonic spatial frequency distributions for arrays with nonuniform tapers. The envelope of the pattern (dotted 1ine) was used in all SPS environment computations (the uncertainties in harmonic phasing and amplitude variations among power amplifiers do not justify confidence in the spatial variations). The array gain at the harmonic fre-. quencies should be valid within a $10 \mathrm{~dB}$ range. The uncertainty is due to the fact that emission power varies according to mode properties and impedance differences between output amplifiers.

The rectenna fundamental frequency reradiation pattern is plotted In Flgure 14 . Th1s was developed from the effective radar cross-section of a resonant dipole at an average illumination angle of $35^{\circ}$ and an impedance ratio of $1.2 / 1$. A cross-section of $300 \mathrm{~m}^{2}$ is assumed for the metal framework supporting the dipoles. Pattern estimates for the second and third harmonic emissions from the rectenna are plotted in Figures 15 and 16. These were developed for an array of dipoles each having a length of $\lambda$ for $f_{2}$ and $3 \lambda / 2$ for $f_{3}$ patterns. No effects of the ground conductivity or reflections from the metal framework are included.

The second harmonic of $2.45 \mathrm{GHz}$ at $4.9 \mathrm{GHz}$ is very near a radio astronomy allocation. In practice radio astronomy operates below the allocated band and would be Impacted by SPS second harmonic radiation unless it was held to very low levels.

The third harmonic at $7.35 \mathrm{GHz}$ falls into a satellite downlink band allocated to government use in the United States. SPS emissions in this band could interfere with communications systems in this band. Many of these are military and resistant to interference but SPS input could degrade their ability to accept additional interference.

The SPS fifth harmonic at $12.25 \mathrm{GHz}$ is adjacent to a satellite downlink band being constdered for TV broadcasting. It is possible that this band could be extended upward in the future (in Europe it already extends to $12.5 \mathrm{GHz}$ ). In ary case, a strong signal from SPS structures could present a serious problem to the use of this band for direct TV broadcasting to inexpensive receivers with small antennas.

\subsection{MEDIA EFFECTS}

The spatial distribution of SPS microwave power can be modified by phenomena in the beam path which either directly scatter power out of the beam or affect the phase control system which maintains beam shape and pointing. Two areas are of particular concern: the lonosphere and the troposphere. The effects of natural lonospheric conditions, including perturbations from average conditions caused by solar activity, are known and expected to be minor. Potential modification of ionospheric electron density and temperature by the SPS power beam has been addressed by an analytic and experimental program in Task 4 of the Environmental Assessment. This program indicates the degree of possible power beam and phase control effects and the effects on the performance of radio systems that use lonospheric refraction for transmission (e.g., low frequency navigation and shortwave communications). The study also includes satellite communication and navigation systems that transmit through the ionosphere. 

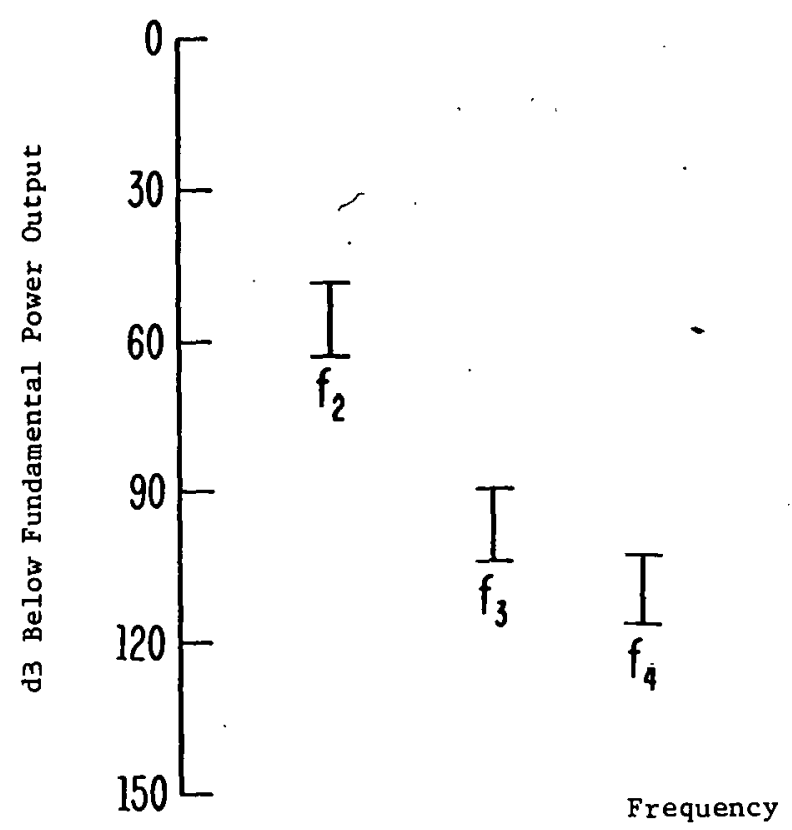

Figure 10. Typical Harmonic Emission from a High Power Klystron.

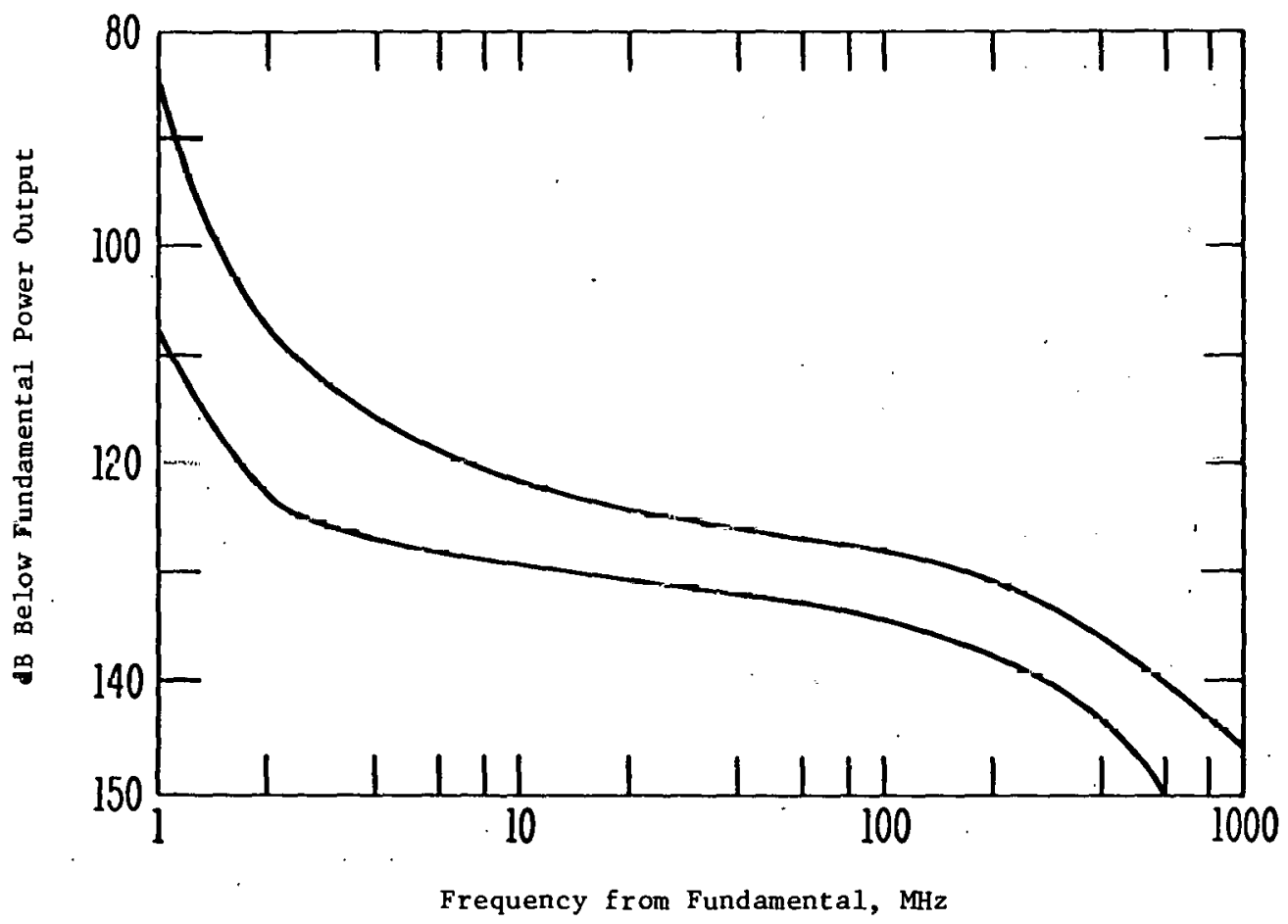

Figure 11. Typlcal Nolse Emissions from a High Power Klystron. 


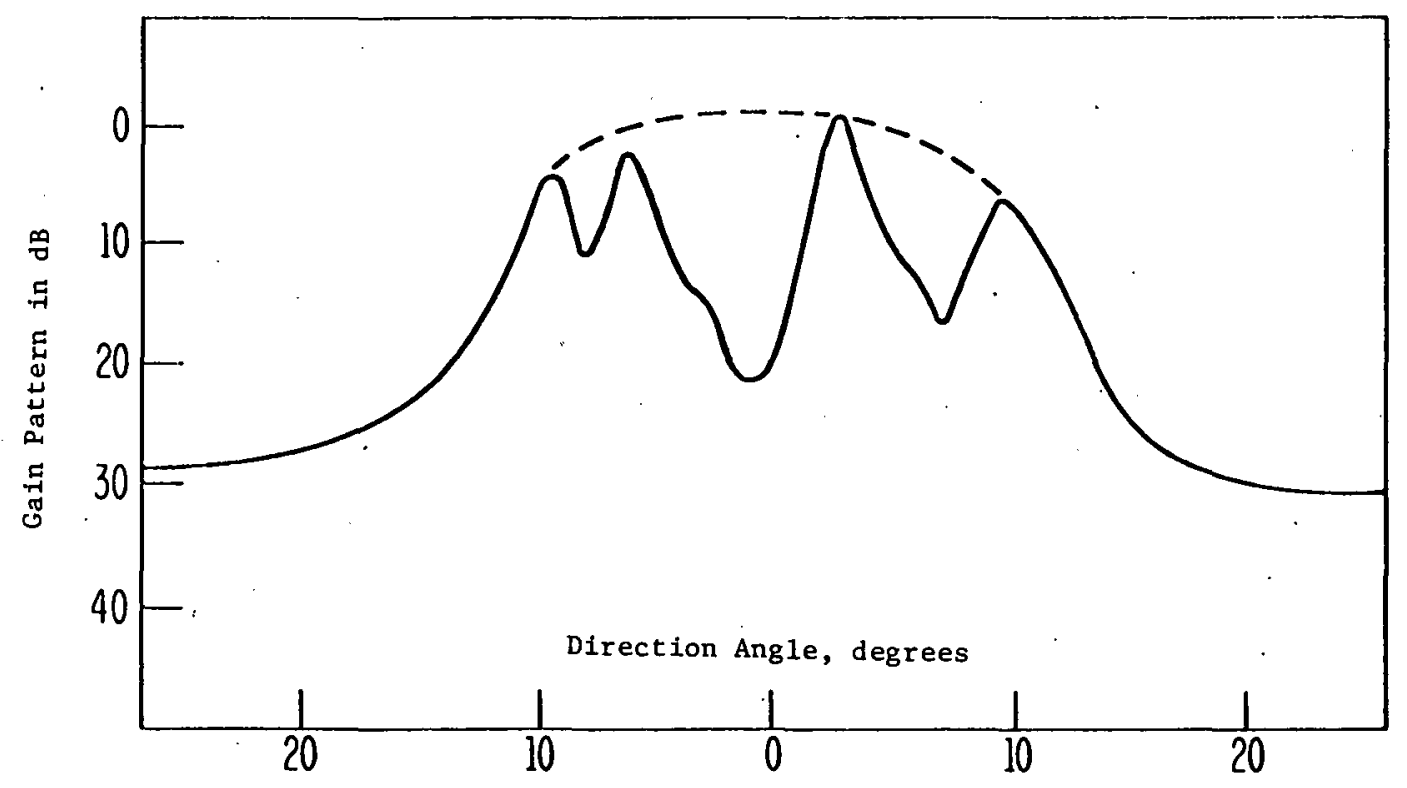

Figure 12. "Spacetenna - $\mathrm{f}_{2}$ Pattern Estimate"

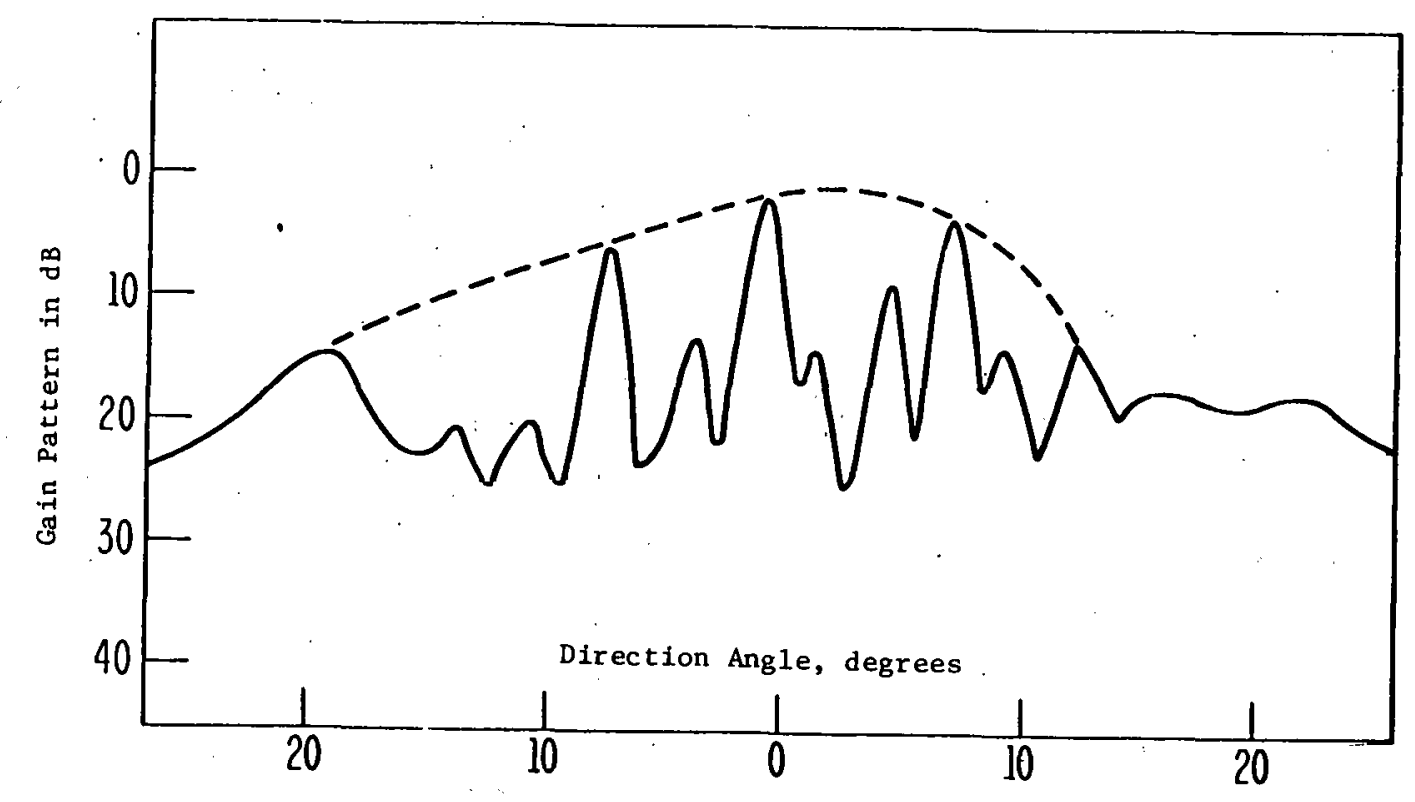

Figure 13. Spacetenna - $f_{3}$ Pattern Estimate". 


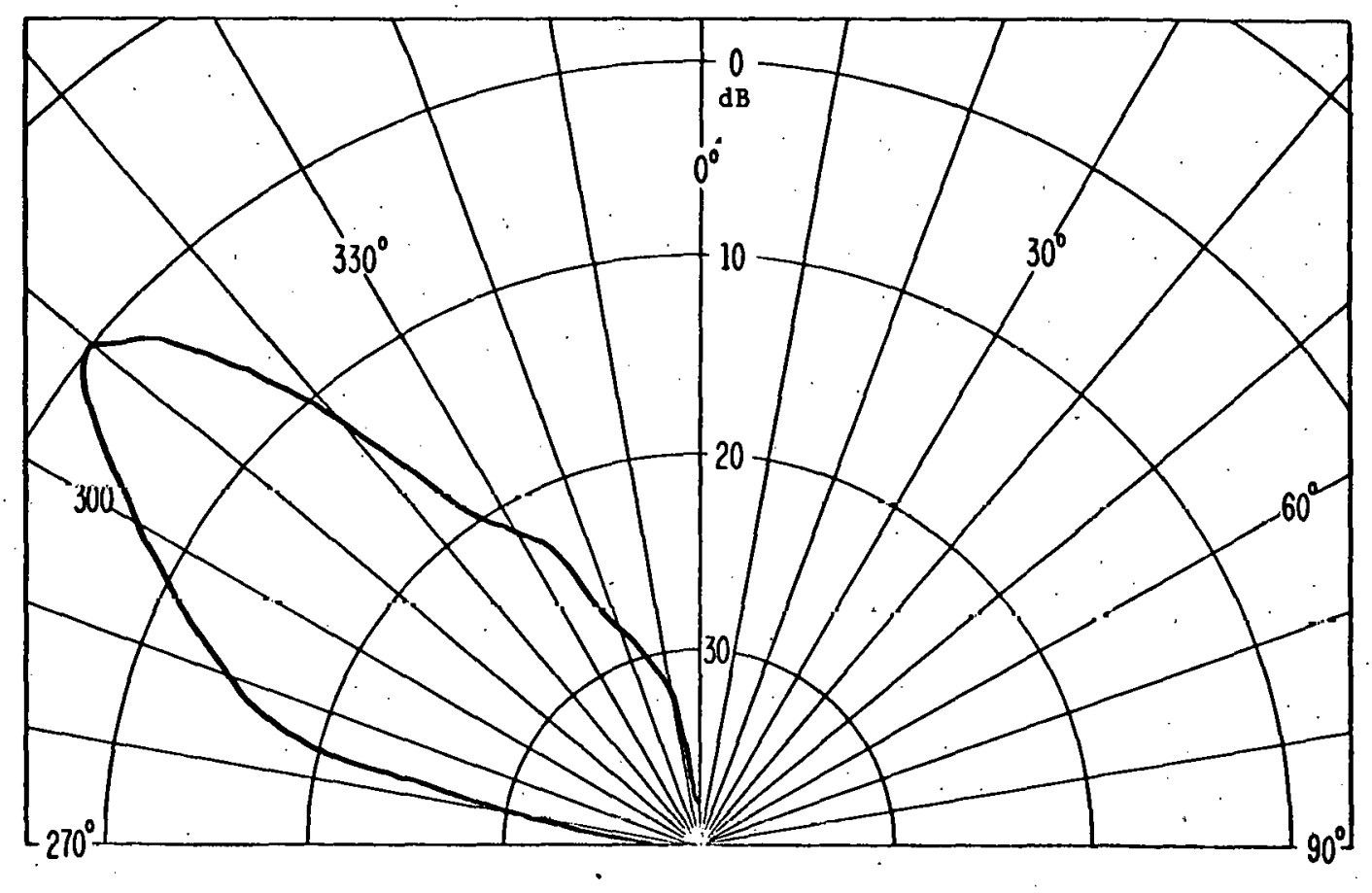

F1gure 14. Rectenna fo Pattern.

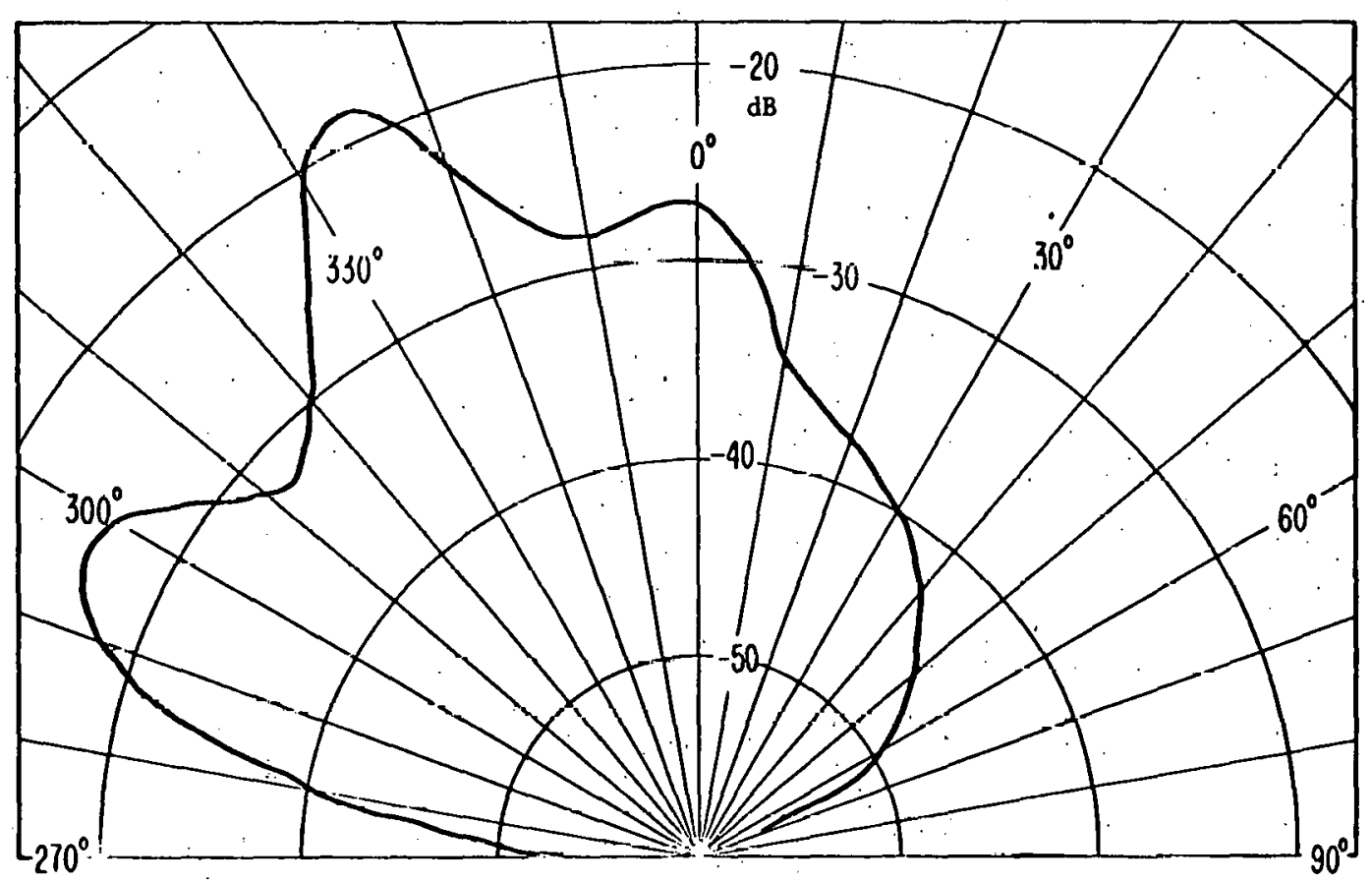

F1gure 15. Rectenna $f_{2}$ Pattern. 


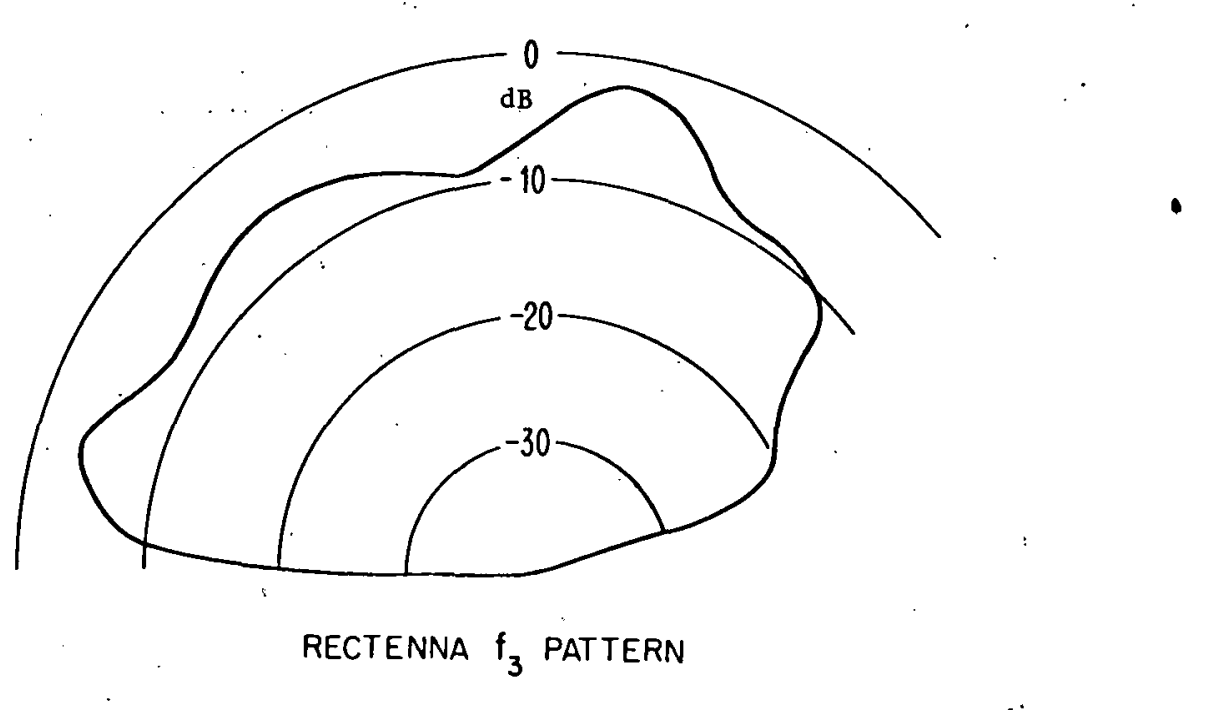

Figure 16. Rectenna $\mathrm{f}_{3}$ Pattern.

The troposphere phenomena of interest are

* hydrometeor (principally.cain and hail) scatter of the power beam,

* scatter of the power beam by dust or other particulates,

* changes in microwave refractive Index with various distance and time scales which might scatter the power beam or interfere with phase control (e.g., layer refraction, dynamic anomalles or radar "angels." and turbulence from rectenna site heating).

The heat island effect has been evaluated by Task 3 of the Environmental Assessment. Results indicate density variations of $0.1 \%$ to $1.2 \%$ of normal for day and night periods due to rectenna heating. This increased turbulence causes no practical reduction in power to the rectenna, and because it occurs only 50 to 200 meters above the rectenna, it contributes no additional scattered power beyond the rectenna area's boundary.

Dust or sandstorms contribute an insignificant microwave power loss and variation of power densities outside the rectenna. For the larger storms in the U.S. southwest arid areas, the maximum power scattered is expected to be in the range of $10^{-5}$ to $10^{-\frac{4}{4}}$ of the power beam, over an angle range of about $\pm 60^{\circ}$.

Rainstorms w11l cause transient power beam scatter, attenuation, and Induced modulation of phase control signals. Rain scattering anticipated, as a percentage of beam power, has been computed for hypothetical rectenna sites in nine states. Rain rates and power loss percentages will be equal to or less than values in columns A of Table 2 for $99 \%$ of an average year. Columns B provide corresponding values for $99.99 \%$ of an average year. That is, for New York most rain storms will be $10.2 \mathrm{~m} / \mathrm{hr}$ or less but some can be ás high as $33.3 \mathrm{~m} / \mathrm{hr}$ tor less than .01\% of a year.

TABLE 2. Total Power Loss Expected for Various Rectenna Sites

\begin{tabular}{|c|c|c|c|c|}
\hline \multirow[t]{2}{*}{$\begin{array}{l}\text { Hypothetical } \\
\text { Rectenna Sites }\end{array}$} & \multicolumn{2}{|c|}{$\begin{array}{l}\text { Rain Rate } \\
\text { (mm/hr) }\end{array}$} & \multicolumn{2}{|c|}{$\begin{array}{c}\text { Power Loss } \\
(\%)\end{array}$} \\
\hline & $\mathrm{A}(99 \%)$ & B $(99.99 \%)$ & $A(99 \%)$ & $\mathrm{B}(99.99 \%)$ \\
\hline $\begin{array}{l}\text { California } \\
\text { Delaware } \\
\text { Ternessee } \\
\text { Florida } \\
\text { Montana } \\
\text { Nebraska } \\
\text { Minnesota } \\
\text { Michigan } \\
\text { New York }\end{array}$ & $\begin{array}{l}2.9 \\
18.2 \\
18 \\
42.4 \\
5 \\
7.3 \\
9.1 \\
8.3 \\
10.2\end{array}$ & $\begin{array}{l}6.3 \\
.87 \\
83 \\
113 \\
21.6 \\
70.8 \\
46.7 \\
52 \\
55.3\end{array}$ & $\begin{array}{l}0.02 \\
1.11 \\
1.08 \\
1.56 \\
0.11 \\
0.7 \\
0.28 \\
0.38 \\
0.4\end{array}$ & $\begin{array}{l}0.06 \\
2.55 \\
2.43 \\
3.1 \\
0.63 \\
1.46 \\
1.12 \\
1.4 \\
1.41\end{array}$ \\
\hline
\end{tabular}

(Power loss percentages shown Include clean air attenuation.) Rain-scattered power was added to directbeam power in determining the separation requirements between rectenna sites and sensitive factlities to ensure that these are conservative. 
Transient meteorological events and refractive anomalles will produce both amplitude and phase modulati of the power beam and beam control signals. If beam spreading or wander results, the geographlc range of EMC problems would be extended. It 1s thus important to understand the effects of these phenomena on any planned beam-control systems and include realistic data on their amplitudes, rates, and spectral densities in evaluations of system stability. Beam parameter sensors employed for spacetenna control will Include processors to extract anomaly modulation components, spectra being in the range of $5 \mathrm{~Hz}$ to $20 \mathrm{~Hz}$.

The EMC assessment Included scatter from the power beam in addition to sidelobe distributions and the reradiated and harmonic components from the rectenna elements in evaluating the geographic extent 4 of EMC probems. Reflected and radiated components from the rectenna are expected to be about $10^{-4}$ to $10^{-6}$ of the amplitude of the direct beam throughout any area in which these components could cause responses in receivers (reference patterns in Figures 14, 15, and 16). Refract Ive index gradients Integrated over the full altitude range are not sufficlent to produce significant power densitles at any terrestrial, alrcraft, or space vehicle location.

In areas that receive comparable amount of power from two or more SPS structures, microwave field strengths will be modified by power-beam interference effects, particularly if all SPS transmissions use the same frequency. Frequency differences between transmissions, due to Doppler shifts associated with orb1t perturbations or spacecraft frequency off set and atmospheric anomalies, w1ll result in modulation of the flelds. "If the SPS orbit position is maintained to $0.1^{\circ}$, modulation frequencles due to Doppler shifts will be less than 10 hertz. Local field strengths will be further modifled by reflectlons from terrain, bulldings, trees, and moving vehicles.

This possible interference effect can be eliminated if the SPS power transmissions are assigned to different frequencies within the ISM band. Frequencies could be reused at least 4 times over CoNUS and allow adequate geographic separation to eliminate these interference effects. Separation of at least $10^{\circ}$ longltude would be satisfactory.

\subsection{MICROWAVE FIELDS IN STRUCTURES}

It is necessary for the EMC analysis to know the SPS microwave fleld strengths that would be expected Inslde various structures, particularly bulldings and vehlcles. Theoret1cally, such structures could concentrate incldent microwave energy to produce fields more intense than would otherwlse be expected. Little work has been done explicitly on this problem, but a substantial body of theoretical and experimental information is avallable on the coupling of microwaves into enclosures and their behavior therein. An exact, detalled analysis of the microwave properties of habitable structures ls not practical because of the tremendous varlety of materlals and complex geometries involved. The problem of estimating the flelds inside habitable structures exposed to microwaves near an SPS rectenna has been analyzed in a topical report by Liebe (1980), with particular attention to the possibility of increases in fleld strength. That study describes and discusses relevant physical processes, 1 ists measured values for many of the quantities involved, and cites actual microwave fleld strengths measured Inside houses exposed to $2.6-\mathrm{GHz}$ radiation from a satellite. Key results are summar1zed below.

To determine microwave field strengths inside a structure, the coupling of energy into the structure, and its behavior inside, including reflections (possibly resonant), must be understood. Coupling to the interior could occur via relatively microwave-transparent openings (windows, for example) or through wall materfals, which in general do not transmit microwaves as well. The following approximate microwave transmissions for representative structural elements have been measured:

\begin{tabular}{|c|c|c|c|}
\hline & \multirow[b]{2}{*}{ Structure } & \multicolumn{2}{|c|}{ \% Transmission } \\
\hline & & Dry & Wet \\
\hline$\cdot$ & $\begin{array}{l}\text { Wooden Wall } \\
\text { Frame Wall } \\
\text { Window (wood sash) }\end{array}$ & $\begin{array}{l}15 \\
40 \\
70\end{array}$ & $\begin{array}{r}6 \\
15 \\
40\end{array}$ \\
\hline
\end{tabular}

Metal walls or screening, or even foll, transmit very 11 ttle $2.45-\mathrm{GHz}$ microwave energy (less than $1 \%$ ) if openings or jolnts are less than an inch long.

Average fleld strengths Inside structures are expected to be less than those outside because of coupling losses. The structure could, however, alter the spatlal distribution of energy to produce localized areas of Increased field intensity. Reflections within structures are the most 11kely causes of locallyincreased field strength. Metallic surfaces are the most common elements of habitable structures likely to produce significant fleld increases. In the absence of any absorbing material, a single metallic reflection could increase power density at some locations by as much as a factor of four above that incident on the surface. More complex geometries involving multiple reflections could, in principle, produce larger fleld increases. However, such large increases require speclal geometries and very little microwave absorption in the system. Neither of these criterla is 11kely to be satisfled by real 
habitable structures. In particular, it' should be noted that the presence of people, who are significant microwave absorbers and reflectors, modifies reflection patterns in a time-varying way; as the people move and absorb energy they reduce the fleld increases that might otherwise occur.

Ratios of microwave fleld strength inside to that outside single family houses 11luminated.by 2.6-GHz microwaves from a satellite have been reported (Wells, 1977). Average fields inside were found to be about $25 \%$ of those outside, although interior fields varied substantially from point to point. For the case of highest ratio for average inside flelds to outside fields, the probability of encountering a microwave fleld inside that was larger than that outside was only $15 \%$. Considering both the losses in coupling microwave energy into structures and the low probability of situatlons that would produce significant concentrations of energy, we conclude that interior field strengths significantly higher than those outside are unlikely. If, In specific cases, intertor microwave flelds were found to be a problem, they could be reduced by reducing coupling or increasing intertor absorption.

Vehicles provide shielding because of the metal construction. Automobiles, alrplanes, buses, and raflroad cars have metal roofs and side panel areas. The future use of composites and plastics in automobiles will reduce shielding effectiveness by 6-10 dB depending on materlal. Window areas provide Iittle attenuation for direct and reflected microwave power.

Previous measurements (NBS, 1974; ITS, 1975) of microwave fields inside automobiles Indicate"an average attenuation of external fields of $\approx$ 6-12 dB for frequencies in the 1-4 GHz range. Energy coupling included windows and body area openings. For vertical incidence fields, the passenger area attenuation would be 9-12 dB, with the varlation primarlly caused by the reflection characteristics of nearby roadway or structures.

Commerclal aircraft flying through an SPS power beam will have powers reflected from wing surfaces in the range of $20-50 \mathrm{~kW}$, with approximately $60 \%$ of this power reflected away from the fuselage because of wing surface curvature and dihedral angle. The short term exposure to passengers is insignificant because of the small window area and the short time exposure $(20.5-1 \mathrm{~min})$. Public vehichles would be excluded from a rectenna area, and would not be exposed to more than $0.5-1 \mathrm{mw} / \mathrm{cm}^{2}$.

\subsection{THERMAL BLACKBODY RADIATION}

The large (approximately $50 \mathrm{~km}^{2}$ ) photovoltaic arrays on the SPS structure w111 operate at temperatures of approximately $300^{\circ} \mathrm{K}$ and are expected to have significant microwave emissivity, The spectral flux density at the earth due to blackbody radiation $1 \mathrm{~s}$ approximately $-265 \mathrm{~dB}\left(\mathrm{~W} / \mathrm{m}^{2} \mathrm{~Hz}\right)$ at $2.45 \mathrm{GHz}(1 \mathrm{ncreasing}$ $6 \mathrm{~dB}$ per frequency octave for a single. SPS structure assuming $10 \%$ microwave emissivity of the photovoltaic array. (Array emissivity might be as much as a factor of 10 larger or smaller.)

Figure 17 shows estimated levels or ranges of spurious emissions from the MPTS, thermal emission from the photovoltalc arrays for a single SPS structure, and some established and estimated interference levels. This plot illustrates power spectral densities for the most sensitive susceptible systems caused by SPS operations, and indicates limits currentiy def ined by CCIR and ITU regulations: The lower ranges of interference $1 \mathrm{imits}$ shown are generally for antennas pointed at or very near (within 10 of) an SPS structure. The noise sidebands are typical of 5-cavity klystrons (Figure 12) and would vary if different. power amplifiers (magnetrons, gyrocons, gyrotrons) were used for SPS.

\subsection{SCATTERED SUNLIGHT}

Because of the. large sunlit area of the SPS structures, they will, unless they are extremely good absorbers, be conspicuously bright objects in the'night sky. Using a value of $4 \%$ for diffuse scattering from the photovoltaic cells, representative of the darkest present cells, each satellite of the Reference System design would appear at midnight to be as bright as the planet Venus ever appears ( -4.3 stellar magnitude) and thus brighter than any other object in the sky except the sun or moon. In addition to the very bright points produced by each spacecraft, large areas of the sky would be brighted because of rescattering of light in the earth!'s atmosphere. The addition of this amount of light to the night sky would seriously affect optical astronomy and other scientific observations requiring dark skies. Scattered sunlight is discussed further in Section 10.2. 


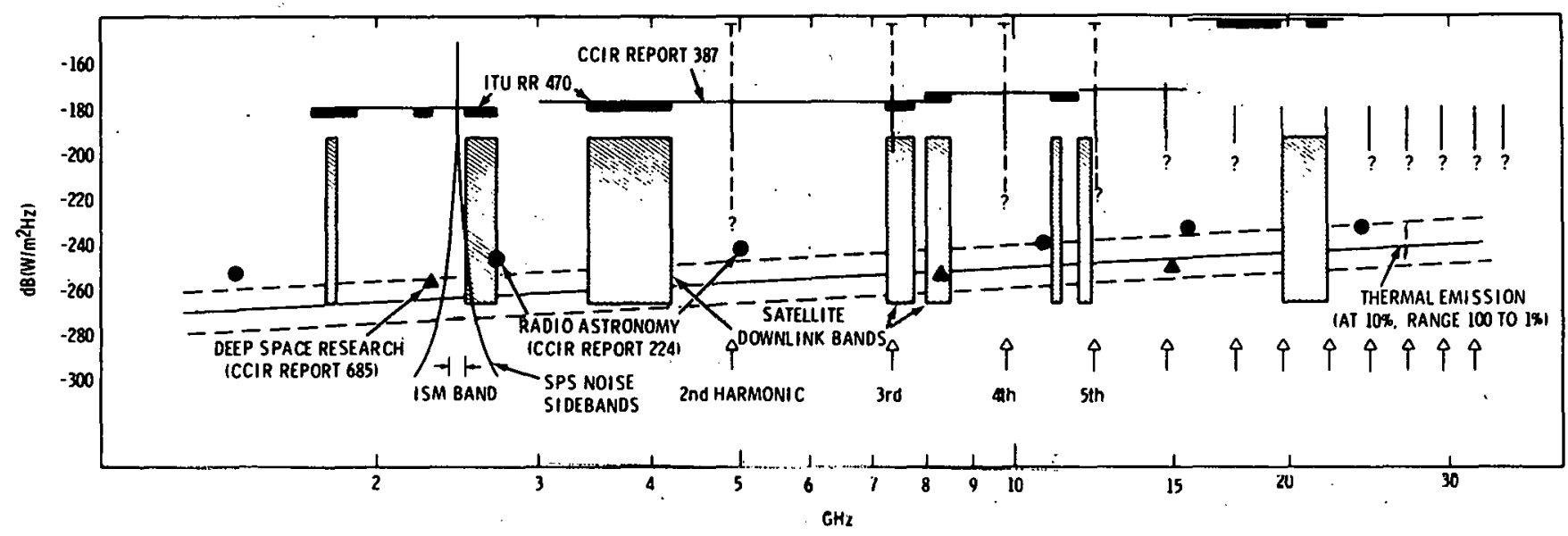

Figure 17. Estimated Microwave Spectral Flux Densities at the Surface of the Earth as a Function of Frequency for One SPS with Relevant Interference Limits.

\subsection{EFFECTS ON MAJOR EQUIPMENT CATEGORIES}

The evaluation of the degradation in performance of electronic equipment because of SPS interference relled primarily on measurements of coupling modes to circuits and devices, and the resulting effects in operations. Discrete component and integrated c1rcuit configurations of the various system categorles were tested to maximize relevance to future equipments. The effects data are relatable to LSI and BLSI configurations that will dominate future electronic equipments, allowing significant increases in processing and control capabilities.

The principal equipment/system categories evaluated include comminications and radar receivers, optical and electro-optical sensors, data processors, computers, and speclal equipments such as radio astronomy receivers and medical clinic diagnostic components.

Specific equipment applications evaluated in this EMC investigation, because of unique sensitivities and future nat Ional priority, include GEO and LEO satellite systems; and military test range and operations support, transportation command/control, and terrestrial common carrier communtcations. Particularly in the satellite services, varlous equipment categorles are represented, including communications and radars, optical sensors for altitude stabilization and earth monitoring, scientific data collection, and computers for station keeping management.

Mitigation techniques to allow these equipment to operate effectively in the sps environment are discussed in Section 6.0. These mitiglation methods include circult and shlelding modifications; and for computer controlled advanced communications and radar systems, the use of processing and control routines to reject or cancel the SPS interference components.

\subsection{COMMUNICATIONS RECEIVERES}

A general radio frequency communications recelver is diagramed in Figure 18. The configuration includes ali functions of a recelver that would be impacted by SPS interference inpuis.

Referring to the dlagram, the inputs Indicated for normal operation include the desired stgnal and external nolse. Typical signal inputs include an unmodulated carrier or an amplitude or frequency (AM or FM) modulated carrler. Familiar communications signals in the microwave spectral region include FM analog voice; $A M, F M$, or $P M$ single channel or frequency multiplexed voice and data transmission (FM/FM or PM/FM); and time multiplexed analog or digital volce and data channels.

General communications recelvers Include the antenna, first conversion, and conversion-detection elements of Figure 18. Basic functions include radio frequency amplification with filtering, signal mixing, intermedlate frequency ampiffication, and signal detection, as diagramed in Figure 19 . These functions are typical of telemetry terrestrial common carrier, dedicated microwave communtcations, and space communications equipment. 


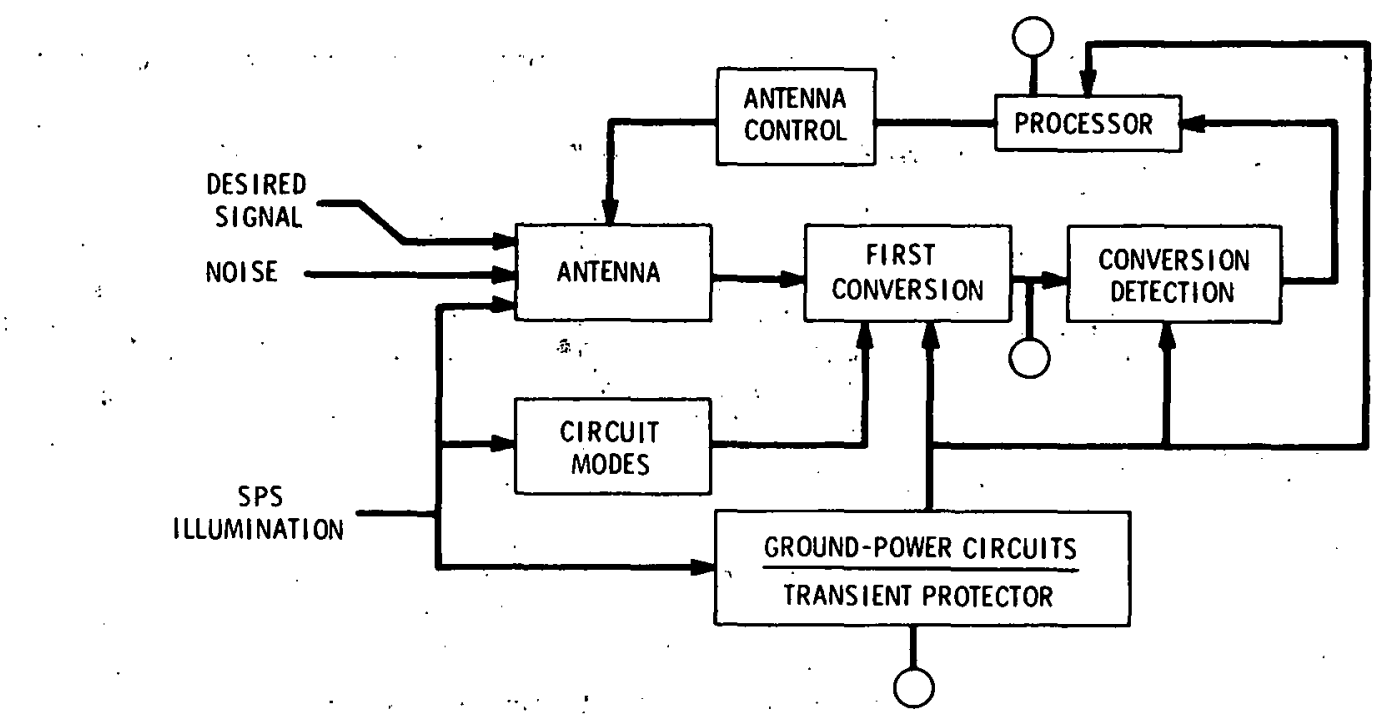

Figure 18: Generalized Block Diagram of a Telecommunication Recelver. Circles indicate EMC performance scoring points.

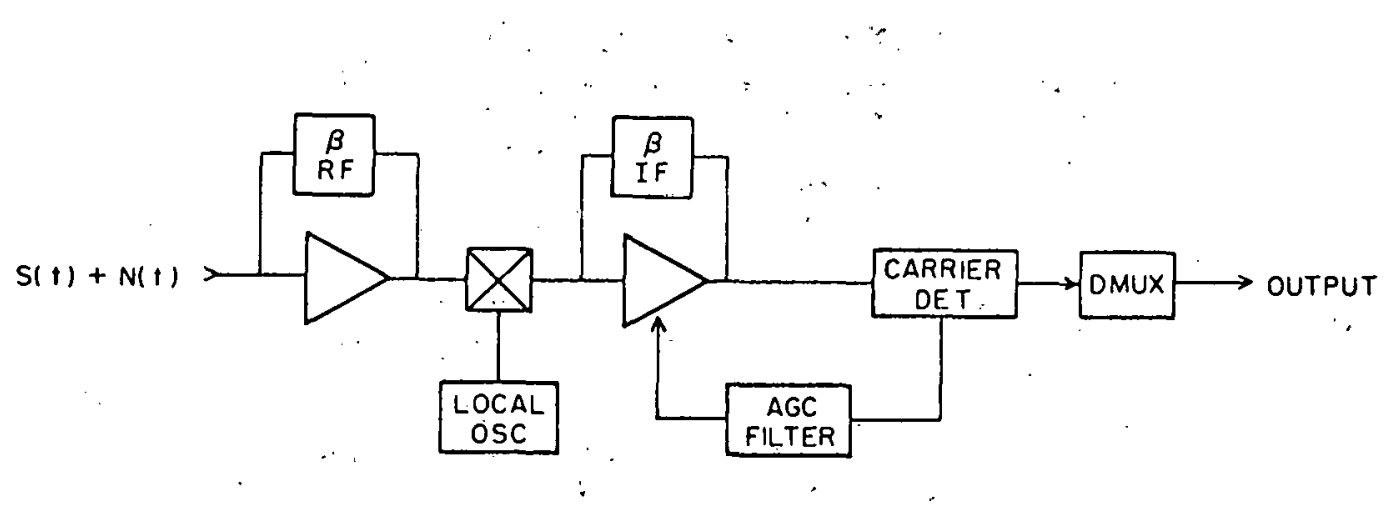

Figure 19. Receiver Functional Diagram

Where a communications receiver is located in a high interference environment, a signal tracking function is necessary to steer the antenna in the direction of the signal source, or steer an antenna nuil in' the direction if the interforor. These tidiklng functions are represented in the Antenna control loop in Figure 18. Actual implementation would use nulilng antennas in conjunction with the primary antenna; or in future systems utilize a phased array where the acceptance beam width for the desired signal and the rejection beamwidth for the interferor would be accomplished by beam forming and pointing computer routines controlled by detector outputs. Phased array receiver systems can perform these beam control functions.

The SPS interferor is coupled to receivers through the modes 11sted (refer to Figure 18).

1. Direct entry into the signal channel-antenna, radio frequency. amplifier, and the first conversion stage.

2. Coupling to radio frequency or intermediate frequency circuits; energy penetration. through: nonmetallic areas of module cases.

3. Coupling to ground circuits and transient protection components. The ground.circuit mode involves cabling having a modest impedance above a ground point commion to other modules ( $\geq 10 \Omega$, : with the junction(s) having a diode characteristic which causes noise transmission in the ground cirçuts to receiver elements. 
These modes are indicated in Figure 18.

The listed types of communications recelvers were tested.

1. 30-channel FM/FM telemetry receiver-IRIG subcarrier channels, analog and PCM data formats.

2. 100-channel frequency multiplexed recelver-system used for common carrier and dedicated network services,

3. 10-channel frequency mult1plexed spread-spectrum recelver, m1l1tary data 11nk, satell1te, or terrestrial point-to-point links.

The desired signal and SPS fundamental and harmonic components were coupled as indicated in Figure 18. Functional data was recorded at points indicated by the circles. The signal combination and output characteristics recorded are listed in Table 3.

TABLE 3. Receiver Evaluation Parameters

\begin{tabular}{cc}
\multicolumn{2}{c}{ TNPUTS } \\
$3 / N(d B)$ & $S / S_{\text {INT }}(d B)$ \\
12 & 3 \\
30 & 9 \\
& 30
\end{tabular}

PERFORMANCE DATA

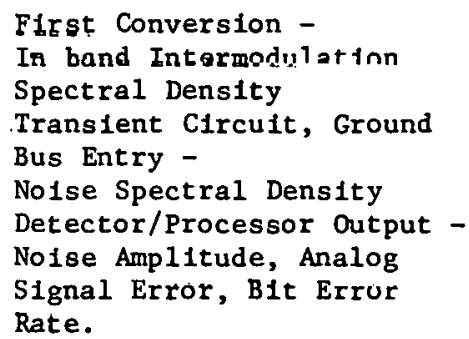

The desired signal(s) was varied as indicated in the S/N values, replicating the signal format appropriate for the various receiver processors. The SPS interferor ( $S_{I N T}$ ) included the fundamental and second and third harmonics with ratios ds defined by the aooumed emission spectra in Figure 10.

A representative intermodulation spectra at the first conversion stage output is displayed in Figure 20. The data with the different $S / I$ values relates to an $S / N$ of $12 d B$. The range of noise generated by transient protectors with two SPS fundamental illumination levels $\left(0.1 \mathrm{mw} / \mathrm{cm}^{2}\right.$ and $\left.1 \mathrm{~mW} / \mathrm{cm}^{2}\right)$ is presented in Figure 21. These data include ground bus junctions and diode protectors as noise sources.

The composite of communications receiver responses are plotted in Figures 22 and 23 . These particular receiver and system metrics indicate the range of SPS interferor effects on communications receiver performance and a typical system level data liput-output impact.

The principal functional effects for a communications receiver are listed.

1. Intermodulation products generated by the first conversion stage.

2. Circuit noise coupled from the ground bus and translent protector devices.

3. Direct coupling into high gain intermediate amplifiers, increasing noise levelo, and, for the larger interferor levels $\left(\sim 1 \mathrm{~mW} / \mathrm{cm}^{2}\right)$, causing desensitizarion becuuse of AGC action.

4. SPS harmonics in a communications band (e.g., third harmonic in the satellite uplink band) cause unacceptable degradation when the $\mathrm{S} / \mathrm{I}$ ratio $1 \mathrm{~s}$ below the 6-15 dB range, depending on data channel bandwidth and modulation employed. If the SPS harmonic amplitudes relative to the fundamental are in the range cited for the klysirun cubes in Figure 10, the harmonic in-band interference will affect satellite termina1s, GEO transponder receivers, and radio astronomy and deep space communications systems. These latter equipments are discussed separately ith sections 9.0 and 10.0 .

\subsection{RADAR SYSTEMS}

Radar equipment evaluated for SPS interference susceptibility includes fixed site alrborne, and future space systems. The applications tested include surface, alrborne, space target detection and tracking, velocity control, and various military command/guidance functions. Radar conflgurations vary significantly for these applications; major functional elements for specific applicat lons are listed below. 


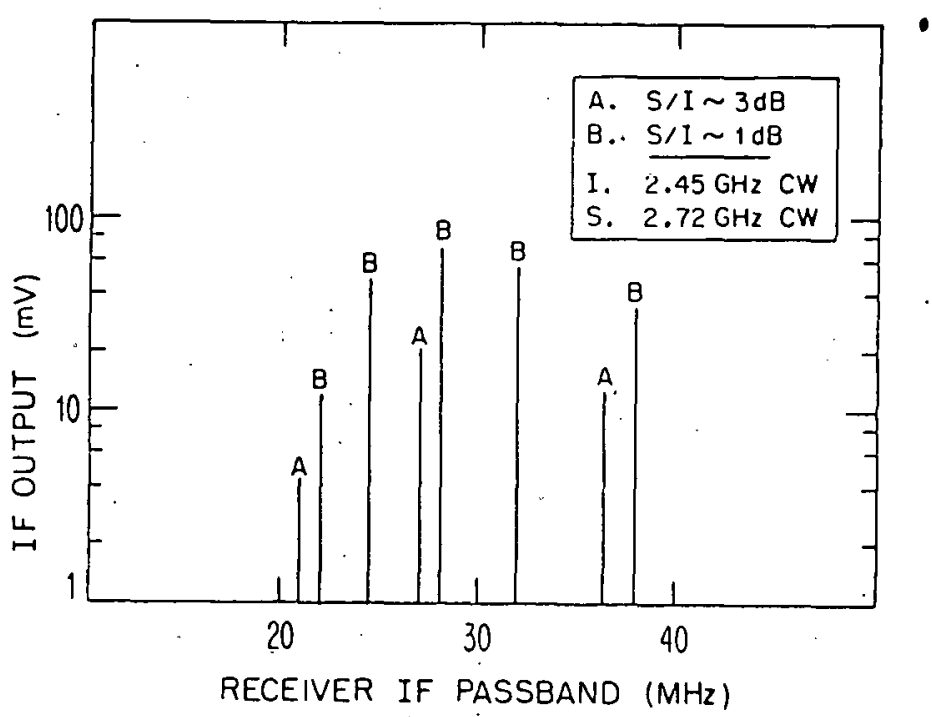

F1gure 20. Example Recelver Intermodulation Responses

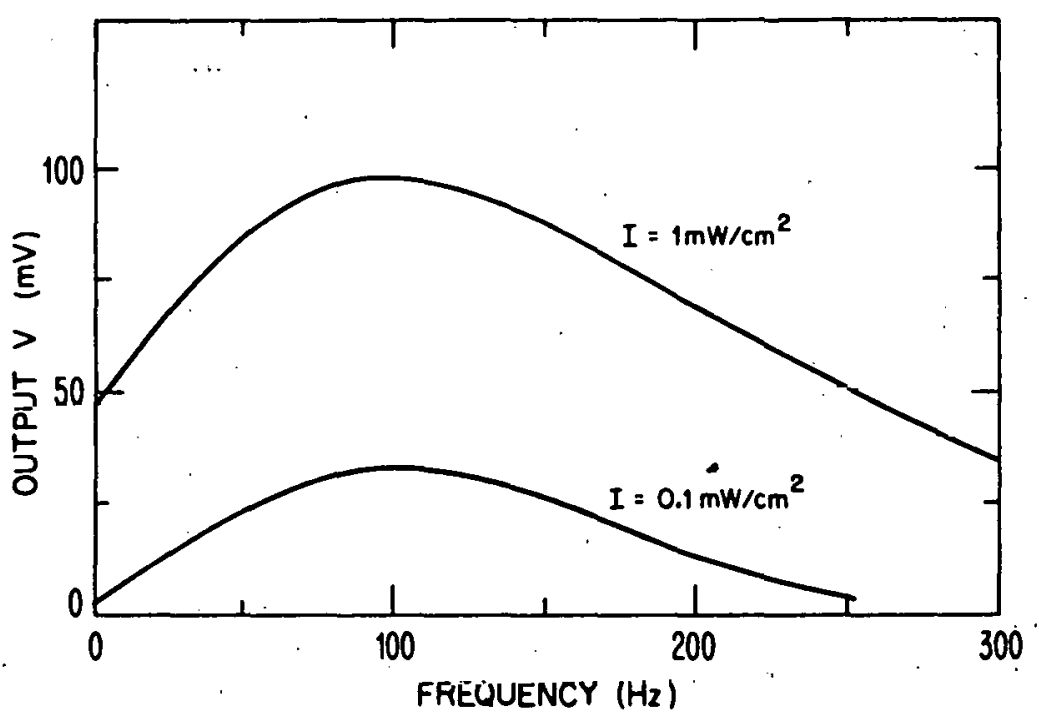

Figure 21. Mejal Translent protector Dlode Nolse Spectra 


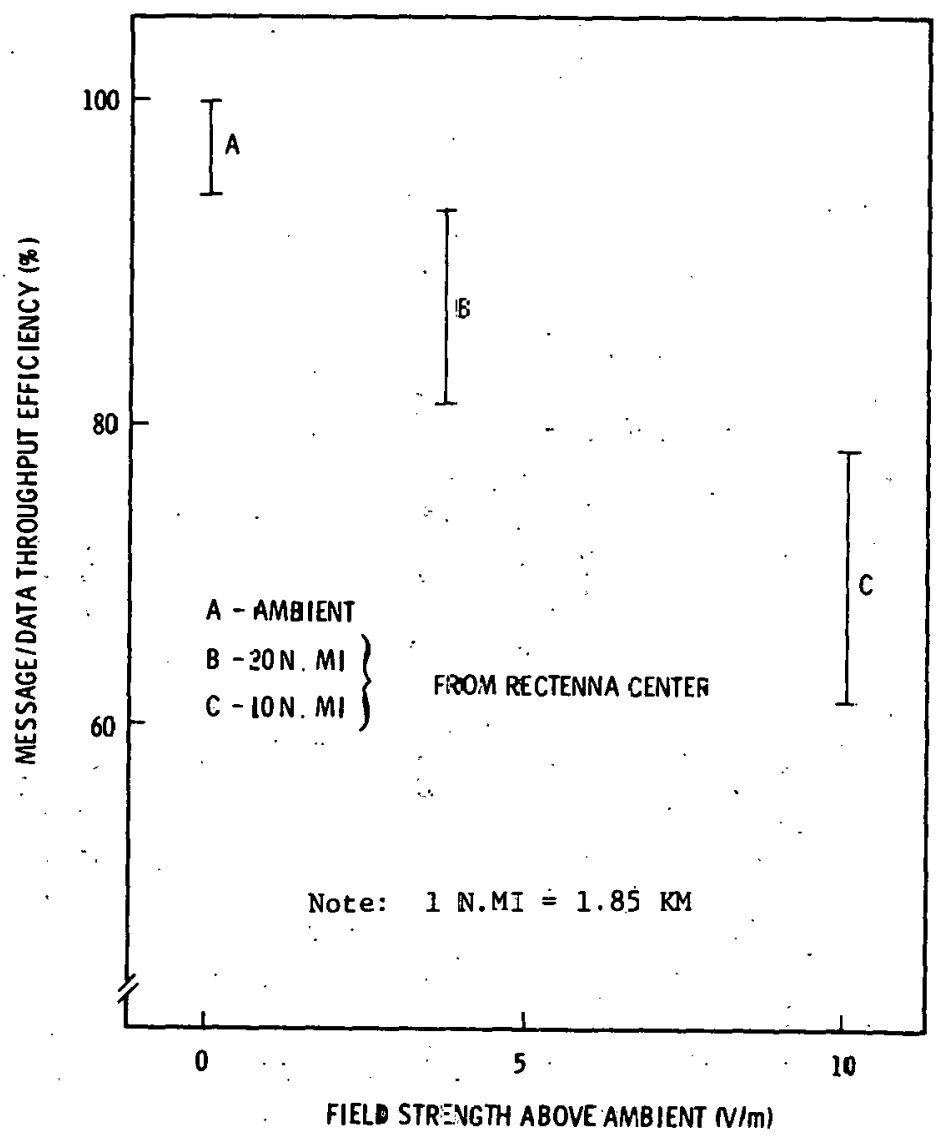

Figure 2i. Effec:s of Microwave Illumination on Throughput Efficiency of Receivers.

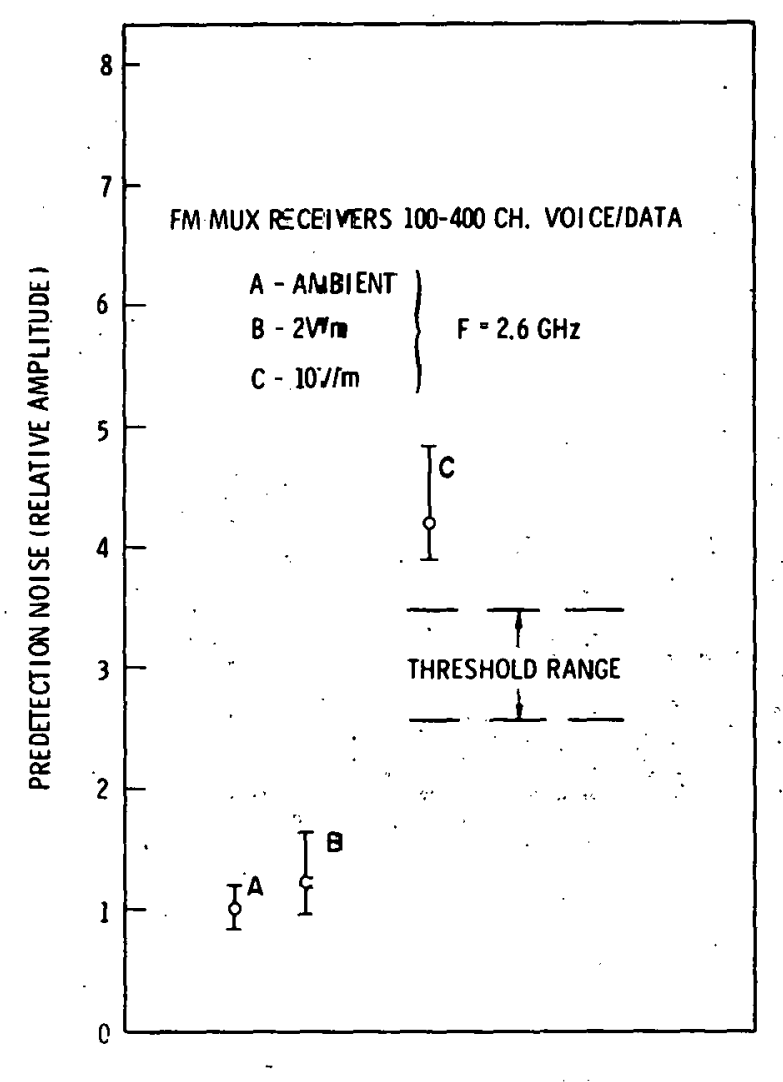

Figure 23. Mu-tichannel Microwaye Recelver System Prædetection no1se Increase due to Mi:rowave Illumination. 


\section{APPLICATION \\ Alr Traffic Control \\ Area Surveillance \\ Early Warnlng/Search}

Instrumentation/Track Military Test Range, Weapon Guldance

Mapping

Terrestrial Target

Detection
FUNCTIONS/MODES

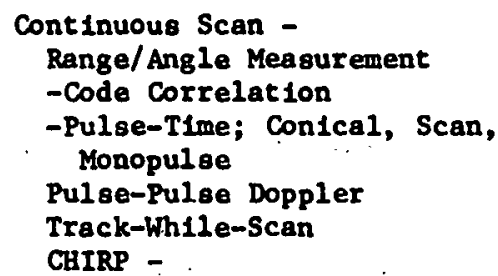

Range/Angle Measure

-Code Correlation

-Pulse-Time; Conical Scan

Monopulae

-ON-AXIS

-Track-While-Scan,

SImultaneous Muit1-Target

Track

Coherent Doppler

-Pulse to Pulse Frequency

hopping

-Pulse Burst, Open Band

Doppler Beam Sharpening

Synthet Ic Aperture Formation
INTERFERENCE REDUCTION FUNCTIONS

Clutter canceller

Clutter filter

ECCM

Antenna nulling

The Interference Reduction Function heading Indicates processes included in radar systems for multipath or external signal interference reduction, and which would be degraded by the SPS interferor. For those listed, the primary initigations would involve computer software modifications.

The performance of the various systems is based on the following characteristics which were used to measure the effects of SPS interference.

a. Surveillance and Search - Target detection range, target Identification time, false target probabilities.

b. Track and Guldance - Target lock-on t1me, track error distribution, loss of 1ock probab1lity, and control action delays (weapon time line actions, interference nulling).

c. Mapping and Terrestrial Target Detection - Target detection range, spatial resolution, and terrestrial feature resolution.

Because many radar detection and preprocessing functions are similar to those of communications systems, radar systems exhibit interference susceptibilities similar to those of communications receivers. Interference 1s coupled through the radar antenna and by conduction from external transient protector devices and multipoint ground busses. Figure 24 shows a generalized radar system diagram with EMC evaluation points indicated by circles. The definftions within the PROCESSOR apply specifically to computer controlled array (Track-While-Scan) systems. Similar functions would be implemented by circuitry for a mechanical pedestal system. The principal interference effects are listed below.

INTERFERENCE PRECURSORS:

Predetection Noise

Intermodulation components

Signal Path Noise

FUNCTIONAL EFFECTS:

Video Pulse Distortion and Jitter

Range and Angle Channel Noise

Target Acquisition Delays and Track Loop Instab1lities

Spot Beam Acquisition Delay and Jitter

Code Track. Loop Errors and Increased Probab1lity of Loss of Lock

Clutter Filter or Map Nolse

-Increased peak of average rat los

Reduced Resolution in Beam Squint and Increased Squint Jitter

Increased Kalman Filter Instabilities 


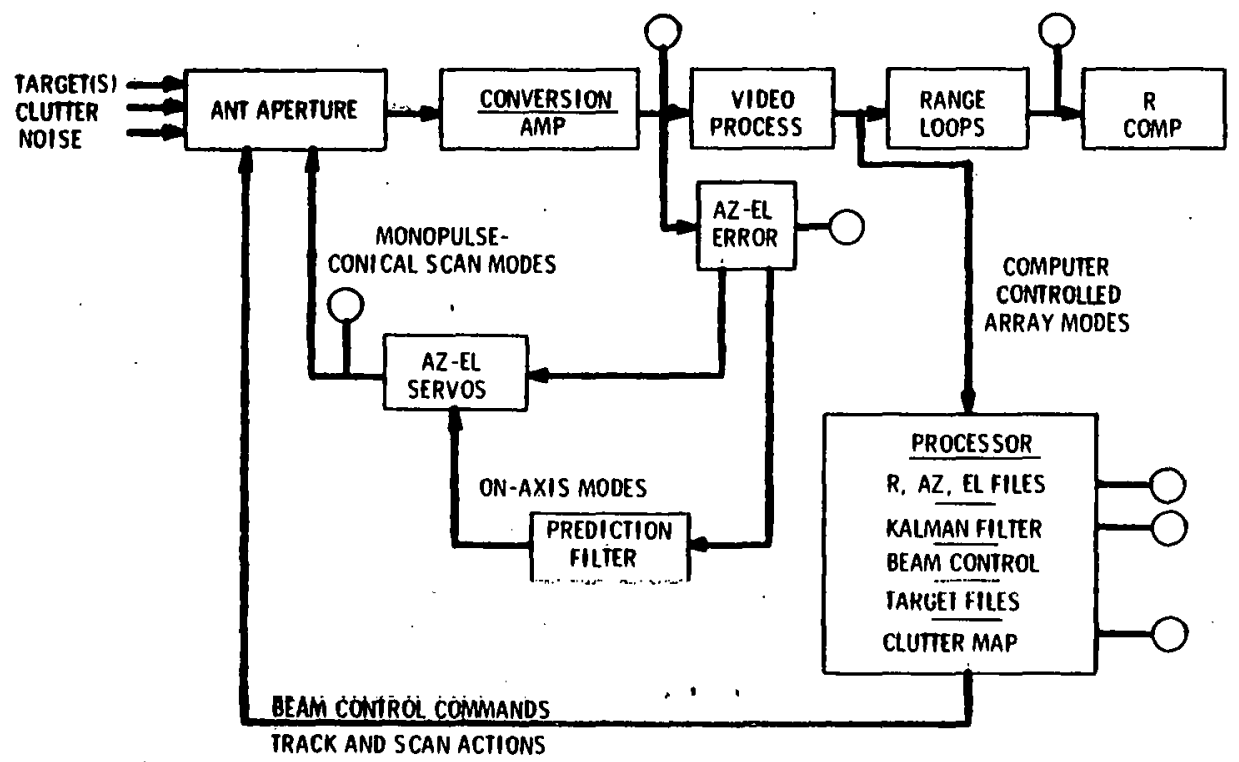

Figure 24. Generalized. Block Diagram of a Radar System.

Circles indicate EMC performance scoring points.

Interference tests were conducted on military instrumentation radar systems in the southwestern United States. The following type of radars were tested: FPS-16, FPS-95, MPQ-25, N1ke Hercules, and N1ke Ajax. These systems represent conlcal scan and monopulse configurations.

Figure 25 indicates the degradation of range detection capability for two different recelved powerto-interference ratios $\left(P_{r} / I\right)$ and conditions of cooperative (or transponder) track, and skin track. The interfering stgnal frequency was $2.45 \mathrm{GHz}$ while the radar operating frequency was in $\mathrm{C}-\mathrm{band}$. It is easily seen that the range performance parameter changed by a factor of approximately two (2) for a decrease of $6 \mathrm{~dB}$ in the $\mathrm{P} / \mathrm{I}$ rat1o. The "worst case" skin track measurements Indicate that the maximum radar detection range was ${ }^{r}$ decreased by approximately $33 \%$. These data include al1 or lentat 1ons of the target relative to the radar. Figure 26 shows the track noise (a contribution to track error) during the sume tests.

Figure $27 \mathrm{is}$ similar to Figures 25 and 26, but with different test stinuil and a different recelver response to the interfering signa1. The interfering oignal was generated-at a frequency of $3.1 \mathrm{GHz}$ from an airborne platform $(A / C)$ covering the interference source. The recelver system incorporated an interference canceller (filter) to reduce the off-frequency interfering signal. Here the radar system response was the target lock time in milliseconds (ms). Again, the radar system's performance is degraded by approximately $6 \mathrm{~dB}$ in the $P_{r} / I$ rat to when the nolse canceller is used in cases $A$ and $B$ (reference Figures 25, 26, and 27). In situation $C$ where $P_{r}=1$ the probability of lock is reduced to approximately 38\%. A single measurement series was accomplished with SPS fundamental interference to a military phased-array radar. The reduced squint resolution in relation to target echo-interference ratio 18 indicated in Figure 28. This effect results from signal channel nolse for the higher range of S/I ratios, with intermodulation components being the major contribution of the lower S/I values.

The SPS interference effects on a varlety of milftary radar Instrumentation used at test ranges near the hypothetical Mojave rectenna site, and other western area test facilitles are summarized in Table 4. These tests apply to radar coverage of the full upper hemlsphere.

TABLE 4

M11 Itary Instrumentation. Radars

Cooperat ive Target Acquistition Range: Reduced by 8 to $20 \%$

Skin Target Acquisition Range: Reduced by 13 to $28 \%$

Cooperative Target Track Error: Increased by 15 to $40 \%$
Skin Target Track Error: Increased by 22 to $65 \%$

Loss of Track Loop Lock (Skin Mode): Probabllity increased by 10 to $40 \%$ 


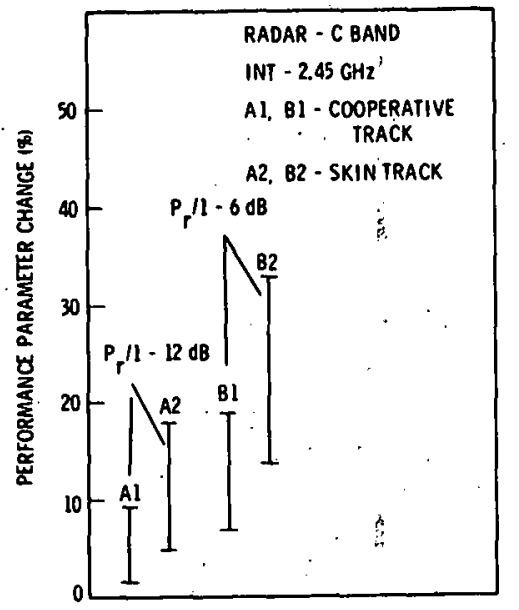

F1gure 25. Decrease in Radar Detection Range caused by $2.45-\mathrm{GHz}$ Interference.

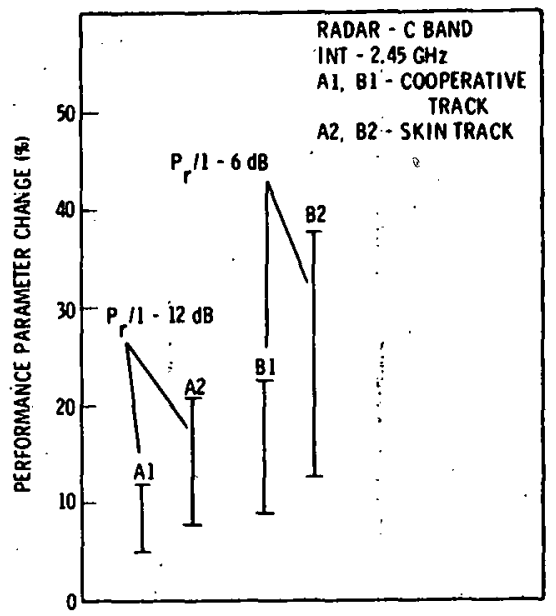

Figure 26. Increase in Radar Track Nolse caused by $2.45-\mathrm{GHz}$ Interference.

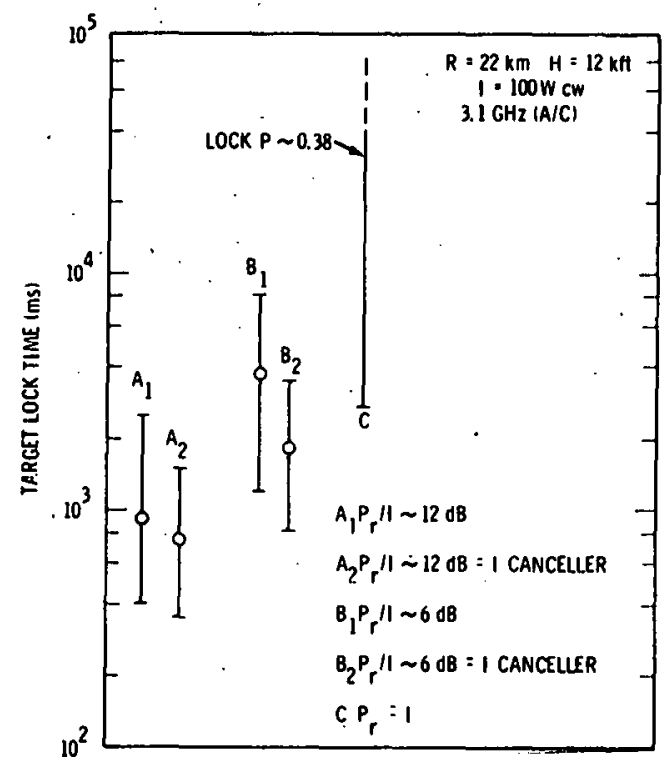

F1gure 27. Increase In Radar Target Lock Time caused by M1,orowave (3.1-CHB Interference. 


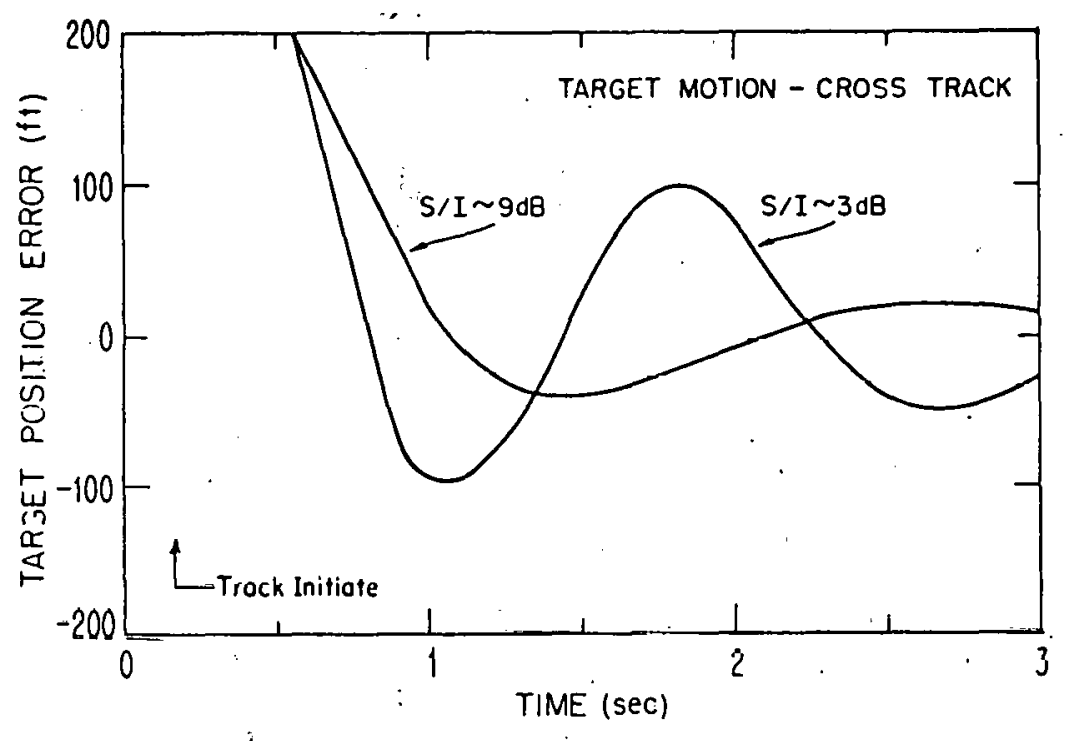

Figure 28. Array Radar Track Characteristic Squint Software - S/I Sensitivity.

Testing so far has Included conical scan, monopulse, on-axis, mechanical steered systems, and a single phased array radar. The phased-array system included software-controlled scan mode control, multitarget (100 maximum) simultaneous track with Kalman prediction routines for the Individual track files, and a single channel squint mode. The computer routines used for squint (signal nulling) control would be useful for SPS interference removal with modifications to accommodate the phase modulation of the SPS signal caused by troposphere anomalies. Existing squint routines have been designed for famer rejection where moving source Doppler or fixed sources are located within a short distance ( $1-5 \mathrm{~km}$ ) from the radar. Filter coefficients and possibly a rate compensation may be required to accommodate the media modulation of SPS components, and maintain a null of 40-60 dB.

\subsection{COMPUTERS AND PROCESSORS}

The primary concern in the susceptibilify of cumpulel and data procoseor oystemis to SPS interference relates to minfcomputers and microprocessors, particularly as employed for remote facility support operations. Areas of application include utility and plpeline command/control, communications network control, transportation service command/control, and military test facility and weapon system control. Computer/processor configurations include centralized units connected to data sources (e.g., remote sensors, entry terminals) and distributed processing systems that interconnect processor modules (central processor, memory, storage) through communications inks. Such configurat Ions of microprocessor and minfcomputer units are used for a-wide range of remote coumand/control operations.

Discrete component and integrated circult modules have been tesţed. Modules include 1nput-output regfaters and central processor (reglsters, memory) functions. The nolse sensitivity and transfer error data presented herein include both circult module types.

Microwave coupling is accomplished by penetration through nonmetallic cover or case apertures, to circult devices and device-component interconnections. Device induced noise is coupled to modules through ground and control lines ui calling, or 1ndueed by input-nut-put connect 1ng cabling. Circuit effects include bias shifts. In $\log 1 \mathrm{c}$ and control units (e.g., FET devices, diode level sets), and nolse conducted onto ground and control module connectors that cause false logic set/reset transitions. This latter effect increases in sensitivity with transition and clock rates. As cited previously, functions affected include input-output reglsters and control logic, central processor units, memory (FET, diode), and control and transfer actions for peripherial devices. The basic functional modules are indicated in F1gure 29. 


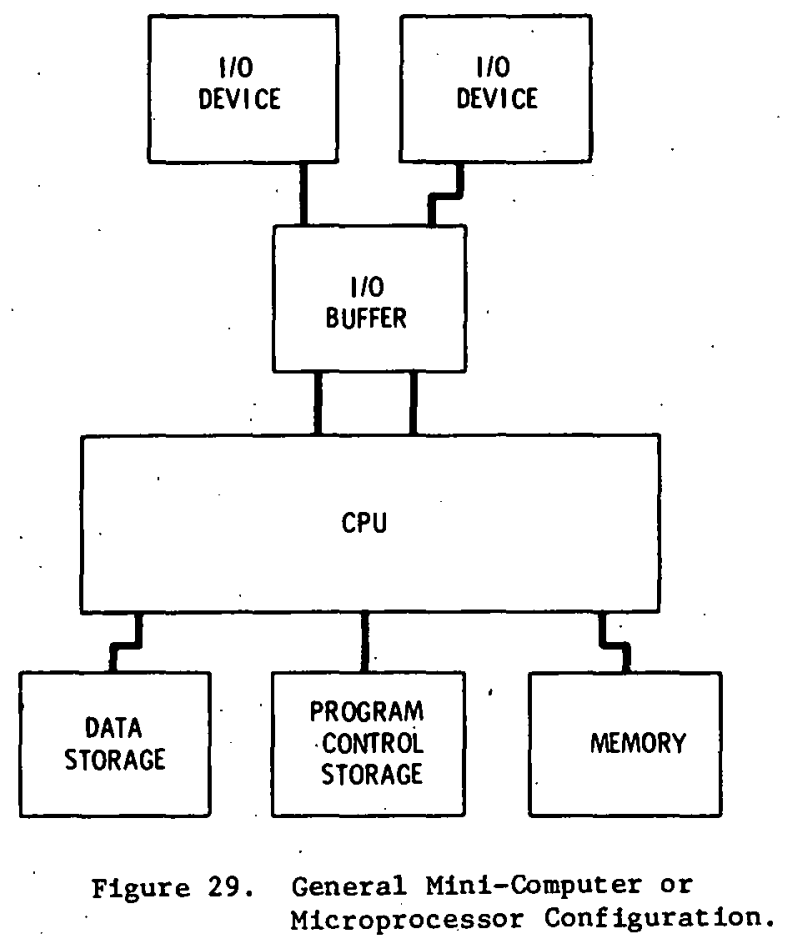

Measurement points for computer modules are 11sted.

1. I/O register read-in and read-out terminals.

2. Arithmet1c register in-out terminals.

3. Ground bus at module interconnections.

4. Memory control gates (OPEN and INHIBIT levels).

5. Register bias levels (discrete component configurations).

Module and system performance criteria Include ground bus noise, clock jitter, control channel noise and jitter (gate pulses, reglster command); and bit-error rates in throughput operations for major modules (e.g., Input-output, processor unit, and memory input-output). Figure 30 illustrates the percent increase in control pulse $j$ itter present in the clock and control circuitry of the $I / O$ memory registers for the microprocessors. The spread in data is due to the different responses to the 2.6GHz interference signal presented by the different manufacturers' equipment and to whether the equipment was deslgued for militäry or commerclal specifications. The percent fitter under normal conditions 18 shown as A (reference Figure 30 ). The jitter increased to $12 \%$ in some equipment when illuminated by a $2.6-\mathrm{GHz}, 2 \mathrm{~V} / \mathrm{m}$ field, shown in $B$. When the interference signal was increased to a $10 \mathrm{~V} / \mathrm{m}$ fleld, the control pulse jitter increased by substantial amounts with the worst case reaching $33 \%$, shown as case $C$. In many circumstances (higher clockrates, large memory fields) the $12 \% \cdot j 1$ tter would not be acceptable, and $33 \%$ would be beyond acceptable level of performance degradation for all circumstances.

Figure 31 shows the increase in a microprocessor's control bus nolse as a function of increased microwave illumination. The threshold is given such that any nolse factor above that ine'would constitute unacceptable performance. In this case the unacceptable interference was coupled through the dlore protector efrcults un the power supply voltages. With a fairly simple modification, the control bus nolse factor could be reduced to an acceptable level (below the threshold 1 ine). The figure shows the data from a repeat test using the same field 1llumination levels but with capacitor bypass modification to the power supply voltages. 


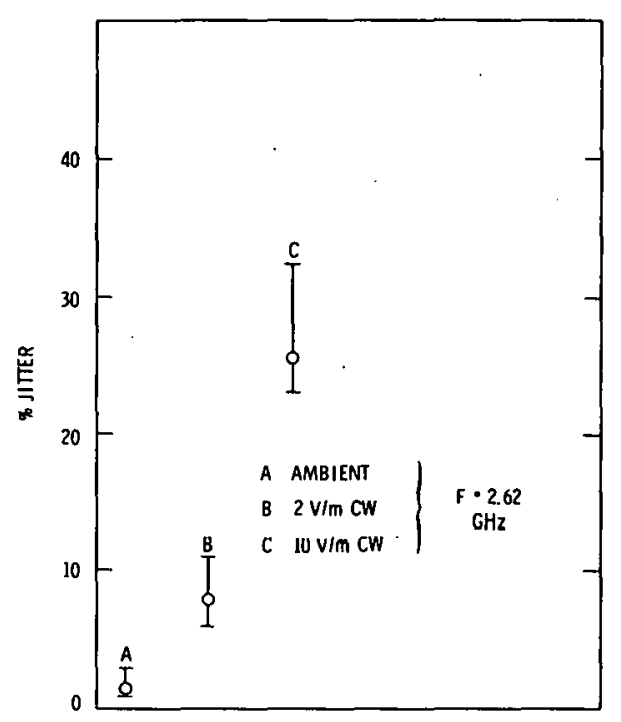

Figure 30. Percent Pulse Jitter in Clock and Control Circuits of Microprocessors illuminated with $2.62 \mathrm{GHz}$ Microwaves.

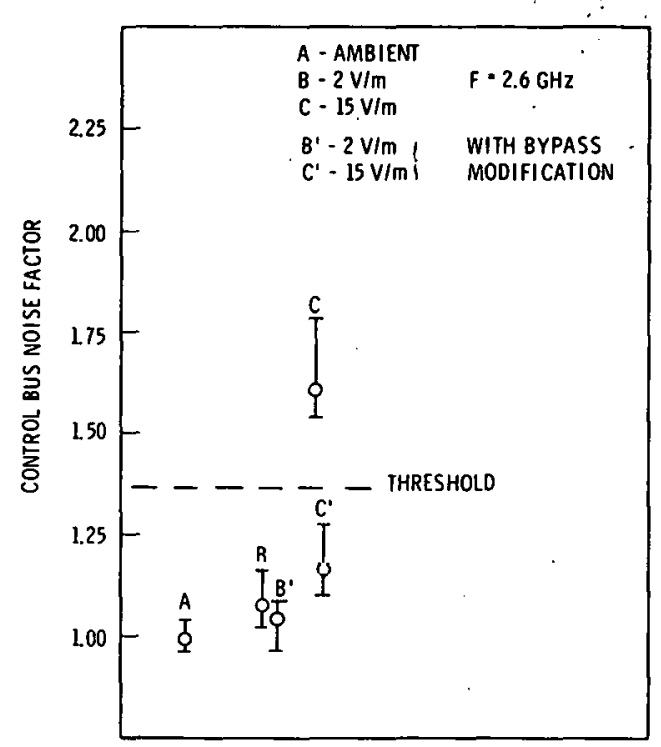

F1gure 31. Increase in Microprocessor Control Bus Noise Caused by Microwave Illumination with and Without Micigating Modiflcat lons.

Figure 32 shows the Increase in memory transfer errors with increased 11lum Inat 1on at the 2.6-GHz frequency. The memory transfer events in the I/O memory register were tracked to measure bit-per-second errors. An additional test with a 200 pulse per second modulation caused unacceptable performance at much lower fllumination levels than the CW signals. Th1s has 11ttle significance for SPS since the present proposed $2.45-\mathrm{GHz}$ signal is $\mathrm{CW}$. It does demonstrate the effects of pulse modulation interaction with clock, control, and data pulses. Pulse Intermodulation events characteristic of medium level interfering levels ( $P_{\text {int }} \geq 0.2 \mathrm{clock}$, control data pulses) are not present with CW interference. For similar effects with CW Interference, amplitudes sufficlent to cause large blas shifts are required. The figure also shows results from a repeat of the above tests for commerclal equipment using a complete wite mesh shield inside the variuus chassis. Much of the chassis material in modern packaging techniques is plastic. Most of these plastics exhiblt very litcle attenuation of miorowave signals. By uslitg. Llie wire mesh with a $9 \mathrm{~mm}$ by $9 \mathrm{~mm}$ grid size, with single point ground where possible, and completely. surrounding the internal electronics, the coupling of the microwave signal was held to an acceptable level. Shielded coaxial cables were also used in place of unshielded or poorly shielded wires for intermodule connections carrying message and control information, further reducling microwave coupling into vital circuitry.

Figure 33 shows the throughput accuracy measured from input port to output purt lor a normal mini... computer operation when exposed to increasing microwave 11 lumination. The data for cases $B$ and $C$ are given with respect to their proximity to the center of a rectenna site; $C$, being closer than $B$ to the rectenna, would of course experience a higher exposure level. Twenty nautical miles would correspond to a field intensity of approximately $4 \mathrm{~V} / \mathrm{m}$, and 10 nautical miles from a rectenna center would correspond to $10 \mathrm{~V} / \mathrm{m}$.

The primary coupling modes for completely shielded modules are ground bus and interconnection cable shielding. Commerclal modules exhibited greater susceptibility because of the reduced effectiveness of system shielding. This latter consideration increased susceptibility to direct circuit coupling through unshielded nonmetallic covers. Increased nolse ( $30 \%-70 \%$ range) in unshielded FET circuitry relative to totally shielded was evident. 


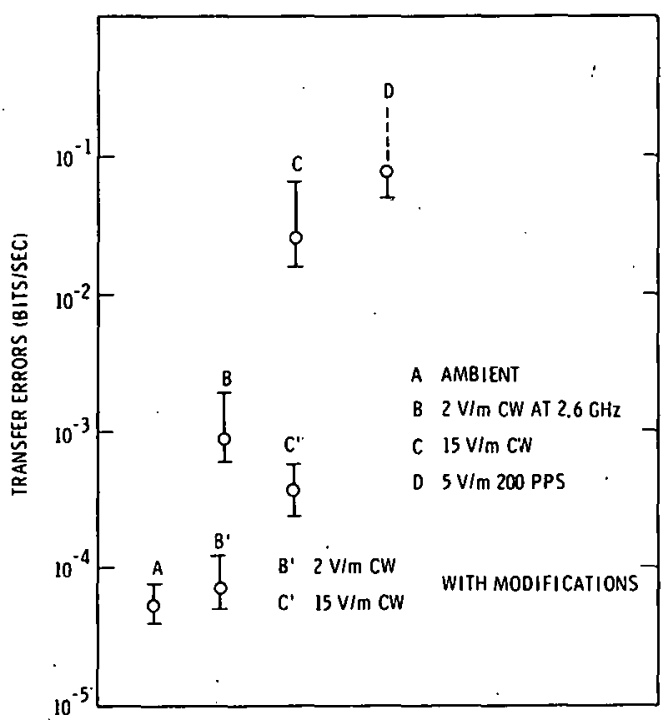

Figure 32. Memory Transfer Error in Microprocessors Illuminated with Microwaves with and without Mitigating Modifications.

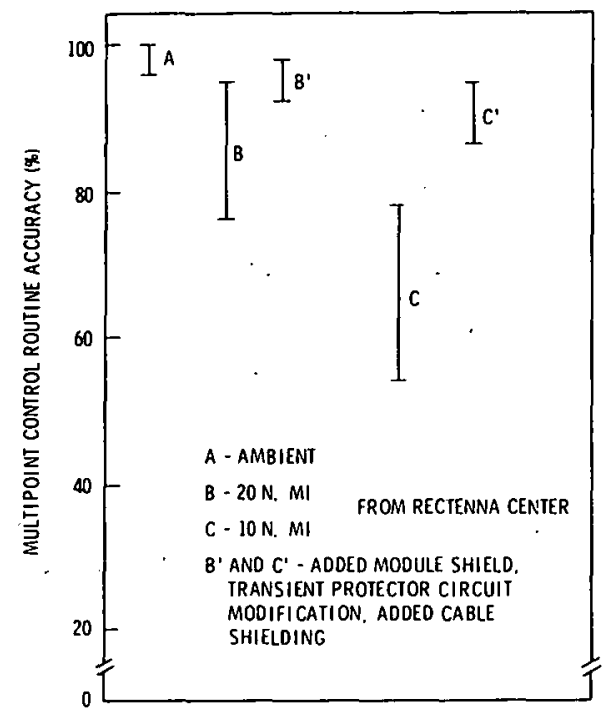

Figure 33. Computational Accuraçy of Mini-Computers Illuminated by Microwaves with and without Mitigating Modifications.

\subsection{INTEGRATED CIRCUITS}

The susceptibility of integrated circults was reviewed to support measurement planning, analysis of effects, specification of mitigation techniques. for computer and control systems and large scale integrated circuits for signal processing in rf receivers and sensor systems.

Interaction between microwave energy and integrated circuits can occur in various ways. Catastrophic failures have been produced in integrated circuits with exposure to rf power levels in the 1 to $100 \mathrm{~W}$ range for 500 microseconds. These failures are typically due to bonding wire melting, metallization failure, and junction shorting. However, nondestructive interference generally occurs at power levels far less than those necessary for catastrophic, failure.

The most important interference mechanism in integrated circults is bel leved to be rectification of microwave energy by the varlous pn junctions found on all devic,es. This rectified current can inhibit or induce state changes or change the quiescent operating point of the device. Changes of quiescent operating point can be particularly harmful in noise environments and can reduce the noise immunity of the device.

Basic rectification theory states that the rectifled current in a pn junction io

$$
\mathrm{I}_{\mathrm{R}}=\mathrm{n} \mathrm{P}_{\mathrm{RF}} \text { (ABSORBED) }
$$

where $n$ is the rectification efficiency and $P_{R F}$ is the $r f$ power absorbed into the junction. The theory also tells us that in the microwave frequency range

$$
\mathrm{n}=\frac{\mathrm{n}_{\mathrm{o}}}{\mathrm{f}^{2}}
$$

where $n_{0}$ is a constant dependent on junction construction and blas conditions, while $f$ is the frequency of the rf energy. That is, junction efficlency is inversely proportional to frequency squared.

This theory allows one to extrapolate measurements made at frequencles other than the SPS frequency of $2.45 \mathrm{GHz}$. Assume, for example, that a measurement is made at frequency $\mathrm{f}_{1}$, where the device absorbs a power $p_{R F 1}$ and produces a rectification current $I_{R l}$. Further assume that this ts the level of current where interference, effects are first noted (interference threshold). Thus one can write that 


$$
I_{R 1}=\frac{n_{0}}{f_{1}^{2}} \quad P_{R F 1} .
$$

If the threshold measurement were made at a different frequency $f_{2}$, one should expect that the same interference threshold would be reached when

$$
\begin{aligned}
& I_{R 1}=\frac{n_{0}}{f_{2}^{2}} P_{R F 2} \text {, and } \\
& \frac{P_{R F 1}}{P_{R F 2}}=\left(\frac{f_{1}}{f_{2}}\right)
\end{aligned}
$$

While these formulas are approximate, they do show that interference thresholds can be expected to vary as the square of frequency.

Measurements were made at 0.91 and $3.0 \mathrm{GHz}$ on three types of integrated c1rcuits, a 7400 bipolar NAND gate, a 4011 CMOS NAND gate, and a 5474 flip flop (Roe, 1975). Interference of varlous power levels was coupled directly into input, output, and power leads of the integrated c1rcults. The leads were appropriately blased and terminated to simulate normal operating conditions. These measurements are summarized in Table 5 where the Interference threshold is defined as that point where deviation in the device normal or quiescent operating conditions are first noted. Note that these measurements were made on a number of devices of the same type and the values shown are representative of those devices that were most susceptible to interference.

TABLE 5. Summary of Interference Threshold Measurements on Integrated Circuits

$\begin{array}{llll} & \begin{array}{l}\text { Measured } \\ \text { Interference } \\ \text { Threshold }\end{array} & \begin{array}{l}\text { Measurement } \\ \text { Frequency }\end{array} & \begin{array}{l}\text { Est Imated } \\ \text { Interference } \\ \text { Threshold } \\ 2.45 \mathrm{GHz}\end{array} \\ 7400 \text { NAND GATE } & 2 \mathrm{~mW}(3.0 \mathrm{dBm}) & 0.91 \mathrm{GHz} & 14.5 \mathrm{~mW}(11.5 \mathrm{dBm}) \\ 4011 \text { NAND GATE } & 10 \mathrm{~mW}(10.0 \mathrm{dBm}) & 3.0 \mathrm{GHz} & 6.7 \mathrm{~mW}(8.3 \mathrm{dBm}) \\ 5474 \text { FLIP FLOP } & 20 \mathrm{~mW}(23.0 \mathrm{dBm}) & 3.0 \mathrm{GHz} & 13.3 \mathrm{~mW}(11.2 \mathrm{dBm})\end{array}$

Before interference estimates can be made, the coupling between the SPS beam and the integrated circuit must be understood. This subject is effectively treated in a report by Ditton (1y/b), which examines the coupling of microwave energy into shlelded and unshlelded wires connected to varitous parts or an integrated circuit, including power supply connections.

The maximum power coupled into an integrated circuit by a connecting wire is given by

$$
\mathrm{P}_{\mathrm{RF}}(\mathrm{MAX})=\mathrm{P}_{\mathrm{d}} \cdot \mathrm{A}_{\mathrm{e}} \times \mathrm{SE}
$$

where

$$
\begin{array}{ll}
P_{R F}(M A X)= & \text { coupled power in } \mathrm{mW}, \\
P_{d} & =\text { incident field density in } \mathrm{mW} / \mathrm{cm}^{2} \\
A_{e} & =
\end{array}
$$

and

$$
\begin{aligned}
\text { SE } \quad= & \text { shielding effectiveness of any } \\
& \text { shielding around the wire. }
\end{aligned}
$$

In many instances, the connecting wire is more than $1 / 2$ wavelength long (a wavelength $1 \mathrm{~s} 12.2 \mathrm{~cm}$ at 2.45 $\mathrm{GHz}$ ), which means that it exhibits properties similar to an antenna. Thus, the wire can recelve energy in a variety of orientations and directions depending on 1 ts length and the termination impedances of the wire. The recelved power will depend on the orlentation of the wire in the fleld. The average received power $P_{R F}$ (avg) is typically 


$$
\mathrm{P}_{\mathrm{RF}}(\operatorname{avg})=\frac{1}{10} \mathrm{P}_{\mathrm{RF}}(\max ),
$$

Another point of interest in the theory of coupling of microwave energy is that the effective aperture, $A_{e}$, of a wire whose length is greater than $\lambda / 2$ is approxtmately equal to the aperture of a $1 / 2$ wave dipole or

$$
A_{e}=0.13 \lambda^{2}
$$

where $\lambda$ is the wavelength of the incident field (Ditton 1975). Note that the effective aperture 1s not a function of wire length but only the wavelength of the incident field. Thus the absorbed power does not increase with increasing wire length.

The values of $P_{R F}$ (MAX) and $P_{R F}$ (AVG) that can be expected at various locations around the SPS rectenna are summarized in Table 6 . This table assumes a shielding effectiveness of $10^{-4}(-40 \mathrm{~dB})$ for shielded wire. Unshielded conditions are represented with a shielding effectiveness of 1.0 or $0 \mathrm{~dB}$. Table 7 presents a summary for the three types of digital integrated circuits results. Forty dectbels of shielding should effectively eliminate Interference at the module level.

TABLE 6: Estimates of the: Maximum Power $P_{R F}(M A X)$ and Average Power $P_{R F}(A V G)$ that can be Coupled into an Integrated

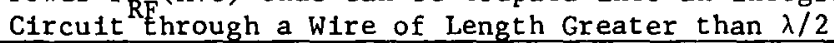

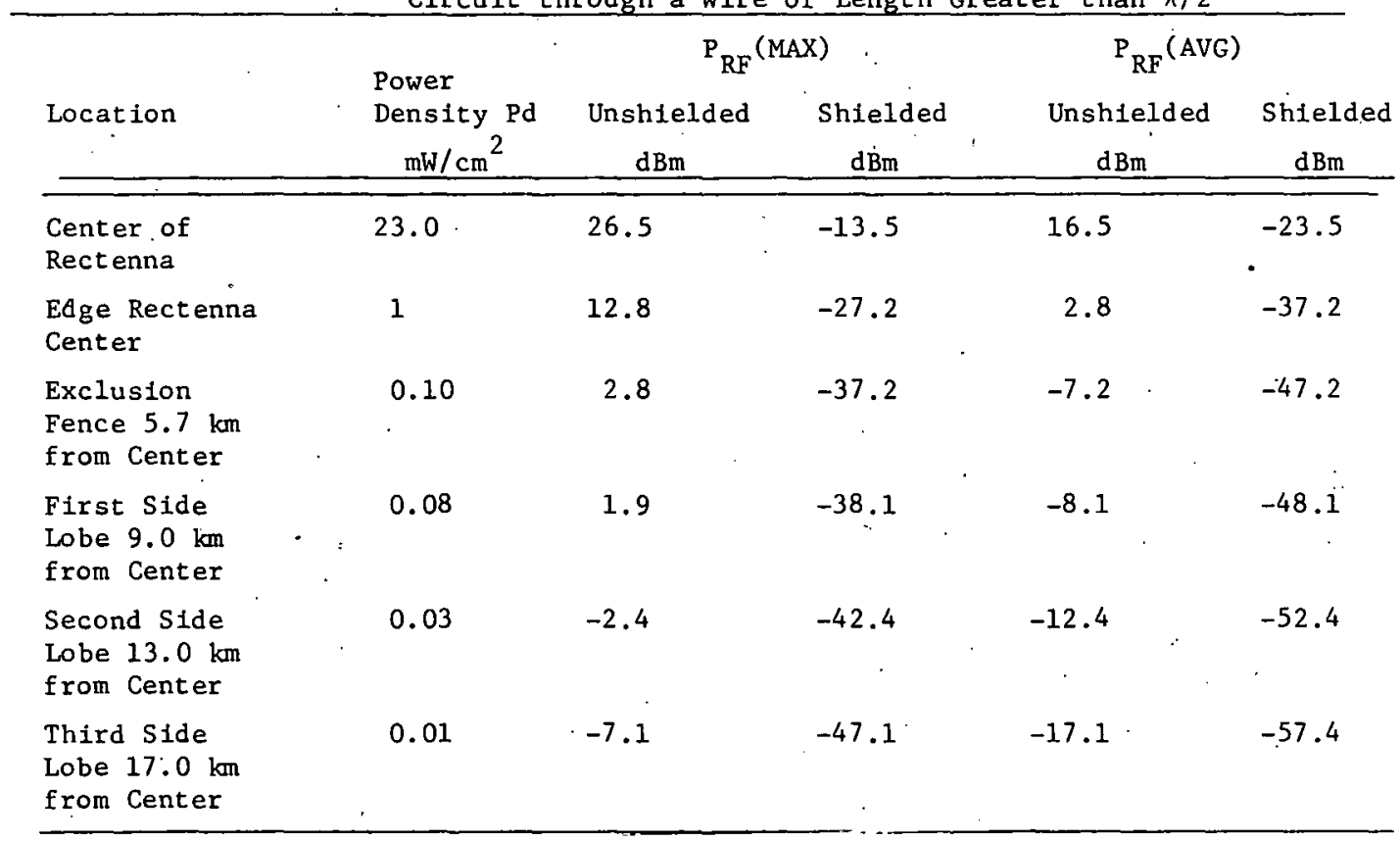

In summary, one can conclude that integrated circuits such as 7400,4011 NAND gates and the 5474 flip flops could be interfered with in SPS field of $1 \mathrm{~mW} / \mathrm{cm}^{2}$ or greater. This conclusion is true only if the circuits are unshlelded. Shielding of the circults with a shielding effectiveness of $40 \mathrm{~dB}$ should eliminate the potential for interference even in $\mathrm{flelds}$ of $23 \mathrm{~mW} / \mathrm{cm}^{2}$.

\subsection{OPTICAL SENSORS}

The high level of power transmitted by SPS could affect a wide range of optical devices used for security monitors, target tracking, communications, resource and atmosphere monitors, altitude control, and astronomy. These sensors are used at terrestrial sites in buildings and fleld locations, on military aircraft and missiles, high altitude research and survelllance afrcraft, and LEO and GEO satcllites. Sensors include electron tubes and semiconductors, used singly and in imaging matrices.

Primary applications of optical sensors are:

1. Astronomy-spectrometry, photometry, and telescope control.

2. Space vehicles - astronomical instrumentation, attitude control, secure wideband communications, and terrestrial survelllance and monttoring. 
TABLE 7. Summary of Susceptibility of 3 Types of Unshielded Integrated Circuits to $2.45-\mathrm{GHz}$ SPS Interference

\begin{tabular}{|c|c|c|c|c|}
\hline Location & $\begin{array}{l}\text { Power } \\
\text { Density } p d \\
\mathrm{~mW} / \mathrm{cm}^{2}\end{array}$ & 7400 NAND GATE & 4011 NAND GATE & 5470 FLIP FLOP \\
\hline Center of Rectenna & 23 & $\begin{array}{l}\text { Exceeds Threshold, Max } \\
\text { and Avg Orlentations }\end{array}$ & $\begin{array}{l}\text { Exceeds Threshold, } \\
\text { Max and Avg } \\
\text { Orientat Ions }\end{array}$ & $\begin{array}{l}\text { Exceeds Threshold } \\
\text { Max and Avg } \\
\text { Orlentations }\end{array}$ \\
\hline Edge of Rectenna & 1 & $\begin{array}{l}\text { Exceeds Threshold, Max } \\
\text { Orlentation Only }\end{array}$ & $\begin{array}{l}\text { Exceeds Threstiold, } \\
\text { Max and Avg } \\
\text { Orfentation }\end{array}$ & $\begin{array}{l}\text { Exceeds Threshold } \\
\text { Max Orlentation } \\
\text { Only }\end{array}$ \\
\hline $\begin{array}{l}\text { Exclusion Fence } \\
5.7 \mathrm{~km} \text { from } \\
\text { Center }\end{array}$ & 0.10 & Below Threshold & Below Threshold & Below Threshold \\
\hline $\begin{array}{l}\text { First Side Lobe } \\
9.0 \mathrm{~km} \text { from } \\
\text { Centér }\end{array}$ & 0.08 & Below Threshold & Below Threshold & Below Threshold \\
\hline $\begin{array}{l}\text { Second Side Lobe } \\
13.0 \mathrm{~km} \text { from } \\
\text { Center }\end{array}$ & 0.03 & Below Threshold & Below Threshold & Below Threshold \\
\hline $\begin{array}{l}\text { Third Side Lobe } \\
17.0 \mathrm{~km} \text { from } \\
\text { Center }\end{array}$ & 0.01 & Below Threshold & Below Threshold & Below Threshold \\
\hline
\end{tabular}

3. Alrborne platforms - astronomical instrumentation, navigarion, terreslrlal suivelllance and monitoring, and secure communications.

4. Target tracking - multiple staring image systems on fixed pedestals, scanning cameras aiding radar and hyperbolic systems.

5. Security and Intrusion alarms - scanning detectors to detect flxed or moving Images; classifica$t$ ion/identification based on image presence, spatial features, and frame-frame vectors, and spectral features used when visual and one or more IR bands combined in the detection criteria.

6. Target detection and guidance - military target detection using scanning or staring sensors (single or multiple spectral bands), and provision of angle track data for weapon guidance.

Norma1 inputs to an Image sensor system (FIgure 34) are the target image and the background notse. The SPS illumination can couple into the optical aperture, any physical apertures such as cooling holes und louvers, plastic cases and unshielded cables, and control 1 ines and supply coupling. Open circles on the diagram at the scan control, video circuit output, and power. circults indicate the signal to interference ( $\mathrm{S} / \mathrm{I}$ ) scorling points. The $\mathrm{S} / \mathrm{I}$ scorling parameters included SPS 1nduced video notse, scan Jitter, and related spatial resolution, and dynamic range effects. Bar targets with a maximum resolution of 2000 lines per inch were used for testing the visual scanners. The IR bar targets include rcflectance elements in the optical range 2 to 6 microns with a resolution of 100011 nes per inch, and differential temperature targets for thermal sensors from 8 to 13 microns with a resolution of 8001 ines per inch.

Specific sensor types tested are listed.

1. Vidicon and plumbicom cameras.

2. Orthicon cameras.

3. Forward looking infraced recivers (FI.T.R).

4. Image dissector tube.

5. Charge coupled device (CCD) matrices.

6. Photomultiplier tubes - In cassegrain telescope applications for star tracking and photometry. 


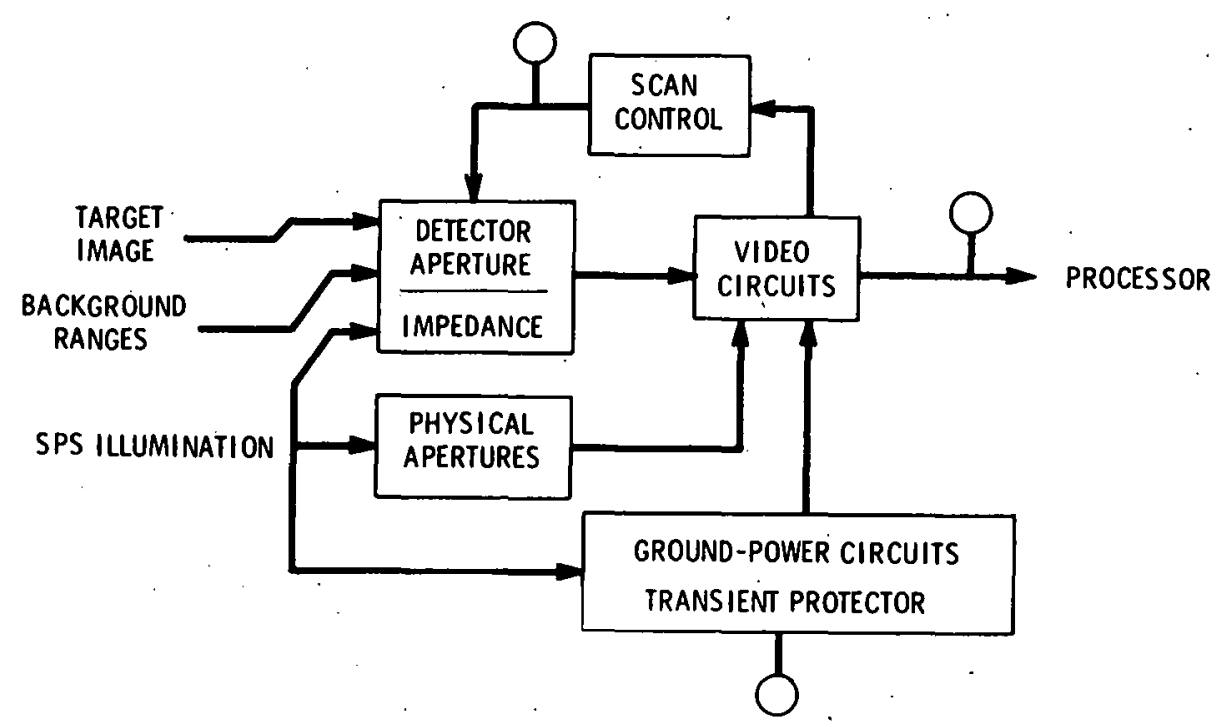

Figure 34. Generalized Block Diagram for EMC Evaluation of Optical Sensor Systems. Circles identify evaluation points.

Energy penetration into optical sensors is primarily through optical apertures, gaps in metal enclosures that exceed 7 to $12 \mathrm{~cm}$ in any dimension, and unshielded module interconnections. Vidicon or orthicon cameras and photomultiplier detectors permit coupling into electron tube anodes and collector surfaces, and into high impedance video and signal amplifiers which are generally collocated with the detector tubes. (These amplifiers are moderate to high gain - bandwidth product circuits using FET circuits in the input stage.) Jitter in scan circuitry results from energy coupling into sync and sweep oscillator circuits from the control gates and matching amplifiers with common interconnections between video and scanning modules, and through common ac return circuits having an effective impedance in the range of 100s. Coupling to staring and scanning IR detectors occurs by direct exposure of the semiconductor detectors and wideband-moderate gain matching circuits and video amplifiers. Optical filters provide no useful attenuation of microwave energy penetrating the optical aperture. As indicated in the performance data, increased video noise and reduced spatial resolution are the primary effects.

Speciflc effects for the various sensors are indicated in Table 8.

TABLE 8. Interference Effects for Optical Sensor System.

\section{SENSOR TYPE \\ Vidicon-Plumbicon Orthicon}

Image Dissector

CCD Matrix

Photomultiplier

FLIR - IR

Semiconductor DET

\author{
INTERFERENCE \\ COUPLING \\ Video Amplifier \\ Scan Generator \\ Sensor Collector \\ * \\ Video Amp1ifier \\ Sensor Collector \\ Video and Gate \\ Amplifiers \\ Matrix Detectors \\ Ecnsor Collector \\ V1deo Amp1ifier \\ Sensor Detector \\ Video Amplifier
}

\section{RESPONSE EFFECTS}

Video Noise Scan Line Jitter Reduced Sensitivity Reduced Resolution

Video No1se Reduced Sensitivity Increased Track Error

Video Noise

Reduced Sensitivity

Reduced Resolution

Reduocd Senoitivity Video Nolse

Video No1se Reduced Resolution 
Figure 35 shows a typical level of degradation in spatial transfer function of a vidicon camera subject to microwave illumination. With illumination by a $10 \mathrm{~V} / \mathrm{m}, 2.6-\mathrm{GHz}$ signal the relat Ive amplitude degraded as shown by the lower curve of the figure. This affects the abllity to detect object movement from frame to frame as time snapshots are recelved from a target, degrades the ability to.1dentify targets quickly and increases the false-target or missed target probabilities.

Figure 36 shows degradation of the total imaging characteristic as a function of distance from the center of a rectenna. These data cover a number of both TV and IR scanning, high resolution sensors, and they represent degradation from induced video noise, scan $\mathrm{fitter}$, spatial resolution and dynamic range due to simulated SPS 1llumination. The $B$ and $C$ cases indicate that the overall degradation increases dramatically from $20 \mathrm{n} \mathrm{ml}$ to within $10 \mathrm{n} \mathrm{ml}$ of a rectenna site. The distances correspond to illumination levels of $4 \mathrm{~V} / \mathrm{m}$ for $20 \mathrm{n} \mathrm{ml}$ and $10 \mathrm{~V} / \mathrm{m}$ at $10 \mathrm{nmi}$. A typical ambient and interference illuminated response for a CCD row is presented in Figure 37. Resolution and sensitivity effects are indicated. Representative signal noise data for a photomultiplier tube under ambient and one interferon illumination level is plotted in Figure 38. Exemplary illumination effects on an image dissector are indicated in Figure 39.

Most TV and IR sensor systems should not be serfously affected if sited beyond $50 \mathrm{~km}$ from a rectenna site depending on how accurate the resolution must be. Certain extremely sensitive military applications may require a distance of 50 to $75 \mathrm{~km}$.

\subsection{MEDICAL ELECLIRONIC DEVICES}

To assess the possibility of adverse SPS electromagnetic Interference with medical electronic devices, an exhaustive literature search was conducted and contacts estab11shed with manufacturers, testing organizations, and government agencles concerned with EMC standards.

The initial analysis focused on cardiac pacemakers, patient telemetry, and the electronic instrumentation associated with mobile clinics and emergency vehlcles (EKG, EMG, and possibly EEG). Federal health agencies are planning mobile and remote dlagnostic facllities to expand preventative medical services. Since rectennas will be sited so as to avoid urban areas and thus most hospitals, these clinical facilities are the areas of medical electronics most subject to SPS interference.

\subsubsection{Cardiac Pacemakers}

Based on their immediate importance to cardiac patients, the large numbers now in use, and the fact that interference related failures have been observed, it is clear that cardiac pacemakers are prime subjects for a study of compatibility with the SPS power beam. Pacemakers are classed as asynchronous or synchronous. The asynchronous pacemakers pulse in response to internal circuit control and are relatively insensitive to external electrical stimul1. The synchronous or demand pacemakers pulse in response to small electrical stimuli from the user's body and are therefore more susceptible to small external electrical stimuli.

Failures related to interference (fallure to pulse within design spectftcations) in demand pacemakers have been attributed to such diverse $r f$ sources as radar, small electrical appliances, lightning strokes, microwave ovens, and motor vehfcles. To identify potential hazards for pacemaker users, the frequency, field intensity and modulation of rf sources that cause fallures must be quantified. Fortunately, many pacemakers have been laboratory tested, and it is now possible to identify important trends in the thresholds of failure of pacemakers as a function of frequency, fleld Intensity, and modulation. These trends aid in evaluating the potential adverse effects of the SPS power beam to pacemakers.

Table 9 Indicates the test conditions employed in establishing levels of potential hazards for pacemakers. Very early work on highly specific testing has been omftted here in favor of later work which tends to identify important trends.

The field intensities or thresholds at which demand pacemakers malfunction increase with frequency. For example Mitcheli and Hurt (1975) found that the average threshold increased from less than $50 \mathrm{~V} / \mathrm{m}$ at $450 \mathrm{MHz}$ to nearly $600 \mathrm{~V} / \mathrm{m}$ at $3200 \mathrm{MHz}$ even when the pulse rate and width of the test source were maintained constant (Figure 40). This observation is qualitatively supported by some earlier work (Figure 40) of Bonney et al. (1973), which shows that the potentially hazardous fleld intensity level increases from about $75 \mathrm{~V} / \mathrm{m}$ at $915 \mathrm{MHz}$ to $250 \mathrm{~V} / \mathrm{m}$ at $2810 \mathrm{MHz}$. Since the SPS power beam is at a $2.45-\mathrm{GHz}$ frequency and the fleld intensity nutside the receiving area is expected to be less than $20 \mathrm{~V} / \mathrm{m}$, pacemakers are not likely to be affected by the SPS power beam.

Pacemakers are more'likely to fail in low frequency pulsed rf fields as opposed to cw fields. Data taken by Mitchell and Hurt (1975) indicate that the average fallure threshold decreased from $117 \mathrm{~V} / \mathrm{m}$ at a pulse width of $10 \mu \mathrm{s}$, to $33.8 \mathrm{~V} / \mathrm{m}$ at $1 \mathrm{~ms}$ and to $18.6 \mathrm{~V} / \mathrm{m}$ at $20 \mathrm{~ms}$, when the PRF and frequency were constant. Denny et al. (1977) found that failures are more likely to occur if the rf source 1s pulsed at a rate of 10 PPS or 1ess. Some demand pacemakers, by design, revert to an asynchronous mode of pulsing if they are subjected to an intense rf source pulsed at a high rate. 


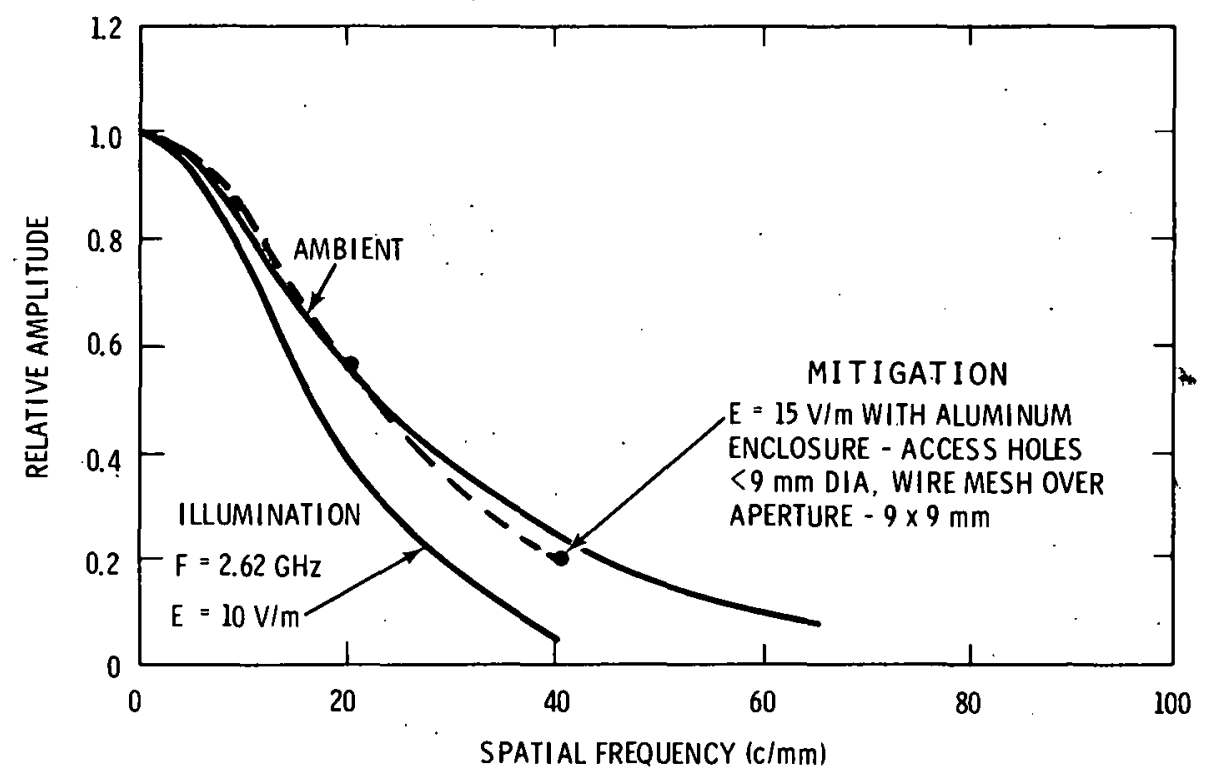

Figure 35. Effect of Microwave Illumination on MTF of a Vidicon Camera with and without Mitigating Modifications.

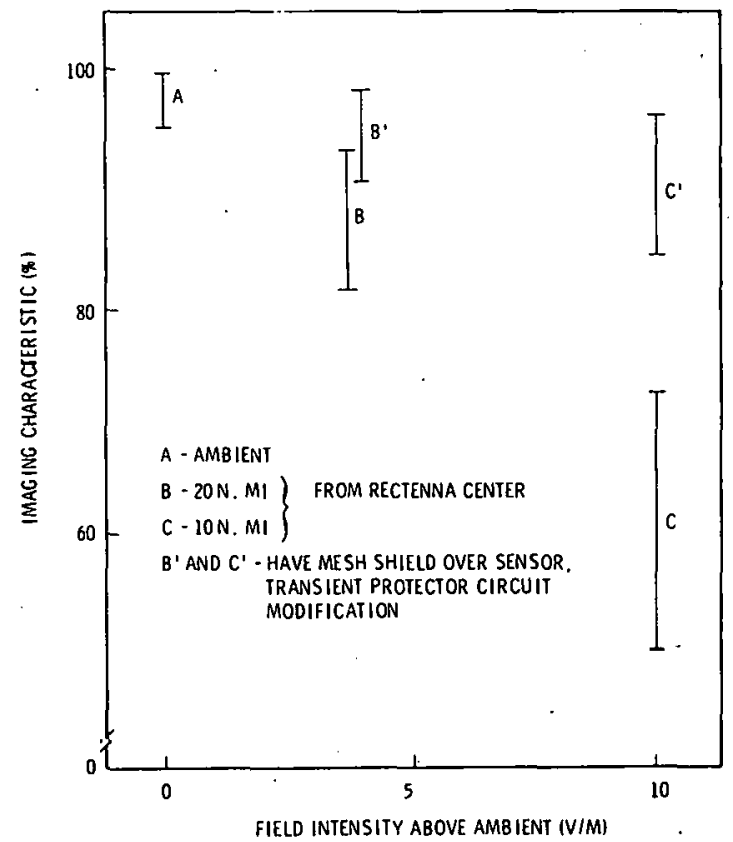

Figure 36. Degradation in Performance of High Resolution TV and IR Scanning Sencors with and without Mitigating Modifications. 


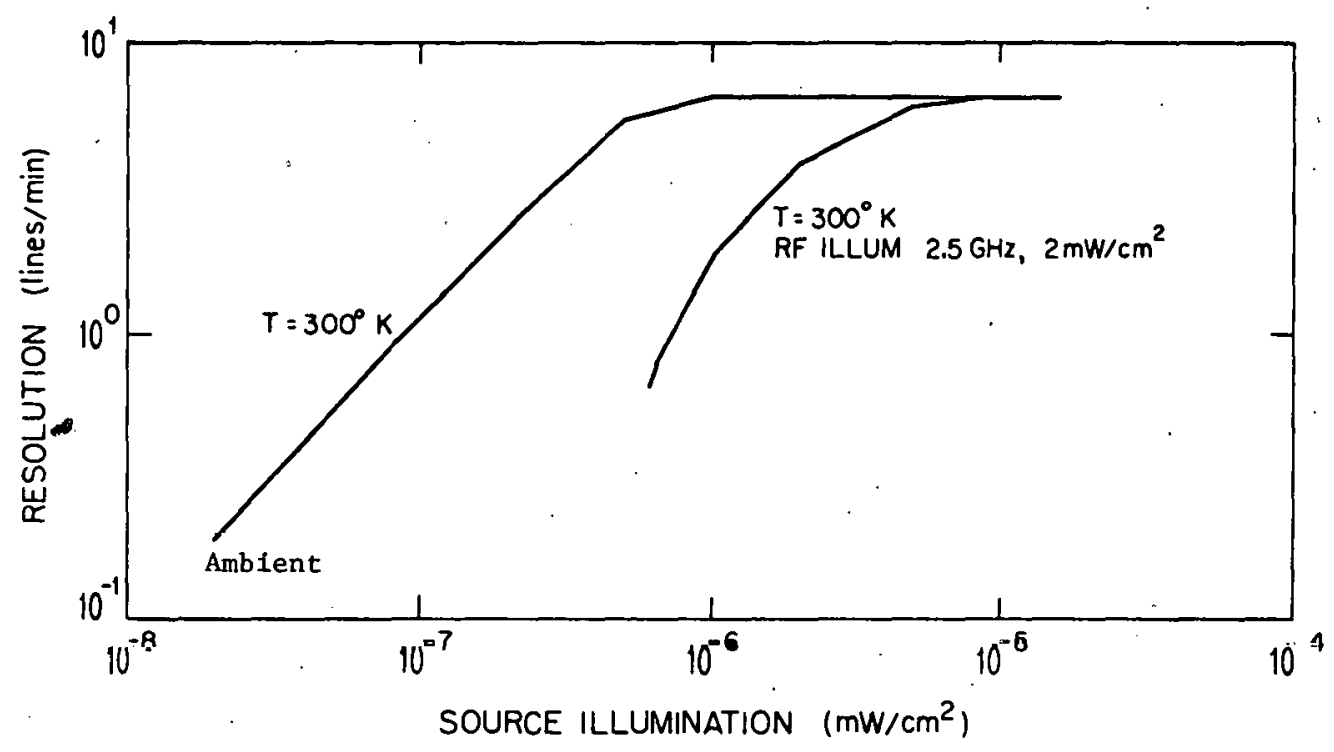

Figure 37. Representative CCD Response Characteristics

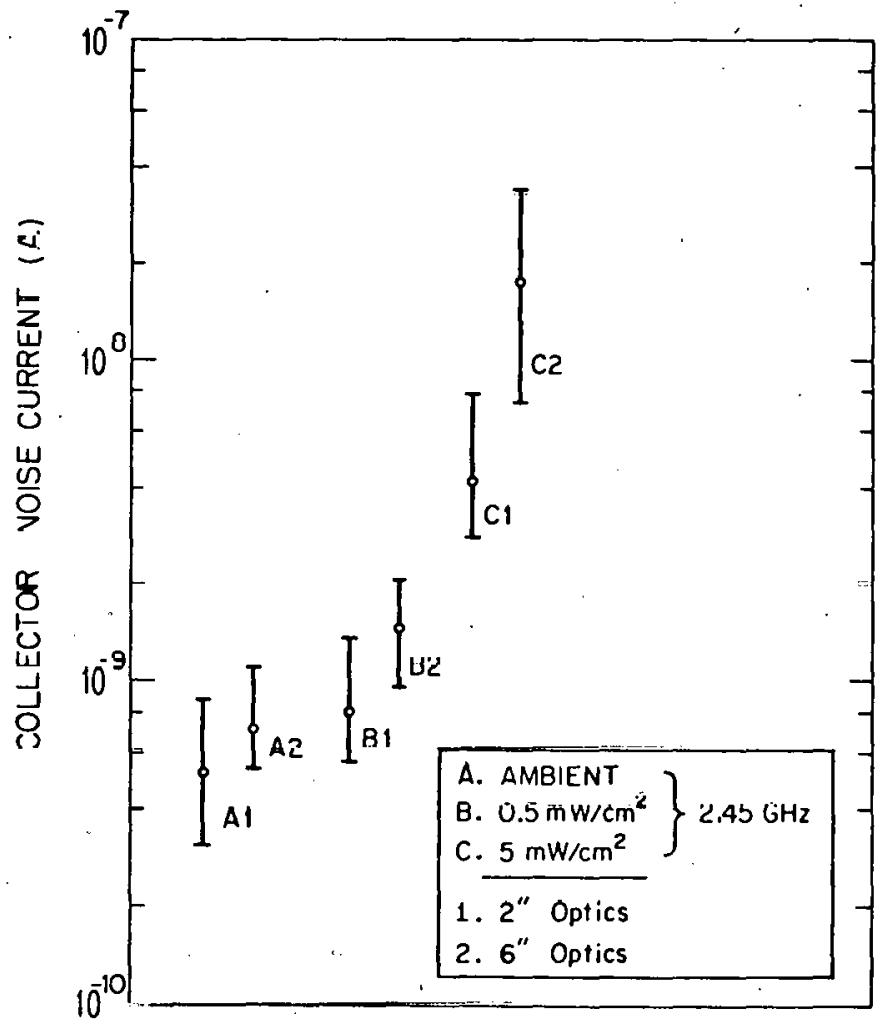

Figure 38. Photomultiplier Response Characteristics ( 10 dynode tübe) 


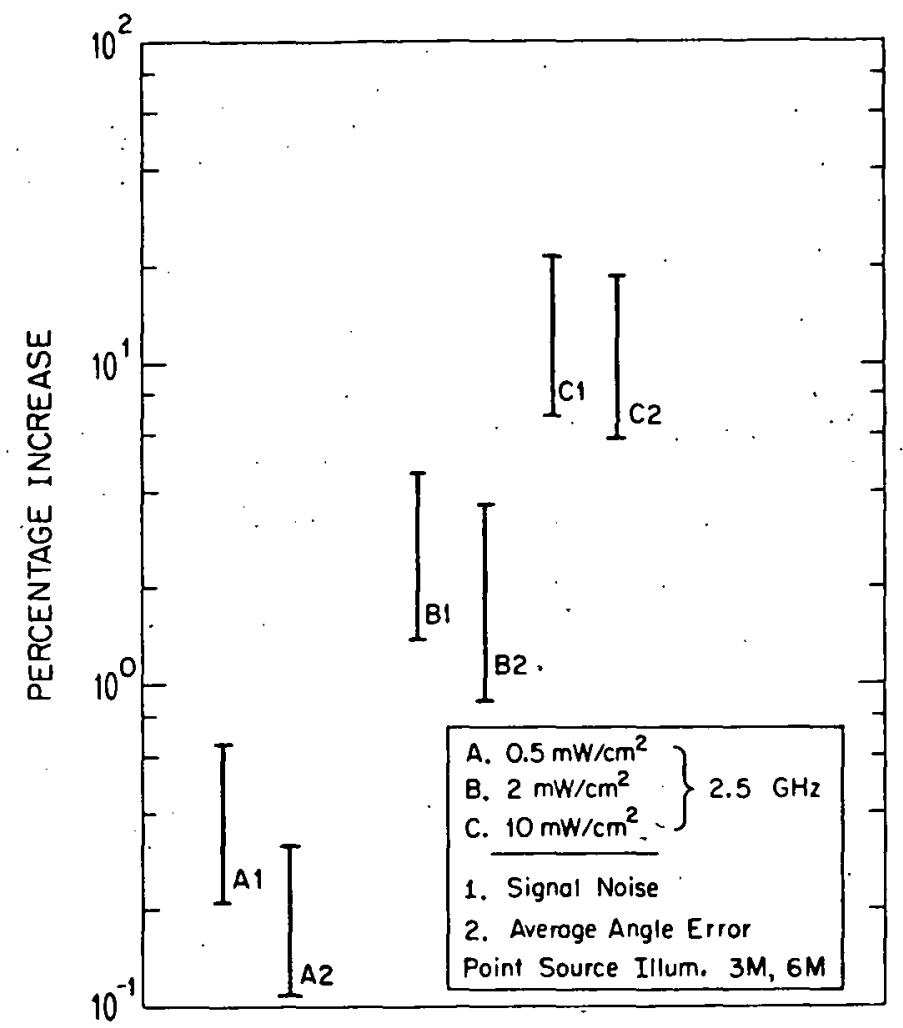

Figure 39. Image Dissector Sensitivity Characteristics

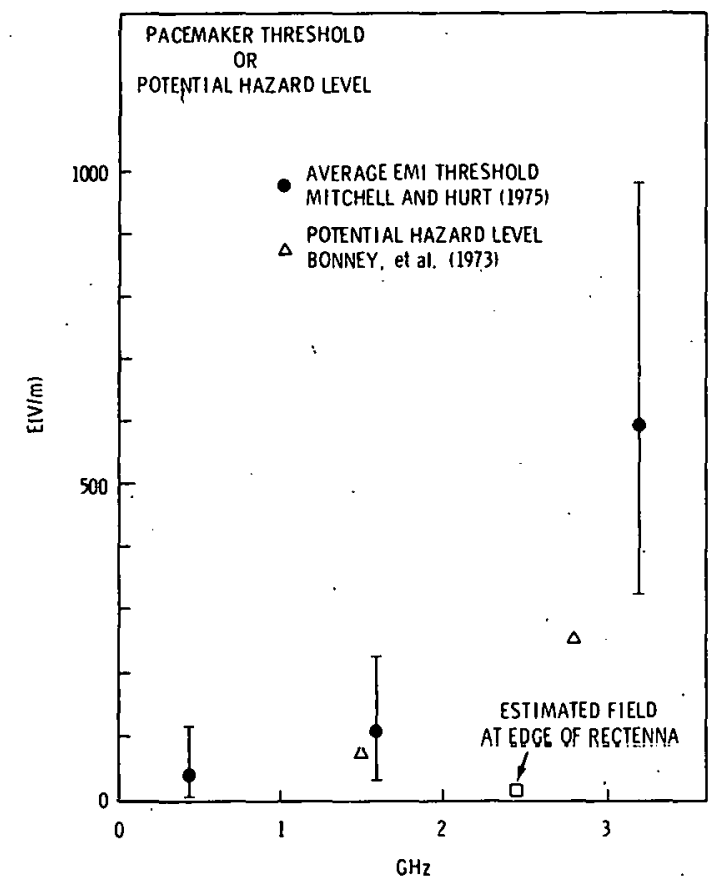

Figure 40. Observed Interference Levels for Cardiac Pacemakers as a Punction of Frequency. 


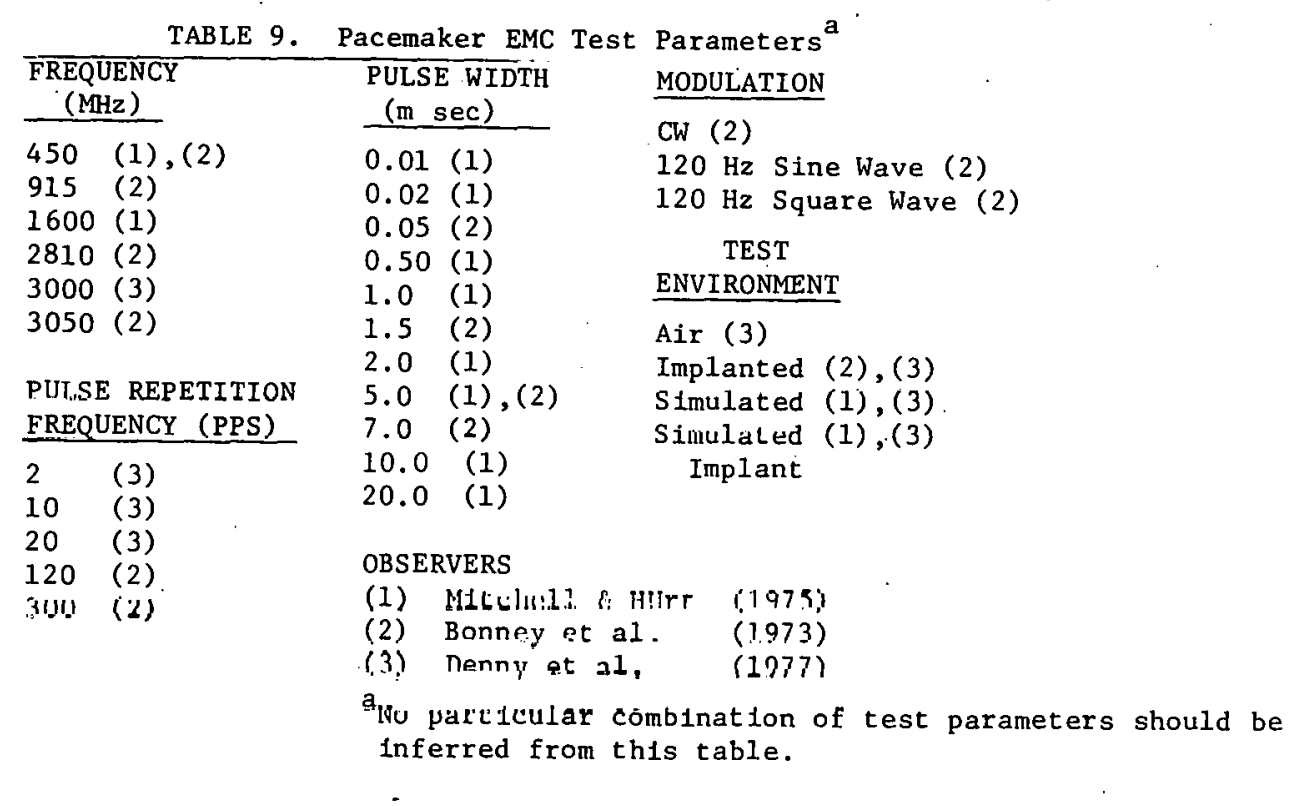

The existence of EM effects on pacemakers has been well-known for several years. As a result researchers have identified interfering EM sources and manufacturers have worked to desensitize the devices against those sources of EMI that users might encounter. The success of these manufacturers' efforts is reflected in a study by Denny et al. (1977). This 5-year study, involving hundreds of pacemakers, showed that the average susceptibility threshold of pacemakers to a pulsed 450-MHz source 1ncreased from $35 \mathrm{~V} / \mathrm{m}$ in 1973 to $144 \mathrm{~V} / \mathrm{m}$ in 1976.

Workers in the pacemaker industry and researchers generally belleve that continuous wave emitters are highly unlikely to produce EMC related fallures but only 1 imited testing with cw sources has been documented. Bonney et al. (1973) found a continuous wave source at $915 \mathrm{MHz}$ to cause fallures if the field intensity were $75 \mathrm{~V} / \mathrm{m}$ or more. Since the vulnerability of pacemakers decreases at the higher frequencies, they are not likely to be affected in the $2.45-\mathrm{GHz}$ field of $19 \mathrm{~V} / \mathrm{m}$ or 1 ess expected outside SPS rectenna areas.

\subsubsection{EMC Standards for Medical Electrontc Devices}

The general class of medical electronic devices contalns many sensitive instruments likely to be susceptible to EMI. The electrocardlograph, for example, is vulnerable to 60-Hz line interference (Huhta and Webster, 1973). Medical devices are used most often in clinfcs and hospitala in large. metropolitan areas. A wide variety of transmitters, appliances and medical electronic devices are likely to contribute to the electromagnetic environment in hospitals.

Diagnostic instrumentation such as electrocardlogram (EKG), electromyogram (EMG), and electroencephalogram (EEG) devices Include high-gain (60-70 dB), dual-channel amplifters, with a maxtmum bandwidth in the $20-\mathrm{Hz}$ to $50-\mathrm{kHz}$ region. Noise induced in ground paths and into each channel (uncorrelated) reduces the detail in the cardiographs and myographs. Input amplifiers are usualiy cascade FET c1rcults, which amplify input circuit and ground path noise, and with higher gain modes reduce the dynamic range of following amplifier stages because of rectification and bias shifts partially induced by intermodulation components. These devices use circuit shields and power-line filters to operate in the vicinity of electro-surgical and diathermy equipment.

The Bureau of Medical Devices at the Food and Drug Administration has supported a study of electronic devices and the amblent electromagnetic environment in several major hospitais: The results of this study establish guidelines for acceptable emisstons from medical devices and safe susceptibility thresholds. These guidelines were published in the report "EMC Standard for Medical Devices," MDC-E 1609, (1976). The guideline for minimum radiated electric field susceptibility from the report is shown here as Figure 41. It covers frequencles from $100 \mathrm{kHz}$ to $1 \mathrm{GHz}$. The existing guideline for electric fleld susceptibility at $1 \mathrm{GHz}$ would permit the manufacture of devices with thresholds ( $\sim 7 \mathrm{~V} / \mathrm{m}$ ) that are lower than the field intensities expected near the SPS receiving area $(19 \mathrm{~V} / \mathrm{m})$. No data are indicated above $1 \mathrm{GHz}$, although a higher susceptibility threshold ts expected since the susceptibility of electronic devices generally decreases with increasing frequency. 


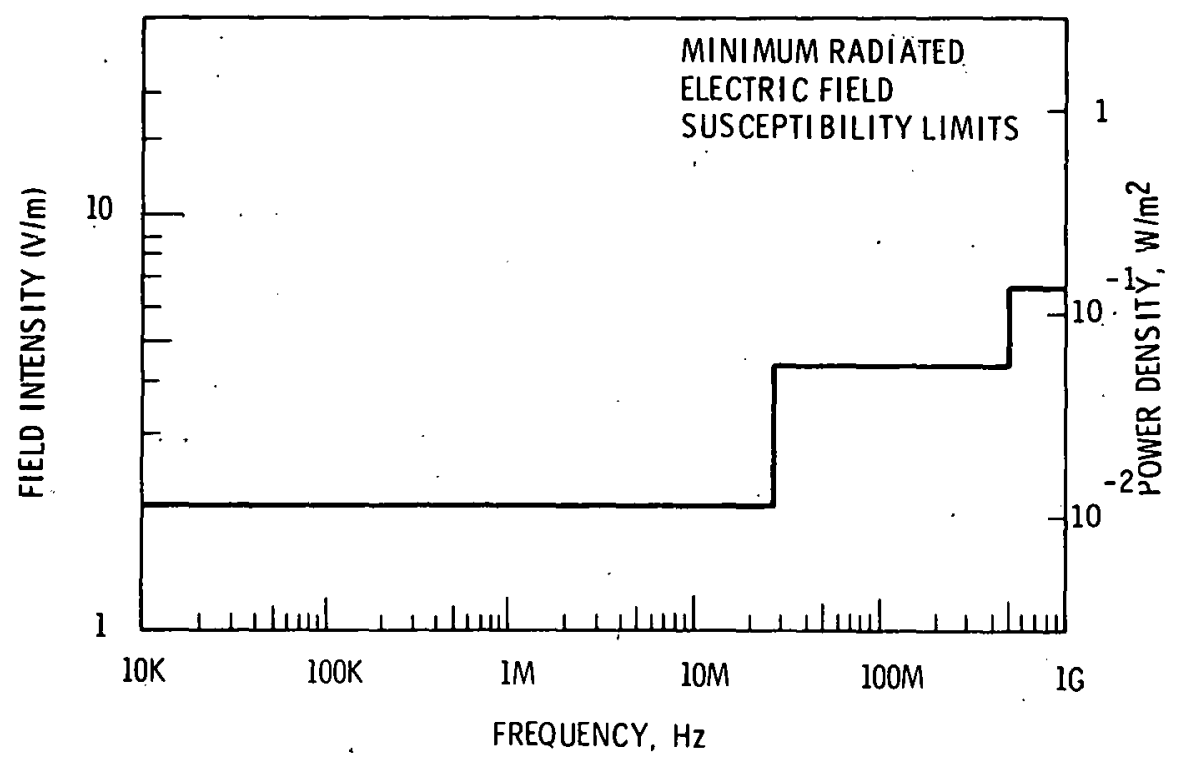

Figure 41. Permissible Interference Levels for Electronic Medical Devices (per MDC-E 1609).

\subsubsection{Conclustions}

Demand pacemakers' susceptibility thresholds are rapldly increasing because of design 1mprovements, and at ultra-high frequencies the average threshold can be in the range of hundreds of $\mathrm{V} / \mathrm{m}$. It thus seems unlikely that pacemakers should fail as a result of the weak SPS-cw power beam outside the receiving areas. The existing guidelines for electric field susceptibility for medical devices recommends a susceptibility threshold of not less than $7 \mathrm{~V} / \mathrm{m}$ for frequencles between 0.5 and $1.0 \mathrm{GHz}$. No 1 imits are given, however, for frequencies above $1 \mathrm{GHz}$. This value is lower than the approximately $19 \mathrm{~V} / \mathrm{m} \mathrm{field}$ intensities expected near an SPS receiving site. The susceptibility of Implanted electronic devices general1y decreases with increasing frequency; therefore no adverse effect should occur outside a range of $10-15 \mathrm{~km}$ from a rectenna. Clinical instrumentation can also operate in the same range with facility shielding similar to that employed for the ordinary radio frequency screen room.

\subsection{SYSTEM INVESTMENT SUMMARY}

The electronic systems exposed to SPS microwave power represent a major investment by industries and government agencies: One task of the EMC Assessment was to collect data on the current investment in categories of communications and electronic equipment and systems identified as potentially susceptible to SPS Interference, and collect budget information on planned enhancements or facility expansion in these services during the next 5-10 year period. System categories include public service communications, transportation radars and communications, commercial service communications, and military support instrumentation and communications systems.

The EMC guidelines developed in the EMC Assessment Indicate both the techniques for the design of communications and electronic systems to operate in the SPS environment and the verification testing methods to ensure compatibility. Any costs associated with the future utilization of these techniques for future system development could be included in the life-cycle costs of these systems. The mitigation and investment costs for the various system categories and geographic reglons also influence rectenna siting, albeit with less weight than other economic factors (e.g., land availability, distribution access, transportation access, etc.).

Data listed for current investments were obtalned from federal and nonfederal government; industrial, and commercial operations organizations. Military operational equipment is not included in this summary.

Major source areas are 11sted.

1. Military test and evaluation ranges.

2. U. S. Department of Transportation.

3. U. S. Department of Interior.

4. National Science Foundation. 
5. Radio and optical astronomy factlities.

6. U. S. operating ratlroads.

7. Communication common carrier companies.

8. State and County government communications departments.

9. Ut1lity and pipeline companies.

10. NASA and A1r Force satelite system project offices.

These data and projections are included in a topical report on investment and mitigation costs. In the case of satellite communications, these data recognize the anticlpated trans1tion to the $12 / 14 \mathrm{GHz}$ and $20 / 30 \mathrm{GHz}$ regions, and the incorporation of signal processing and switching operations into the orbit vehicle. Mitigation costs are based on clrcuit, antenna, and shlelding modifications to accomodate the SPS environment.

Investment Data for Affected Categorles of Electronlc Systems

System Category

General Servico Communications

Terrestrial communications networks Satelitte terminals

Dodicated Bervice Cümunlealluns State backbone networks County microwave systems Rallroad microwave networks Ut1lity/pipeline command/control \& telemetry networks Air traffic control networks

Radar Systems Air traffic control Rallroad hump control Military T\&E

Sensors

Rallroad hot base detectors

Ra1lroad car Identification

M1litary T\&E

Resource monttors-terrestrlal, alrcraft, satellite

Control-Processing Computers Remote radar-communtcations control Utility-pipeline remote control and data processing Resource monftor/control - watershed monitor and water storage, meteorologlcal stations, pollution monftoring

Research Support Systems

Deep space tracking station

Radio astronomy facilities

Optical telesçope guldance

Astronomy instrumentation

Satelite Vehteles

Monftor and control instrumentation transponder

Total Current Investment Estimate

\section{Investment}

$\left(\$ \times 10^{6}\right)-1980$ dollars

$\$ 1,700$

$\$ 1,200$

$\$ 500$

$\$ 30$

$\$ 300$

$\$ 80$

$\$ 400$

$\$ 4210$

\subsection{MTTTGATTON SIMMABIES}

Technlques to mit1gate SPS microwave field pffects on electronio oquipmcnt were descilleul lil Suctiun 1. Test results for simulated SPS 1ilumination both of systems in their original condition and as modified to reduce interference susceptibility were given for a number of systems. Th1s section summarizes the nature and scope of mitigation measures, elther equipment modification or geographic separation, that would be required in achleving electromagnetic compatibility between SPS and electronic systems.

\subsection{COMMUNICATIONS RECEIVERS}

Techniques to remove SPS Interference from communications recelvers include removal of the interferor from the signal channel, and the other Inadvertant coupling modes to c1rcultry and through ground bus components (reference FIgure 18). The methods 1isted are designed to ensure a 30-40 dB discrimination, 
which will allow receiver operation with SPS power densities equal to that expected at the edge of a rectenna.

1. Notch filter at the antenna terminals.

a. Rejection bandwidth: 5 to $20 \mathrm{MHz}$.

b. Attenuation: 7.0 to $80 \mathrm{~dB}$.

c. Insertion 108s: <.1 dB.

d. Ripple peaks: 1 to $2 \mathrm{~dB}$.

2. Shielding and grounding.

a. All nonmetallic openings or gaps $1 \mathrm{n}$ the enclosures $<1 \mathrm{~cm}$ in the largest dimensions.

b. Dual shlelded signal and control cables for if and signal processing modules.

c. Single point grounds $R<0.1 \Omega$

d. Shield cover for transient protector devices; bypass capacitors (c $\sim 50$ pf - 200 pf) across the protector device.

3. Software controlled squint for a phased-array antenna system.

a. Interference rejection - 60 to $80 \mathrm{~dB}$, assuming one principal reflection multipath component. In addition to the direct beam. The tracking bandwidth must be $\sim 20 \mathrm{~Hz}$ to accommodate troposphere-induced, small-angle variations in the direction(s) of arrival of the interferor components.

With the exception of the array application, these techniques were tested with FDMA and TDMA recelvers. The rejection achleved allowed restoration of a $95 \%$ to $99 \%$ performance level. In relation to receiver signal-nolse rat1o, data error rate, and signal acquisition characteristics.

Consumer electronic equipment such as television and other VHF microwave recelvers often have only plastic enclosures. If these equipments are operated within 10 to $15 \mathrm{~km}$ of a rectenna site, conductive foil or paints could be added to the interior surfaces of the enclosures to reduce interference.

\subsection{MINICOMPUTERS AND MICROPROCESSORS}

The mitigation techniques listed will allow full performance restoration for centralized or distributed processors when operated at field intensities expected at the edge of the rectenna.

1. Enclosure shielding with nonmetallic openings $<1 \mathrm{~cm}$ in the largest dimension.

2. Louvers for temperature control should have a wire mesh ( $<1 \mathrm{~cm}$ openings) covering the open area.

3. Dual shielded message and control cabling.

4. Single-point grounding ( $R<0.1 \Omega)$.

5. Shielding of transient protectors with capacitor bypass (C $\sim 50 \mathrm{pf}-200 \mathrm{pf}$ ).

6.3 OPTICAL SENSORS

The techniques recommened for optical sensors are listed.

1. Dual shielded cabling for video and control cabling.

2. Single-point grounding ( $R<0.1 \Omega)$.

3. Shielding and bypass of transient protector devices.

4. Shielded enclosures with nonmetallic openings $<1 \mathrm{~cm}$ in the largest dimension.

5. For visual range sensors with focused optics, a thin wire mesh (38-42 guage copper wire diagonal $<1 \mathrm{~cm}$ ) positioned at a defocused point with mesh connected to electrical ground.

\subsection{RADAR RECEIVERS}

Radar recelver mitigation techniques are functionally identical to those indicated for communications recelvers.

One test was completed for the software driven squint technique using a military phased array tactical radar. With a minor modification of the array-control signal filtering software, a null in the range of $30-40 \mathrm{~dB}$ could be achieved $w 1 t h$ the media-1nduced angle-of-arrival modulation in the $1-10 \mathrm{~Hz}$ range on the interferor. This software mitigation method represents a viable and cost-effective method for. phased array systems having adaptive capabilitles in array control, signal bandwidth, and modulation format. 
The methods listed below provide effective mitigation for SPS frequency interference to a level of $20 \mathrm{~mW} / \mathrm{cm}^{2}$ for the radar systems tested.

1. Input notçh filter - (between antenna and first.mixer).

a. Rejection bandwidth: 5 to $20 \mathrm{MHz}$.

b. Attenuation: 70 to $80 \mathrm{~dB}$.

c. Insertion 1oss: $<1 \mathrm{~dB}$.

d. Ripple peaks: 0.5 to $1 \mathrm{~dB}$.

2. Shielding and grounding.

a. All nonmetallic openings or enclosure gaps $<1 \mathrm{~cm}$ largest dimension.

b. Dual shielded signal and control cables for rf and signal processing modules

c. Single-point grounds $R<0.1 \Omega$.

d. Shield cover for all transient protector devices.

e. Low pass filter between transient protectors and external if coupling aperture(s).

3 Array heam squint - phased array/rnmputer rontrolled radar.

a. Software controlled squint for SPS interference - effective attenuation 40-60 dB, depending on array characteristics.

b. Rejection notch filter (only for alrborne or satellite systems exposed to SPS ma1n beam).

\subsection{GEOGRAPHIC SEPARATION}

Although most equipment can be modified to operate in the microwave flelds expected from SPS, systems having critical relationships to public safety or national security should be protected by separation from rectenna sites. Typical operations for which separation is recommended include alr transportation control, military operations evaluation areas, sensitive power generation and nuclear fuel processing facilities, and research facilities requiring the most sensitive radio frequency recelvers or electrooptical detectors. The 11st below shows recommended separation distances between SPS rectenna sites and sensitive facilities. These separation constralnts have been included in rectenna siting studfes.

Recommended Geographic Separation between SPS Rectenna Sites and Sensitive Facilities

\begin{tabular}{ll} 
Separation & Facility \\
\hline $50 \mathrm{~km}$ & Nuclcar Powcr Plant \\
& Nuclear Fuel Processing \\
& Nuclear Research \\
& Optical Astronomy Observatory \\
& Military Development Test and Evaluation. \\
& $1 \mathrm{r}$ Traffic Control Badar \\
& Alr Defense \\
& Ballistic Missile Detense \\
& Deep Space Communication \\
& Radio Astronomy Observatory \\
$100 \mathrm{~km}$ & Military Operation Test and Evaluation \\
& .
\end{tabular}

'l'he facilities in the $50 \mathrm{~km}$ separation category would ut1lize EMC shieiding and protection procedures recommended as a result of this program for modules and systems. The indicated nuclear facilities include complex instrumentation systems that are serviced and calibrated frequently, and have a high sensitivity to public safety and performance criteria. Separation from an sps rectenna site will eliminate the possibility of illumination levels sufficient to cause instrument actions contributing. to intolerable safety risks and unstable operation. Optical astronomy facilities located at a minimum distance from a rectenna site will have no possibility of degraded operations for data collection instruments (photometers, spectrometers) and telescope guidance sensors if the mitigation recommendations are followed for sensors and circuitry. 
The separation distances for military facilities and deep space communications equipment (60 km, 100 $\mathrm{km}, 150 \mathrm{~km}$ ) are based on system susceptibilities to SPS fundamental and harmonic components. Mitigation techniques are not recommended for military facilitles because unacceptable performance might result in operation in real military scenarios.

Radio astronomy receivers present major uncertainties in practical SPS Interference mitigation. Sensitivity and bandwidth parameters present serlous constraints for using in-channel rejection filters. Signal nulling techniques appear to offer promise since no device would be required directly in the signal channel. These considerations require that radio astronomy recelvers be located at a distance to assure minimum coupling, and minimum separations of about $150 \mathrm{~km}$. The 1dentifled mitigation requirements are: a rejection capability of $60-80 \mathrm{~dB}$, a dynamic range of at 1 east $30 \mathrm{~dB}$, and a nulling error of less than $10^{-6}$ regardless of separation distances.

\subsection{ALTERNATE FREQUENCY ANALYSIS}

The Industrial Scientific and Medical (ISM) band at 2.40 to $2.50 \mathrm{GHz}$ has been chosen in the Reference System design for the power transmission frequency. Th1s is a logical cholce but is not the only possibility. The major considerations on the frequency choice are:

1. Efficiency of power transfer through the atmosphere.

2. Interaction with the ionosphere.

3. Technological feasibility, i.e., the ability to efficiently convert DC to the frequency and recover it at the rectenna.

4. Electromagnetic interference to other systems, and

5. Size of required transmitting and recelving antennas.

Interaction of the power beam with the lonosphere has been the primary topic of Task 4 of the SPS CDEP Environmental Assessment. We will only note here that the power beam can both be influenced by the lonosphere and modify the ionosphere by transferring energy to 1t. The latter effect in particular is of major concern because it may determine the upper limit on microwave power density in the beam and thus the size of the rectenna array required to receive a given amount of power. The power beam cannot be allowed to modify the ionosphere to the extent that communications using the 1onosphere, or the power beam itself, are disrupted. Transfer of power from a microwave beam to the ionosphere is highly frequency-dependent, decreasing with the square of frequency. If the fonosphere were the only concern, the desire to increase power density and thus minimize rectenna area would suggest the use of higher frequencies.

The use of higher frequencles would also allow a smaller satellite transmitting antenna to produce the same power density at the earth or allow higher power densitles, and thus smaller rectennas, for a given transmitting antenna size. In general, the antenna sizes required are inversely proportional to the frequency used.

The higher microwave frequencles, from roughly $10 \mathrm{GHz}$ upward, are also now less extensively used than lower frequencles. An MPTS operating above $15 \mathrm{GHz}$ would thus be less 11kely to interfere with communication and other services as its spurious emissions, particularly harmonics, would occur at less used frequencies. Greater use of higher frequencies is expected however as technological advances make them more accessible and as the need for more channels continues to grow.

Interaction of microwave power from the system with other electronic equipment would also generally be expected to be somewhat reduced, although the size of apertures in shielding would have to be reduced, proportional to wavelength, to block the higher frequencies effectively.

The major constraint on the use of higher frequencles for the MPTS is the microwave propagation characteristics of the earth's atmosphere. There are three propagation effects of concern: clear air absorption, scatter by solids- notably rain or hail, and refractlve anomalles. Clear air absorption is caused by molecules in the atmosphere, principally water and oxygen. Absorption in the 15- to 30-GHz range is due largely to water vapor and is thus dependent on altitude and humidity. For a typical rectenna site in a temperate climate, with an elevation angle of $30^{\circ}$ to the sPS structure, clear air attenuation would cause about $1.6 \%$ loss of power at $2.45 \mathrm{GHz}$ but $4 \%$ to $10 \%$ at $20 \mathrm{GHz}$, depending on humidity. Above about $50 \mathrm{GHz}$, absorption by atmospheric oxygen becomes severe, producing $25 \%$ or greater absorption for the same geometry. (For more information, see CCIR Report 719.)

Rain, hail, and other particles such as sand or dust in the atmosphere can absorb and scatter microwave energy from the SPS power beam. A study of power loss from the microwave beam as a function of rectenna site and frequency has been made by Ott and James (1980). Calculated values of this loss or attenuation for four rectenna sites are shown in Figure 42 for frequencles from 2.45 to $50 \mathrm{GHz}$. The rain-rate data on which the calculations are based are glven below. 


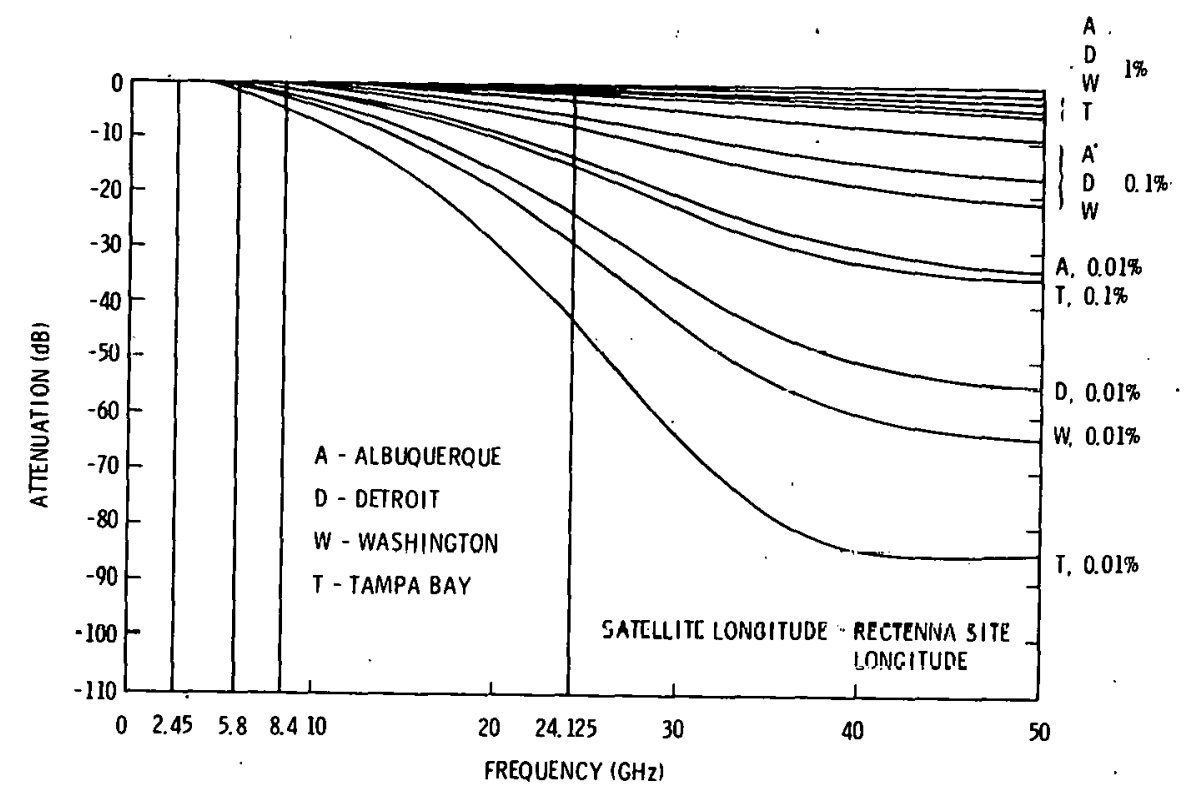

Figure 42. Predicted Atmospheric Attenuation as a Function of Frequency for Four Rectenna sites. Attenuation would be expected to exceed the values shown for no more than the percent of a year indicated for each set of curves.

Rain Rate Distribution (mm/hr) Versus Percent of Year Rain Rate is Exceeded

\begin{tabular}{|c|c|c|c|}
\hline & $0.01 \%$ & $0.1 \%$ & $1.0 \%$ \\
\hline Albuquerque, NM & 23 & 5 & 0.8 \\
\hline Detroit, MI & 37 & 11 & 2.2 \\
\hline Washington, DC & 49 & 15 & 3.0 \\
\hline Tampa Bay, FL & 98 & 35 & 4.0 \\
\hline
\end{tabular}

Note that the vertical scale of Figure 42 is logartthmic-10 dB attenuation corresponds to a $90 \% 10$ ss of power, $20 \mathrm{~dB}$ to $99 \%$ loss. The vertical bars mark higher frequency ISM bands which are potentially favorable candidates for MPTS frequency assignments.

A calculation of the attenuation expected due to a dust or sandstorm was performed by ITS using the theoretical scatter and absorption of small spherical particles and the known dielectric constants of sand and clay. The results show very little effect on power transmisston to the rectema.

It is important to realize that rain or other particles remove power from the microwave beam predominantly by scattering, i.e., dispersing it over a wider area. This would aggravate EMC problems within $100 \mathrm{~km}$ of rectenna sites by increasing the microwave fleld strengths in these areas.

The index of refraction of the lower atmosphere at microwave wavelengths is a function of atmospheric density, which is directly related to temperature and water vapor content. Gradients in refractive Index are observed on a wide range of temporal and soatlal scales: from hours and miles for storms or weather fronts to minutes or seconds and meters for radar "angels". Deflection or scattertng from the microwave power beam due to refractive anomalies is not expected to contribute directly either to EMC problems or significant power losses. There is concern, however, that their presence could adversely affect the power beam control system and thus degrade beam forming or pointing, which would have the same effects as rain scatter. Higher microwave frequencies would be more sensitive to rapid, smallscale anomalies and thus might present a more complex control problem.

In summary, ionospheric effects, scaling of antennas and, to some extent, interference considerations suggest the use of higher frequencles but mlcrowave propagation effects in the lower. atmosphere present some serious problems above about $5 \mathrm{GHz}$. 


\subsection{MOJAVE SITE ANALYSIS}

Ear1y in the SPS CDEP a site in the Mojave Desert was Identifled by NASA Marshall Space F11ght Center as a hypothetical rectenna location for study purposes. An inttial exercise in the EMC Assessment addressed this site in order to demonstrate the importance of EMC considerations in site selection.

Figure 43 shows the Mojave site and the surrounding area that would be affected by SPS emisstons outside the rectenna exclusion area. The inner ellipse corresponds roughly to the foot print of the main beam. The outer ellipse is roughly $78 \mathrm{~km}$ east-west by $100 \mathrm{~km}$ north-south and corresponds roughly to the smoothed pattern of Figure 44. Figure 44 shows a smoothed estimation of the EM energy from boresite to $50 \mathrm{~km}$ for the SPS main beam using the $10 \mathrm{~dB}$ taper. (To convert $\mathrm{V} / \mathrm{m}$ to $\mathrm{mW} / \mathrm{cm}^{2}$ use: $\mathrm{mW} / \mathrm{cm}^{2}=(\mathrm{V} / \mathrm{m}$ ) $2 / 3770$ ). For a perspective on the amount of energy beyond the rectenna site due to side lobe structure, note that field intensitles measured at an antenna are given in microvolts per meter ( $\mu \mathrm{V} / \mathrm{m})$ for communications systems. For high-power televisions or AM or FM broadcast stations, the field intensity beyond a mile, but within a few tens of miles, may be measured in millivolts per meter. The field intensity measured at the home antenna for the average TV owner would be in the microvolt per meter range. Many conmunication system receivers also have $V$ sensitivities. Thus SPS represents a large input to communication systems operating within $100 \mathrm{~km}$ of the rectenna site. In addition to the field due to sidelobe structure, microwave power will be scattered from the main beam by propagation effects.

\subsection{APPROACH}

The potential effects of SPS illumination on the performance of electromagnetic and electronic systems operated within $150 \mathrm{~km}$ of the hypothetical Mojave rectenna stte were evaluated. A retrleval from the NTIA Spectrum Allocation and Assignment files and from FCC commercial license records were used to identify electromagnetic systems in operation in the vicinity of the Mojave site. Other electronic systems (sensors, computers) were 1dentified through contact with transportation, utility, and pipeline organizations and operators in the California Mojave area, southwestern Nevada, northwestern Arizona, California Communications Department, and the Clty and County of Los Angeles Telecommunications Agency. Information retrieved from the federal files included systems within a $145 \mathrm{~km} \times 145 \mathrm{~km}$ boundary around the Mojave rectenna site, and with operating frequencies between $15 \mathrm{MHz}$ and $5 \mathrm{GHz}$. A total of 813 government systems and 685 civilian authorizations were identified within these boundaries.

The equipment and systems identified in the ffle retrieval are categorized as follows:

1. Military Development and Operational Test and Evaluation

a. Instrumentation radars--conical scan and monopulse modes

b. Traffic monitor/control radars

c. Radar transponders

d. Radar signal and functional replicators

e. Wideband monitor receivers with recognition/dectsion software scan and instantaneous frequency modes

f. Television cameras for target position track

g. Electromagnetic system operational monitors--multiple wideband receivers with processing software

h. Range command/control communications nets

i. Range telemetry communications networks

2. Industrial Communications

a. Utility network command/control and telemetry

b. Plpeline network command/control and telemetry

c. Water resource telemetry

d. Multiplexed carrier networks--two major service systems

3. Transportation Support Systems

a. Rallruad mobile equipmencs--yards and enroure cothp̈lex

b. Air traffic control network

c. Emergency services--mobile, base station, and relay equipments--medical and general emergency applications

d. Railroad "car condition" monitors 


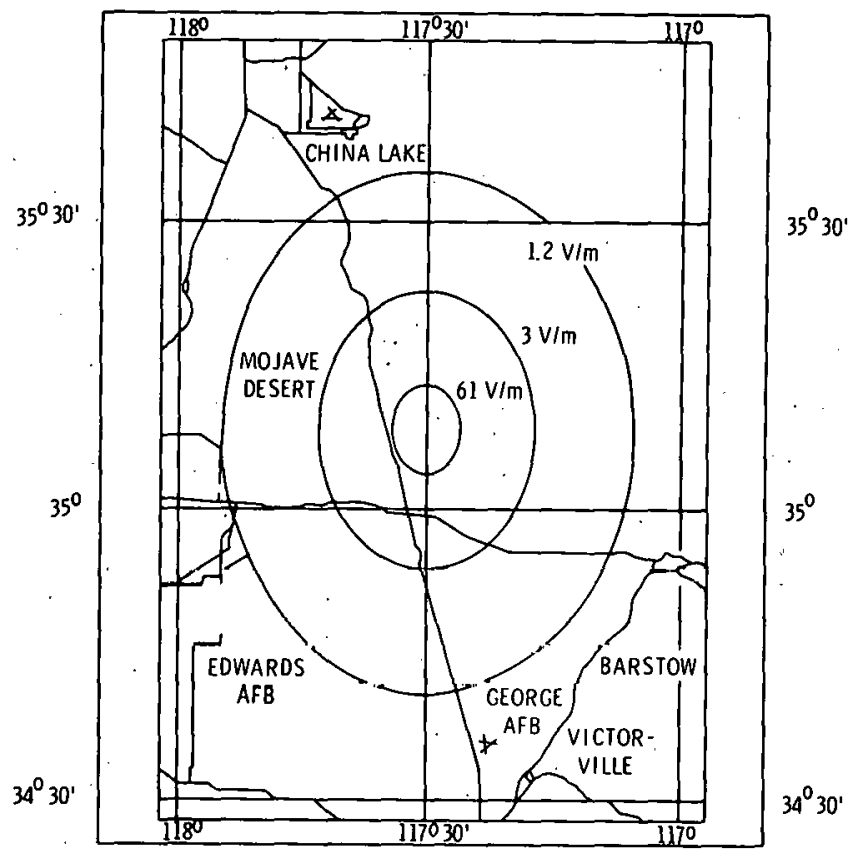

Figure 43. SPS Microwave Field Intensities near Proposed Mojave Rectenna Site.

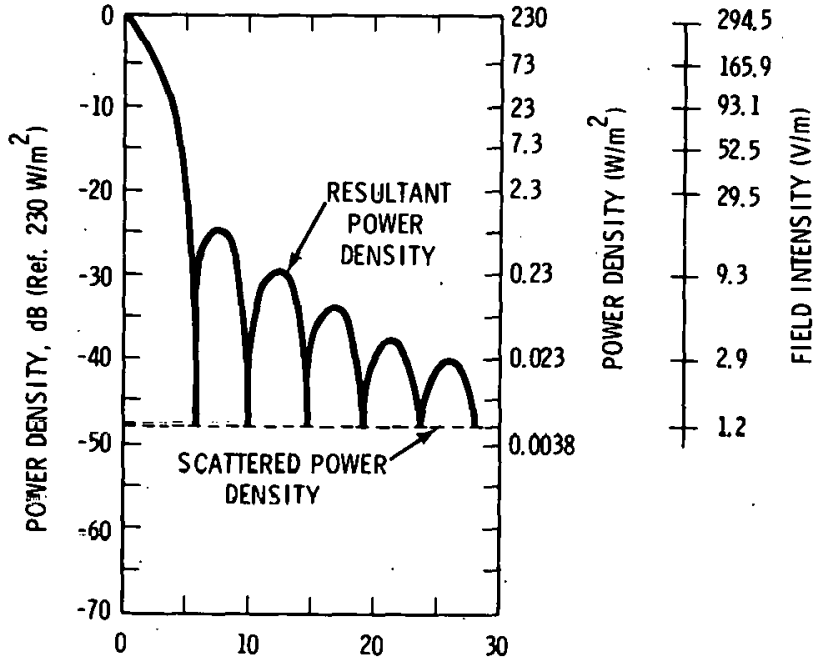

RADIAL DISTANCE FROM BEAM AXIS, km

F1gure 44. SPS Microwave Field Strengths near Rectenna Sites.

\section{Public Service Communications}

a. State of California backbone network (law enforcement, resource management, emergency communications)

b. Law enforcement systems--state, county, city--mob1le, relay, and base station equipment

c. Forest service units

d. Fire and government emergency systems--county and c1ty operations

e. Common carrier networks--telephone, data, television services--remote area voice links

5. Specialized Services

a. Space tracking and monitoring facilities (Goldstone area)

b. Railroad hump radars

The China Lake and Edwards AFB test ranges Include var1ous radar, command/control and telemetry, and optical tracker scanner systems. For specific applications, IR trackers may be employed for moving surface vehicles and airborne vehicles having low radar cross section and not accommodating a transponder:

Range instrumentation will soon be expanded to include distributed mint-computer and microprocessors for event command and functional control, and varlous data verification and formatting and network control requirements. Remote computer control capabilities will be required for complex interactive system operations (e.g., multispectral recognition and assessment, and computer managed mission profiles), as well as more effective data processing and range instrumentation. Data security improvements in the control and data networks will also be achleved through the distributed processors.

The types of instrumentation and communicatforis equipment deployed at the military test ranges are:

1. Radars--

$\begin{array}{ll}\text { FPS }-16 & \text { MSG-3A } \\ \text { FPS-105 } & \text { MPS-19 } \\ \text { TPQ-39 } & \text { NIKE AJAX } \\ \text { M-33 } & \text { NIKE HERCULES }\end{array}$




\section{Television Cameras--}

Plumbicon units mounted on radar antennas for tracking aid, and mounted on high terrain pedestals for multiple camera target tracking.

3. Command/Control and Telemetry--

UHF FM multiplexed analog, $L$ and $S$ band FM multiplexed. All recelvers use monopole or low gain antennas.

Enhanced radar capabilities anticlpated within 5 to 10 years include on-axis track modes (Including digital prediction filter for range gate and pedestal angle control), phased array units for simultaneous multi-target track and integrated event control and telemetry, and simultaneous multiple frequency track modes to minimize multipath errors. Tests involving complex electronic warfare scenarios will require increased use of time- and event-sequenced multiple frequency modes to assure instrumentation compatibility with equipment and procedures being evaluated. Compatibility and short-period accuracy considerations will increase SHF applications.

Evolution of communications systems is expected to include increased microwave operations because of expanded data channel requirements. With the use of distributed processors for instrumentation control, preliminary data processing and formatting will be done at remote nodes before transmission to a central facility. Ultimately, frequency division multiplex (FDM) will be replaced by time-division, multipleaccess (TDMA) to accommodate high data rates and for most efficient spectrum utilization. When operating communication systems in high interference environments with severe accuracy and data rate requirements, atmospheric and fiber optical links will be utilized.

Scanning or staring optical sensors are expected to be used increasingly for spat lal tracking for highaccuracy requirements, particularly in complex electromagnetic environments. Passive tracking of vehicles (skin or exhaust plumes) with modulated sources will use scanning (vidicon, orthicon, plumbicon) and staring'scnsors (cooled semlconductor, charge coupled devices) for visual or IR band detection.

Distributed mini-computer and microprocessors will be used for communications and sensor control (data acquisition, verification, formatting, network control, sensor orlentation and lock cycling) and various levels of data processing. Modular elements will be interconnected by dedicated cables or through microwave channels.

\subsection{RECEIVERS}

Range safety and mission operating area uncertainties (alrcraft flight paths, missile trajectories, etc.) require that instrumentation radar and communication recelvers operate without restriction over the entire upper hemisphere. A tracking antenna could therefore have its main beam or principal side lobes pointed at the SPS source. For distances between the Mojave rectenna site and the China Lake and Edwards AFB and the intervening terrain, the SPS interference is principaliy from the direct illumination at the fundamental SPS frequency. The direct second harmonic is estimated to be lower by 70 to $80 \mathrm{~dB}$. The fundamental power density contours around the rectenna site are plotted in Figure 11 . These are based on only the transmitted pattern, and do not include any scatter or refractive distortion of the power beam.

SPS interference effects include channel nolse and, at higher SPS amplitudes, intermodulation products introduced into the input amplifier and/or first mixer. Scoring criterla for radar and communications receivers are listed below. Communications criteria are identified for both analog and digital modes.

$\underline{\text { RADAR }}$

a. Target detection range: skin and cooperative target modes

b. Radar lock delay

c. Target track error

d. Loss of track probability

\section{COMMUNICATIONS}

a. Signal acquisition delays.

b. Signal errors -- Analog mode DMUX cross coupling Data errors

-- Digital mode BER sync notse and loss address error data error 
For radar testing purposes the $\mathrm{S} / \mathrm{N}$ rat10 measured at the radar signal detector inputs was. varled from a level corresponding to minimum radar target cross section (smallest target that can be detected when skin tracking) or transponder power from lowest detectable signal to mid-range amplitudes (when tracking target with an active on-board transponder). When testing communfcation systems, the desired signal was varied from minimum usable signal at the recelver to average communication link signal amplitudes. An interfering signal in the $2.45 \mathrm{GHz}$ frequency range was then introduced to the radar and communication systems under test. Noise and intermodulation spectral densities were measured and tabulated for various S/I combinations. Commercial and industilal communication recelvers tested showed nearly Identical responses for S/I ratios in the 10 to 20 dB range. The principal prediction response involved induced nolse with an amplitude 0 to $3 \mathrm{~dB}$ higher than for comparable military FDM equipment. This difference is attributed to shielding and electrical grounding design because of the more stringent requirements of military specifications. At lower S/I ratios ( 1 to $6 \mathrm{~dB})$, the level at which 1 thermodulation products were first detectable was about $2 \mathrm{~dB}$ lower with commercial equipment.

Commerclal communications, In the $2 \mathrm{GHz}$ and $6 \mathrm{GHz}$ bands, Include systems operated by the Union Pacific and Santa Fe Rallroads, and the State of California backbone network. These systems operate 200 and 400 channel FDM analog equipment. Other networks using 50-200 channel configurations serve ut1lity and pipel tine control and utility operations. The commerclal equipment uses parabolic and high gatn yag1 antennas, since they do not require the flexibility of military test range operations. Commerclal microwave systems are generally signal frequency fixed path configurations where military microwave systems require moving antennas and multiple frequency use.

\subsection{MILITARY SIGNAL MONITORS}

This class of equipment Includes the various configurations of tactical recelvers used for signal search, classification and Identification, posture assessment, and electrontc counter. measures (ECM) management. The system can include 2 or 4 antennas, a frequency scanning recelver, analog or digital modulation component separation equipment, and a computer for signal files, comparison logic, alarm and display operation, and ECM control. The susceptibility scoring criterla were:

\section{RECEIVER}

a. Intermodulation related signal density

b. Extraction of signal modulation components

c. Signal direction of arrival errors

\section{COMPUTER}

a. Signal density saturation

b. False alarm--control action probabilities

c. Signal 1dentification errors

d. Signal processing delays

Th1s recelver system (typical of a threat warning system) is generally employed with military operational test and evaluation exercises, and is therefore important to the capabilities of range factlities located near the China Lake range. The evaluation of this equipment demonstrated the level of degradation to be experienced by such operations. During war games that are designed to simulate various real tactical situations for design of battle field strategy, erroneous information or wrong procedural specification could result if systems were modifled for SPS mitigation purposes biasing the interaction between this type of recelver and the signal environment. These operational ranges Include control and monitorfing facilities that require functional authenticity and would be very sensitive to the electromagnetic environment. Simulation of tactical situations in parts of the world where no sPS exists could not be achlevable.

\subsection{SENSOR EVALUATION}

Scanning sensors such as TV cameras were tested by subjecting them to simulated SPS fleld intensities that would be encountered outside a rectenna exclusion area. The sensors were checked under these conditions for increased video nolse and scan $j$ itter and decreased spatial resolution and dynamic range. These parameters are related to requirements for security monitors and target tracking. The scoring criteria have different welghting for these two applications; software feature extraction employed for security systems exploits spatial tmage charactéristics and movement (frame to frame culipiarloon doteation).

Sensor testing for the Mojave site analysis included 525 and 10001 ine video cameras, forward looking infrared (FLIR) detectors, and small mosalc staring visual and IR sensors. Bar targets were usej for the visual scanners, the maximum resolution being 2000 lines/1nch. The IR bar targets used from 2 to $6 \mu$ consisted of reflectance elements with a 1000 ines/inch resolution. Differential temperature bar targets with approximately 800 lines/inch resolution were used for the thermal sensors (8 to $13 \mu$ ). 
Microwave radiation coupling was by means of a horn radiator. 1lluminating the sensor and control systems directly into the optical aperture, $+30^{\circ}$ off the optical axis, at the sides of the camera and electronic control units, and directly into nonmetallic and cable entry areas of the outer casing. The most sensitive areas by a 2- to 10-dB range were the nonmetallic casing (openings >10 $\mathrm{cm}$ in one dimension) and the optical aperture. Generally, semiconductor detectors exhib1t a susceptib111ty 1- to 3-dB greater than vidicon or plumbicon tubes. Large-aperture photomultiplier tubes exhibited approximately the same notse increase.

The scoring criterla for the two sensor categorles are listed below:

\section{SCANNING SENSORS}

a. Video nolse amplitude

b. Video dynamic range

c. Image resolution

d. Scan jitter

\section{STARING SENSORS}

a. Signal channel noise amplitude

b. Minimum detectable target

c. Dynamic range

\subsection{COMPUTER AND PROCESSOR EVALUATION}

The susceptibility testing for mini- and microcomputers included direct radiation of modules and nolse conductivity tests for signal and power ground connections. Distributed processors and integrated systems were tested for the following parameters.

\section{INTEGRATED PROCESSOR}

a. I/O channel no1se

b. I/O reglster nolse and transfer errors

c. Control and clock bus noise

\section{DISTRIBUTED PROCESSOR}

a. Module I/O channel notse

b. Module control and clock bus notse, pulse jitter

c. Module-module transfer errors

d. Arithmetic module errors

Tests were conducted on 4-, 16-, and 32-b1t processors, as used and proposed for the following applications: central/distributed computation and file mantpulation, mobile terminal, and data logging. Military processors included weapon data computation, sensor control, and file processing functions. Commercial and military modules varied significantly in shielding integrity and grounding practice. These areas are major contributors to the susceptibility of these systems to interference problems.

\subsection{RANGE INSTRUMENTATION}

Th1s category of equipment includes the numerous radars and assoclated TV camera equipment employed for spatial position and orientation tracking at ChIna Lake, Edwards AFB, and Echo Range. These radars track airborne vehicles that test equipment effectiveness, including simulated engagement with surface defense units. The radars, identifled in the previous section, include units that are "slaved" through command/control networks for target acquisition and "hand-over" to cover large-area flight operations. Data telemetry from these radars includes rectangular spatial position coordinates, rectangular coordinate velocity data, and signal characteristics employed for diagnostics. These instrumentation radars must satisfy an accuracy requirement of 1.5 to 5 meters in position for elevation angles above $15^{\circ}$, and 5 to 15 meters for the lower elevation angle tracking modes. Where increased accuracy in lower angles is required, the video records can be employed with the radar range and coordinate data to improve resolution.

The primary effects of the SPS power densities predicted for China Lake, Edwards AFB, and Echo Range are: 1) increased nolse in the predetection components of the recelvers, 2) reductions in target acquisition range, and 3) increased data errors in tracking. Considering the deployment of radars at these factlitles, reduced detection range would increase the gap in coverage. These comments also apply to the TV cameras at Edwards AFB.

This tracking instrumentation must operate over an entire hemisphere to support effectively the operational exercises at these facilities. The SPS effect would be reduced if elevation were 11mited to approximately $50^{\circ}$, but this represents an impossible compromise for the milttary exerctses.

The primary effects, as noted in the previous section, for the data networks at these factlities involve signal acquistion and data error rates. These effects translate into operational problems in greatly increased activity through the data network because of synchronization and error effects. A combination of errors and an increase in the net activity at the varlous test ranges would reduce the capability to support simultaneous missions. This capability is particularly important in engagement evaluation where numerous remote-controlled facilities may be involved and where delays in communication would represent an unacceptable experimental bias. Since such engagements generally involve event-related activities, for example, alrcraft evasive maneuvers or electronic countermeasure initiations in the response to 1dentification of a specific recelved signal node or the onset of a transmission on a 
particular signal frequency, the validity of most multiple vehicle experiments would be unacceptable. These comments are qualitatively correct on the basls of the deployment of command/control and instrumentation equipment, the magnitude of the SPS interference, and previous histories at other test ranges where an EMC problem caused similar compromises in instrumentation and network performance.

\subsection{OPERATIONAL SYS.TEMS}

The China Lake ranges are generally used to evaluate weapons systems performance and limited operational engagements. The latter includes, for example, delivery of ordnance and the collection of surveillance data in a simulated hostile environment. These tests are thus highly dependent on the electromagnetic support systems such as radars, command/control, and sensors. Considering the frequency range of military operational equipment employed for tactical aircraft, and the aperture of electro-optical devices supporting tactical missions, the SPS power densities would eliminate effective testing except for very short ranges of deployment. Modifications to tactical equipment to accommodate the SPS are not possible because they could compromise and blas the realism of event sequences and reduce the correlation between operational and functional events such as the interaction between electronic instrumentation and combat and support equipment operations.

The primary function of operational test facllities in the area is to evaluate proposed electromagnetic penetration support equipment and procedures, and provide operational training and doctrine testing for tactical Air Force penetration against hostile air defense systems. Environments are replicated that interact with penetrating electronic warfare systems, control maneuvers, and equipment operation for testing and training purposes. Critical events for electromagnetic systems include signal detection, signal source recognition and mode analysis, and counteractive interaction events. The capabtlity to detect, Identify, and classify specific signal characteristics, and to locate emitters is fundamental to the self-protection or standoff support for aircraft penetrating protected zones. These include air-air and air-ground electromagnetic system interactions.

The facility includes operational monitoring capabilities to evaluate all events relating to the survivability of surface elements and aircraft. The SPS power densities would reduce capabilities in range of coverage and event recognition, thus presenting bias and error in doctrinal and procedural decisions and improper event histories for training exercises.

\subsection{EFFECTS AND IMPACTS}

The functional degradation of radars, telecommunications systems, sensors, mini- and microcomputers, and the threat warning receiver has been evaluated for varlous conditions (Table 10). Ranges of effects are indicated because of variations in operational modes and different SPS power densities for equipment deployed at a number of sites (e.g., range radars, command/control and telemetry, railroad and California state microwave systems). The elements of performance degradation cited represent an average over all operating modes and geographic ranges. For example, instrumentation radar detection and tracking performance includes operation over a full hemisphere and the range of cross sections for military target vehicles (e.g., tactical fighter and reconnaissance aircraft, target drones, and transponder variations) during a tracking perfod. Vartations include low elevation angle modes, where the accuracy degradation and loss of lock probabilities due to interference are greater because of propagation factors. On-axis radar configurations are also represented since this mode will probably be increasingly used at test ranges. The track error scores include normal smoothing, prediction filtering, and coordinate computations both in real time and with postmission processing software.

The communications system degradations cited in Tabie 10 include single channel and frequency and time multiplexed units operated by the military test ranges, the State of California, local county and municlpal governments, and resource control and service industries.

The performance changes cited must be translated into effects on a supported operation or service to assess an impact on public service or safety. These operational impacts are described in decision trees relating functional characteristics to action events and resulting service capabilities or safety risks. These relationships are particularly evident in relating radar and associated communications system performance to the air space monitoring misston and transportation safety through the alr traffic control procaes.

There are a number of fixed microwave multi-user communication systems which traverse the Mojave area. These include the State of California backbone network which handles communtcations involving law enforcement, forest.fires, natural resource management, natural disasters (flood, earthquake, etc.) and other state administrative information and data; national communication trunks providing common carrier services such as Bell Telephone, GTE, and MCI microwave links; railroad microwave systems which carry train information and data. For these systems a direct relationship to safety is evident only during local emergencies, i.e., forest fire, train wreck, high winds, etc. Even in such cases, the situation is not immediately managed through these systems but through local polfce, fire departments, emergency 
TABLE 10. SPS Effects on Systems in the Mojave Area

\begin{tabular}{|c|c|c|c|}
\hline Function & & Characteristic Effects & \\
\hline $\begin{array}{l}\text { Instrumentation Radar } \\
\text { (M111tary Test Ranges) }\end{array}$ & $\begin{array}{l}\text { a. } \\
\text { b. } \\
\text { c. } \\
\text { d. } \\
\text { e. }\end{array}$ & $\begin{array}{l}\text { Cooperative target acquisition range: } \\
\text { Skin target acquisition rangc: } \\
\text { Cooperative target track error: } \\
\text { Skin target track error: } \\
\text { Loss of track loop lock (skin mode) } \\
\text { probability increase: }\end{array}$ & $\begin{array}{l}-(8-20 \%) \\
-(13-28 \%) \\
+(15-40 \%) \\
+(22-65 \%) \\
+(10-40 \%)\end{array}$ \\
\hline $\begin{array}{l}\text { Command/Control and } \\
\text { Telemetry Communications } \\
\text { (Military Test Ranges) }\end{array}$ & $\begin{array}{l}\text { a. } \\
\text { b. } \\
\text { c. }\end{array}$ & $\begin{array}{l}\text { Signal acquisition threshold: } \\
\text { Data error: } \\
\text { Sync loss probability: }\end{array}$ & $\begin{array}{l}+(5-20 \%) \\
+(5-28 \%) \\
+(3-25 \%)\end{array}$ \\
\hline $\begin{array}{l}\text { Tactical Signal Identifi- } \\
\text { cation - Analysis System }\end{array}$ & $\begin{array}{l}\text { a. } \\
\text { b. } \\
\text { c. } \\
\text { d. } \\
\text { e. }\end{array}$ & $\begin{array}{l}\text { False alarm probability outside } \\
\text { mission zone: } \\
\text { False alarm probability within } \\
\text { mission zone: } \\
\text { Receiver notse threshold: } \\
\text { Signal processing time: } \\
\text { Software overload probability } \\
\text { increase: }\end{array}$ & $\begin{array}{l}+(3-25 \%) \\
+(18-60 \%) \\
+(5-40 \%) \\
+(45-115 \%) \\
+(2-26 \%)\end{array}$ \\
\hline IR Scanner (Tactical System) & $\begin{array}{l}\text { a. } \\
\text { b. }\end{array}$ & $\begin{array}{l}\text { Video noise threshold: } \\
\text { Target detection/1dentification } \\
\text { error probability: }\end{array}$ & $\begin{array}{l}+(2-26 \%) \\
-(5-33 \%)\end{array}$ \\
\hline $\begin{array}{l}\text { Utility and Pipeline } \\
\text { Command/Contro1/Telemetry }\end{array}$ & $\begin{array}{l}\text { a. } \\
\text { b. } \\
\text { c. }\end{array}$ & $\begin{array}{l}\text { Signal acquisition threshold: } \\
\text { Data error: } \\
\text { Link noise: }\end{array}$ & $\begin{array}{l}-(5-15 \%) \\
+(10-30 \%) \\
+(5-20 \%)\end{array}$ \\
\hline Image Intenstfiers & $\begin{array}{l}\text { a. } \\
\text { b. }\end{array}$ & $\begin{array}{l}\text { Video noise level: } \\
\text { Standard target detection/1dentifi- } \\
\text { cation range: } \\
\text { Multiple target spatial resolution: }\end{array}$ & $\begin{array}{l}+(10-45 \%) \\
-(5-30 \%) \\
-(2-60 \%)\end{array}$ \\
\hline
\end{tabular}

disaster teams, etc., closest to the problem area. Any potentlal functional degradation caused by SPS in these types of fixed position microwave systems can be mitigated by falrly stralghtforward techniques. A detalled analysis of operational impacts of SPS 1llumination on military systems surrounding this particular Mojave site is not warranted. Functional modifications of operational equipment at these test and evaluation factlities represent an unacceptable risk in the training and doctrinal study missions. These considerations led to the decision that this particular hypothet ical Mojave site would not be acceptable.

8.9 CONCLUS IONS AND RECOMMENDATIONS

This preliminary assessment of SPS microwave emissions on "victim" systems demonstrates the operational degradation that would occur to electronic systems in the SPS generated environment within approximately $100 \mathrm{~km}$ of the hypothetical site. This Mojave site evaluation reveals a wide range of performance degradation particularly in military systems. The basic functional and operational impacts of SPS are of such magnitude that in many instances they represent unacceptable compromises and biases to sensitive test and evaluation exercises.

The evaluation of this Mojave site provided impact data to NASA, contributed to site selection and evaluation criterla, and allowed a limited. exercise of the data retrieval and analysis procedures that would be required for the EMC analysis of candidate rectenna sites. This Mojave site allowed reasonable rectenna siting because of its isolation from areas of even modest population density. Most of. the interference problems concerned military operations, the degraded systems being integral components of complex development and operational test and evaluation programs. These military programs require the degree of isolation afforded by the Mojave region.

Based on the degradation of operational systems near the Mojave site and the inab1lity to establish mitigating strategies without unacceptable operational compromise, a second hypothetical site north and east of the original site was reviewed. A cursory look at the "victim" systems surrounding the 
new site indicates different classes which lend themselves to mitigating strategles. There were only 400 operational systems, mainly civilian and FAA links. Most of these systems could be modified to be compatible with the SPS generated environment.

The functional degradation of military, nondefense government, and commerclal systems in the Mojave area is basically characteristic of the effects that will be encountered in other conUS areas as far as the generic systems of Table 10 are concerned. Operational impacts, and therefore the associated economic impact, will vary by area because of differing uses, configurations, and prtorities of affected systems.

The Mojave area lends itself well to resiting because of the large expanse of open, flat terrain. The development of new sites in most geographic areas would be more difficult, if not Impossible, because of population density, terrain features, "victim" system density, etc.

As given by FCC and NTIA printouts of EM systems operating in northern and eastern coNUS regions, generally there would be a smaller concentration of military equipment in proximity to rectenna sites in these regions. These regions, however, include major transportation and commercial communications facilities and relatively large populations of susceptible computers, sensors, and control complexes associated with power generation and distribution, mass transportation, and industrial control facilities, Because of the higher population and business densities compared to the Mojave desert area, the total number of affected systems could be larger. This may mean more systems may need mitigation within a given area, but more complex techniques may not be necessary.

An EMC analysis and impact evaluation of rectenna sites has been demonstrated and shown to be fundamental in supporting site selections, helping to determine impacts on system performance, and helping to develop mitigating strategies for "victim" systems.

\subsection{SATELLITE SYSTEMS}

The compatibility of SPS and other satellite systemis is a major concern because of the widespread use of satellites both within the United States and internationally. A premium currently exists for geostationary orbit slots, and any potential change in the number of these slots due to SPS or otherwise needs to be carefully evaluated. Satellite receivers typically operate in extremely weak fields and $c$ an be affected by other comparably weak fields. The following discussion addresses some of the sattellite issues. However, the reader is cautioned that many unknowns exist in this field. For example, no measurements currently exist for satellite receivers in high level interfering microwave fields such as those expected from SPS. Thus the causes of interference and the coupling mechanisms are not understood in detail. However estimates have been made based on the best engineering judgement.

\subsection{EARTH TERMINALS}

Although it is difficult to generalize the allowable interference levels for satellite systems, approximate calculations can be made. The actual received signal levels that will cause interference in practice depend on a number of factors such as the victim antenna size, interference characteristics, recelver sensitivity, and modulation characteristics.

A general guide for estimating interference to satellite systems 1s contained in CCIR Report 713 . This report shows that the maximum acceptable interference power flux density incident on the victim antenna ie given by,

$$
p f d=10 \log \left(k t_{s} b_{r}\right)+10 \log \left(n_{1} / n_{s}\right)-G_{e}-10 \log \cdot \frac{\lambda^{2}}{4 \cdot \pi}
$$

where

$$
\begin{aligned}
& \mathrm{k}=\text { Boltzman's constant } \\
& t_{s}=\text { eftect tve syšteñ noise temperalure } \\
& b^{s}=\text { reference bandutith } \\
& n_{i} / n_{s}=\text { ratio of allowable interference noise power } \\
& \text { relative to normal system noise } \\
& G_{e}=\text { effective victim antenna gain in } d B \\
& \lambda^{e}=\text { victim wavelength }
\end{aligned}
$$

However, since the effective aperture, a, of the victim's antenna is

$$
10 \log a_{e}=G_{e}+10 \log \frac{\lambda^{2}}{4 \pi} \text {, }
$$

equation (9) can be rewritten as

$$
\text { pfd }=10 \log \left(k t_{s} b_{r}\right)+10 \log \left(n_{1} / n_{s}\right)-10 \log a_{e} \text {. }
$$


The reference bandwidth, $b_{r}$, in these equations is defined as the "bandwidth of concern to the interfered-with system, over which interference power can be averaged." The reference bandwidth for narrowband, single channel per carrier systems is generally assumed to be $4 \mathrm{kHz}$. Protection requirements for conventional FM-FDM (frequency modulation with frequency division multiplex) are also generally specified in a $4-\mathrm{kHz}$ bandwidth. The reference bandwidth for wideband digital systems, however, is usually taken to be $1 \mathrm{MHz}$. Both the $4-\mathrm{kHz}$ and $1-\mathrm{MHz}$ reference bandwidths will be used as appropriatc to the system being studied. The $r$ atio of system noise due to interference relative to the normal system noise $\left(n_{i} / n_{s}\right)$ is typically assumed to be of the order of 0.1 or 0.01 . These values are explained in CCIR Report 713. If one assumes an effective system noise temperature at $t_{s}=60^{\circ} \mathrm{K}$, then $p$ fd can be plotted as a function of $a_{e}$ as shown in Figures 45 and 46.

In Figure 45, one can see that the interference power flux density would have to be between -185 and $-195 \mathrm{~dB}\left(\mathrm{~W} / \mathrm{m}^{2} \cdot 4 \mathrm{kHz}\right)$ to prevent interference to systems with reference bandw1dth of $4 \mathrm{kHz}$ and antenna apertures of 1 to 10 square meters. Figure 46, on the other hand, shows that a protection of -161 to $-171 \mathrm{~dB}\left(\mathrm{~W} / \mathrm{m}^{2} \cdot 1 \mathrm{MHz}\right)$ is needed to prevent interference to these systems with 1 MHz reference bandwidths and antenna apertures of 1 to 10 square meters. The extreme value of $-221 \mathrm{~dB}\left(\mathrm{~W} / \mathrm{m}^{2} .4 \mathrm{kHz}\right)$ is required to protect a large antenna INTELSAT system. However, one should note that this extreme protection is needed only if the interfering source is within the main beam of the INTELSAT antenna. Since these antennas have a beam width of approximately 0.3 degrees, it is likely that the SPS will be off-axis, which means that the protection criterla can be relaxed.

The satellite bands primarily affected by adjacent channel noise from sps are three direct broadcast bands assigned within the frequencies of 2500 to $2690 \mathrm{MHz}$. The satellite band most susceptible to harmonic interference is the 7300- to 7450-MHz band assigned to government, fixed satellite, space-to-earth communications.

\subsubsection{GPS Navigation Terminal}

The Global Position Satellite System (GPS) is a network of satellites that, when completed, would transmit navigation signals. Current plans for GPS envision a constellation of 18 satellites that provide accurate three-dimensional position and velocity information to users anywhere in the world (Milliken 1978 and Lassiter 1977). The navigation signal is transmitted at two rf frequencies of $\mathrm{f}_{1}=1575.42 \mathrm{MHz}$ and $f_{2}=1227.6 \mathrm{MHz}$. The $f_{1}$ signal is modulated with a secure pseudorandom code (P code) for military navigational uses, as well as a clear access (C/A) code for general civilian navigation. The $f_{2}$ frequency contains only the $P$ code. Both codes use spread spectrum signaling techniques with the $P$ code occupylng an rf bandwidth of approximately $10 \mathrm{MHz}$ while the C/A code occupies a 1-MHz bandwidth. The C/A code is a "clear access" code available to the general public while the $P$ code is restricted to military users. The data rate of the navigation signal that is carried by the codes is 50 bps. Representative parameters for this type of system are:

Power flux density, $1575.42 \mathrm{MHz} \mathrm{C} / \mathrm{A}$ signal at surface of earth

Power flux density, $1575.42 \mathrm{MHz} P$ signal at surface of earth

Approximate rf bandwidth of $\mathrm{C} / \mathrm{A}$ signal

$-155 \mathrm{~dB} W / \mathrm{m}^{2}$

Approximate $r$ bandwidth of $P$ signal

Power flux density per $4 \mathrm{kHz}, 1575.42 \mathrm{MHz}$ C/A signal at surface of earth

Power flux density per $4 \mathrm{kHz}, 1.575 .42 \mathrm{MHz} P$ sigrial at surface of earth

Satellite Earth Terminal noise temperature $T$

$-165 \mathrm{~dB} \cdot W / \mathrm{m}^{2}$

Satellite Earth.Terminal noise power density per $4 \mathrm{kHz}$ ( $\mathrm{kTB}$ with $\mathrm{B}=4 \mathrm{kHz}$ )

$1 \mathrm{MHz}$

$10 \mathrm{MHz}$

$-178 \mathrm{~dB} \mathrm{~W} / \mathrm{m}^{2} \cdot 4 \mathrm{kHz}$

$-199 \mathrm{~dB} \mathrm{~W} / \mathrm{m}^{2} \cdot 4 \mathrm{kHz}$

$60^{\circ} \mathrm{K}$

$-210.8 \mathrm{~dB}$ W/4 kHz

GPS has been specifically designed to be useful in a hostile jamming environment, and the navigation signals are inherently interference resistant. In fact, as shown below, this system can operate even though the interference is stronger than the signal.

The increase in recelver output noise of a GPS satellite receiver, or any spread spectrum recelver, is given by

where

$$
D=10 \log \left(1+\frac{1}{s} \cdot \frac{s}{n_{0}} \cdot \frac{1}{b_{R F}}\right) d B
$$

$$
\begin{aligned}
& \frac{1}{s}=\text { interference to signal ratio, } \\
& \frac{s}{n_{0}}=\text { receiver signal to noise power density ratio in the absence } \\
& \text { of interence, }
\end{aligned}
$$




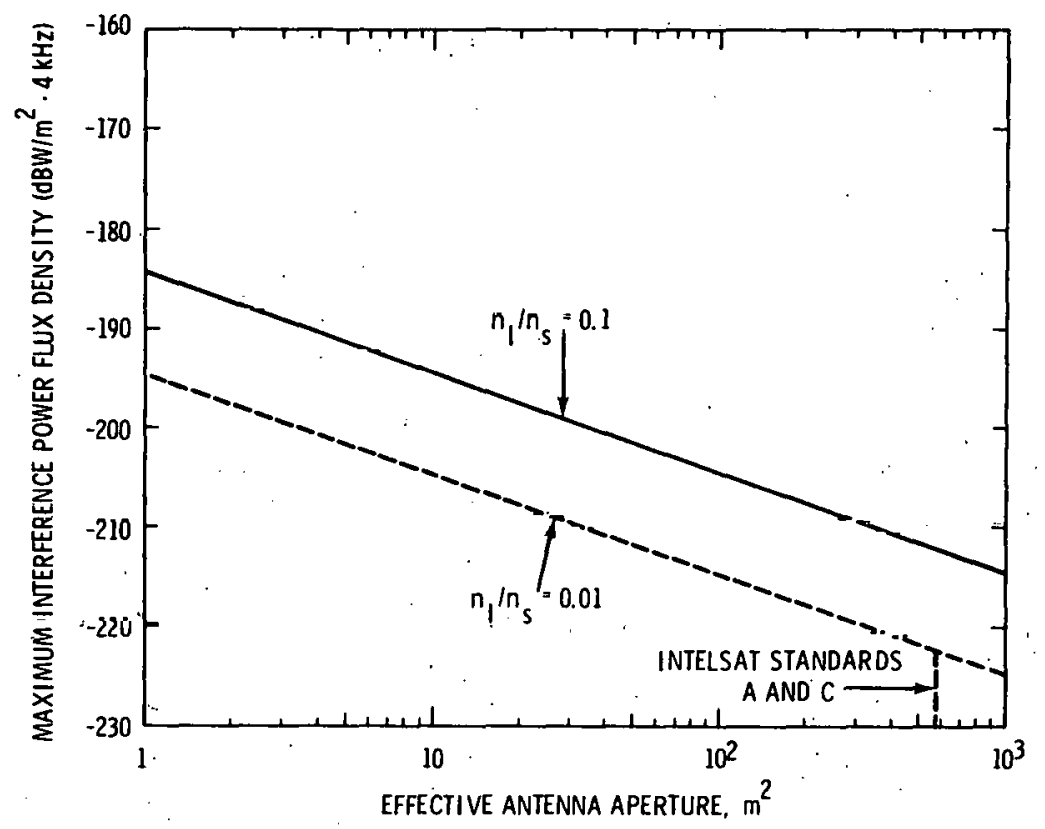

Figure 45. Maximum Interference Power Flux Density in a 4-kHz Reference Bandwidth. Versus Effective Victim Antenna Aperture.

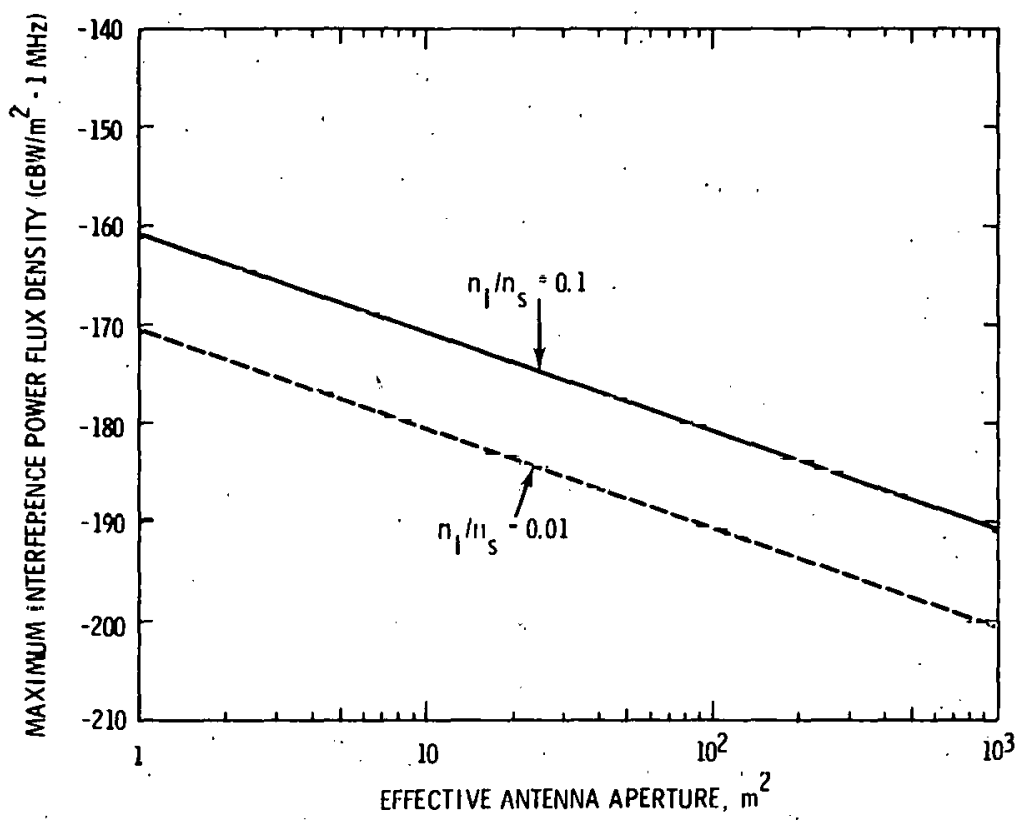

Figure 46. Maximum Interference Power Flux Density in a 1 MHz Reference Bandwidth Versus Effective Victim Antenna Aperture. 
and

$$
b_{R F}=\text { recelver rf bandwidth. }
$$

Equation (12) Is plotted in Figure 47. Since these recelvers can typically withstand a degradation of 3 or more $d B$ without serlous consequences, we see that the GPS can function in an interference environment of $I / S=20$ to $30 \mathrm{~dB}$ without significant performance degradation.

At this point, we are forced to ask what constitutes interference. Consider the hypothetical example of an interferer with $\mathrm{I} / \mathrm{S}=5 \mathrm{~dB}$. Strictly speaking, this does not significantly affect the GPS recelvers navigational capabilities. However, it does affect the recelver in other ways since it increases the normal system background noise. This affects the signal acquisition capabilities as well as the ability to reject additional interferers or jammers. Thus, to determine if SPS interferes with GPS, we looked for any significant increase in recelver background noise.

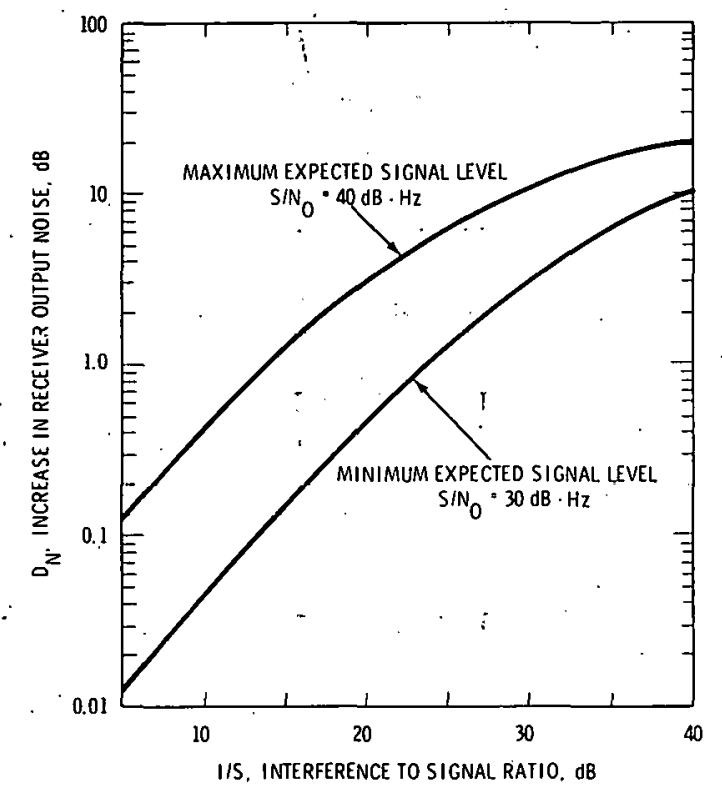

F1gure 47. Expected Increase In GPS Spread Spectrum Recelver as a Function of Interference to Signal Strength Ratio.

Calculations of the SPS signal levels coupled into a GPS receiver are relatively stralghtforward as shown in Table 11. A value of $130 \mathrm{~dB}$ has been chosen for the amount of receiver filtering expected for the interfering SPS signal because of the large frequency separation between victin and interferor (1575 MHz and $2450 \mathrm{MHz}$, respectively). Leakage from connectors and chassis components, generally limits the maximum filtering of modern receivers to values in this range. After filtering, the expected interference-to-noise ratio $(\mathrm{I} / \mathrm{N})$ is $9 \mathrm{~dB}$ in a $-10 \mathrm{~dB} \mathrm{~W} / \mathrm{m}^{2}$ field and $-21 \mathrm{~dB}$ in a $-40 \mathrm{~dB} \mathrm{~W} / \mathrm{m}^{2} \mathrm{field}$. Ideally, the $I / N$ ratio would be less than $0 \mathrm{~dB}$ to ensure no interference. Although the $\mathrm{I} / \mathrm{N}$ ratio is greater than $0 \mathrm{~dB}$ in a $-10 \mathrm{~dB}$ W/m $/ \mathrm{m}^{2}$ field, it is significantly less than 0 in the $-40 \mathrm{~dB} / \mathrm{m}^{2} \mathrm{fleld}$. Neither of these fields would be expected to alter"significantly the receiver's tracking accuracy.

\subsubsection{MARISAT Ship Terminals}

The MARISAT is a satellite system that provides maritime communications for both Navy and civil users. Two satelites located at $15^{\circ} \mathrm{W}$ and $176.5^{\circ} \mathrm{E}$ longltude provide coverage over the Atlantic and Pacific oceans. A general block diagram of the system is shown in Figure 48 (Gould 1975). The closest MARISAT frequency to SPS is the 1540-MHz satellite-to-ship link. 
- TABLE 11. Estimate of SPS Signal Levels in a 1575.42-MHz GPS Navigation Receiver

\begin{tabular}{lll}
\hline SPS power density & $-10 \mathrm{dBW} / \mathrm{m}^{2}$ & $-40 \mathrm{dBW} / \mathrm{m}^{2}$ \\
GPS reference bandwidth & $1 \mathrm{MHz}$ & $1 \mathrm{MHz}$ \\
$\begin{array}{l}\text { GS noise power in reference } \\
\text { bandwidth (t } 60 \mathrm{~K})\end{array}$ & $-151 \mathrm{dBW} / \mathrm{MHz}$ & $-151 \mathrm{dBW} / \mathrm{MHz}$ \\
$\begin{array}{l}\text { Effective GPS antenna aperture } \\
\text { at SPS frequency (1.0 m diameter; }\end{array}$ & $-2.0 \mathrm{~dB} \cdot \mathrm{m}^{2}$ & $-2.0 \mathrm{~dB} \cdot \mathrm{m}^{2}$ \\
$\begin{array}{l}\text { 8\% efficiency) } \\
\text { SPS power received on GPS antenna }\end{array}$ & $-12 \mathrm{dBW}$ & $-42 \mathrm{dBW}$ \\
$\begin{array}{l}\text { I/N prior to receiver filtering } \\
\text { Estimatc of rcecivcr filtering } \\
\text { attenuation (1575 MHz to 2450 MHz) }\end{array}$ & $139 \mathrm{~dB}$ & $109 \mathrm{~dB}$ \\
I/N after receiver filtering & $9 \mathrm{~dB}$ & $130 \mathrm{~dB}$ \\
\hline
\end{tabular}

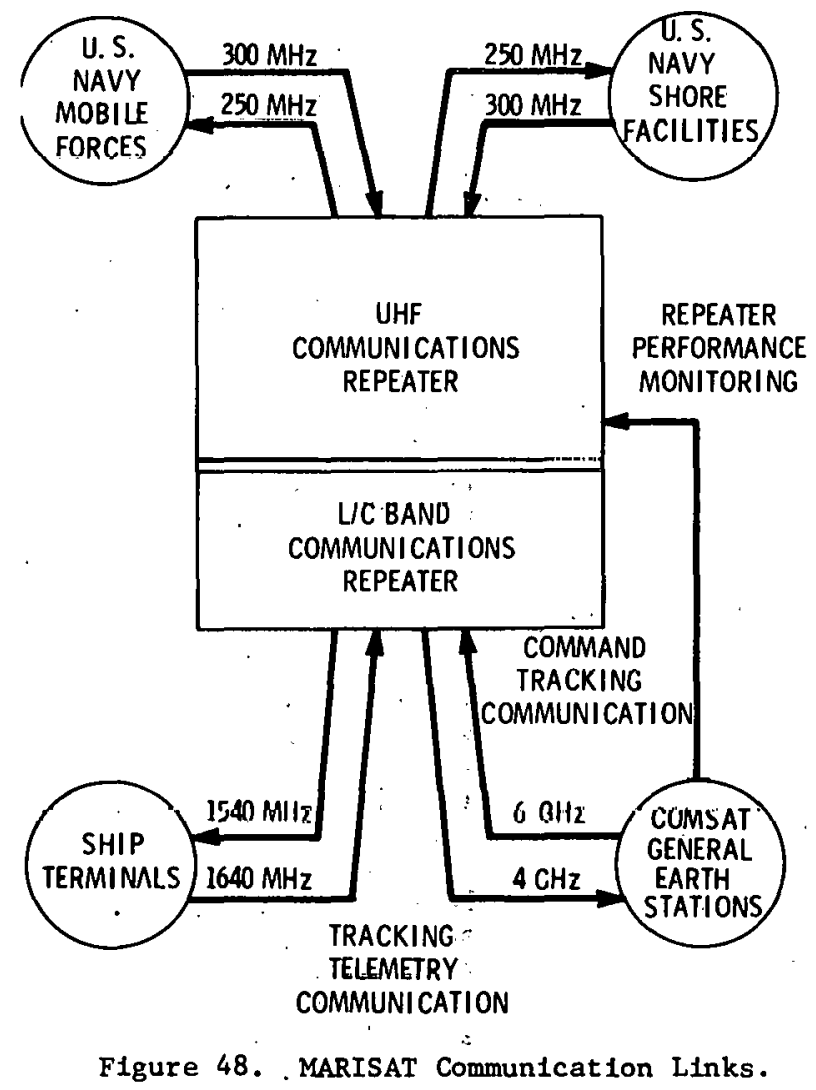

The 1540-MHz satellite-to-ship link transmits volce via a single-channel-per-carrier frequency modulated signal. Some of the typical technical characteristics for this 1 ink are:

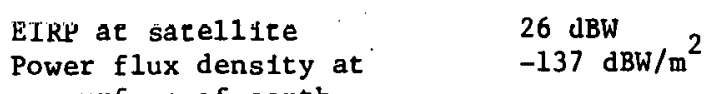

Power flux density at surface of earth

$$
\begin{aligned}
& 26 \mathrm{dBW} \\
& -137 \mathrm{dBW} / \mathrm{m}^{2}
\end{aligned}
$$

$25 \mathrm{kHz}$ $-145 \mathrm{dBW} / \mathrm{m}^{2}: 4 \mathrm{kHz}$ 
Although the interference calculations for this system are similar to those described for GPS, MARISAT does not use spread-spectrum techniques and therefore cannot operate with the positive I/S ratios shown for GPS.

The SPS signal levels that can be expected in a MARISAT sh1pboard receiver were calculated (Table 12). These calculations indicate that interference 18 a potentlal problem in $\mathrm{f} 1 \mathrm{elds}$ of $-10 \mathrm{dBW} / \mathrm{m}^{2}$ and that interference should not be expected in a $-40 \mathrm{dBW} / \mathrm{m}^{2}$ field.

TABLE 12. Estimate of SPS Signal Levels in a 1540-MHz MARISAT Sh1p Terminal

\begin{tabular}{lll}
\hline SPS power density & $-10 \mathrm{dBW} / \mathrm{m}^{2}$ & $-40 \mathrm{dBW} / \mathrm{m}^{2}$ \\
MARISAT reference bandwidth & $4 \mathrm{kHz}$ & $4 \mathrm{kHz}$ \\
$\begin{array}{l}\text { MARISAT noise power in } \\
\text { reference bandwidth }(\mathrm{t}=60 \mathrm{~K})\end{array}$ & $-175 \mathrm{dBW} / 4 \mathrm{kHz}$ & $-175 \mathrm{dBW} / 4 \mathrm{kHz}$ \\
$\begin{array}{l}\text { Effective MARISAT antenna aperture } \\
(1.3 \mathrm{~m} \text { diameter, } 80 \% \text { efficiency) }\end{array}$ & $0.3 \mathrm{~dB} \cdot \mathrm{m}^{2}$ & $0.3 \mathrm{~dB} \cdot \mathrm{m}^{2}$ \\
SPS power received on MARISAT antenna & $-9.7 \mathrm{dBW}$ & $-39.7 \mathrm{dBW}$ \\
$\begin{array}{l}\text { I/N prior to receiver filtering } \\
\text { Estimate of receiver.filtering, }\end{array}$ & $165.3 \mathrm{~dB}$ & $135.3 \mathrm{~dB}$ \\
$\begin{array}{l}1540 \mathrm{MHz} \text { to } 2450 \mathrm{MHz} \\
\text { I/N after receiver filtering }\end{array}$ & $130 \mathrm{~dB}$ & $130 \mathrm{~dB}$ \\
\hline
\end{tabular}

In summary, one should note that in a $-40 \mathrm{dBW} / \mathrm{m}^{2}$ SPS field the estimated $\mathrm{I} / \mathrm{N}$ ratio after receiver filtering was $-21 \mathrm{~dB}$ for GPS and $5.3 \mathrm{~dB}$ for MARISAT. Ideally both of these flgures should be significantly less than zero to insure that no interference exists. However, netther estimate necessar $11 y$ shows, significant potential for interference considering the unknowns involved. On the other hand, the I/N ratios incrcasc to $9 \mathrm{~dB}$ and $35.3 \mathrm{~dB}$, respectively, in a $-10 \mathrm{dBW} / \mathrm{m}^{2}$ field. Thus, one can see that the potential for interference significantly increases in a $-10 \mathrm{dBW} / \mathrm{m}^{2}$ fleld for earth terminals such as MARISAT with reference bandwidths of $4 \mathrm{kHz}$.

\subsection{GEOSTATIONARY SATELLITES}

Since SPS can radiate substantial amounts of power in directions other than the antenna boresite, one must also consider the possibility of interference to other satellites in geosynchronous orbit. This section examines the potential for interference to geostationary satellites spaced within a.few degrees of SPS as well as geostationary satellites at approximately ant1podal orbit locations. Geostationary satellites within a few degrees of SPS will be subjected to microwave energy radiated 90 degrees off boresite while satellites located antipodal to an SPS will be subjected to microwave energy radlated within a few degrees of SPS boresite.

As in the previous examples, many unknowns exist. The radiation pattern for the SPS at 90 degrees off of boresite is unknown. The microwave energy radiated 90 degrees off of boresite 1 s 11 kely to be caused by a number of phenomena, such as scattering from surface irregularities and structural components, diffraction from surface discontinuities, as well as leakage from chassis, connectors, etc. Given these assumptions one can visualize various conditions that would apply to the energy radiated 90 degrees off of boresight. For example, one line of thought is that the energy will appear to be radiating from numerous independent sources spaced throughout the surface of the SPS antenna with 11 ttle phase coherence of the radiated energy over any significant distance. Thus, locations a few hundred $\mathrm{km}$ and $90 \mathrm{degrees}$ off of boresite from an SPS antenna will be in the antenna's far fleld. However, other arguments are that there will be a significant degree of phase coherence in this energy and therefore one cannot assume that such locations will be in the far fleld. Energy coupling between two antennas is significantly more complex if one of the antennas is in the near field of the other.

An analysis of the power transfer from a large antenna to a small antenna when the small antenna is within the near field of the large antenna is discussed by Jacobs (1963). Th1s analys1s shows that the power transferred between the two antennas 18

where

$$
\frac{P_{r}}{P_{t}}=\frac{g_{t} a_{s}}{4 \pi r^{2}}
$$




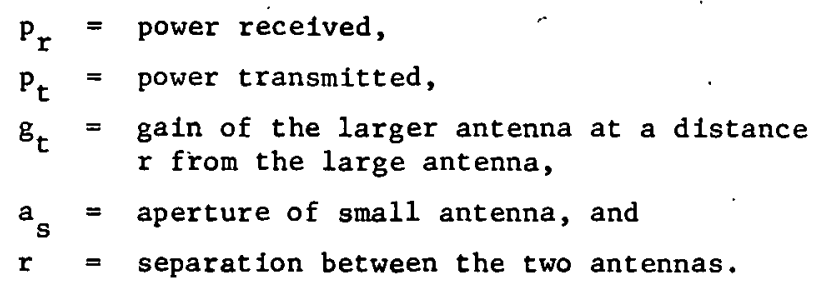

The above formula is applicable as long as $r$ is greater than the near field distance of the small antenna as given by

$$
r \geq \frac{2 d_{s}^{2}}{\lambda}
$$

where $d_{s}$ is the largest dimension of the small antenna and $\lambda$ is the wavelength. Note that $g_{t}$ is the gain of the larger antenna at the distance $r$. Estimating $g_{\text {t }}$ when $r$ is within the near field ${ }^{s}$ is a complex problem that is beyond the scope of this limited analysis. However, the near field gain of an antenna is always less than or equal to the far field gain.

The power flux density at the smaller receiving antenna is given by

$$
\mathrm{f}_{\mathrm{d}}=\frac{\mathrm{p}_{\mathrm{r}}}{\mathrm{a}_{\mathrm{s}}}=\frac{\mathrm{P}_{\mathrm{t}} \mathrm{g}_{\mathrm{t}}}{4 \pi \mathrm{r}^{2}} .
$$

When $r$ is in the direction of the geostationary orb1t, it is useful to express $r$ in terms of degrees of orbital arc $\phi$ where

$$
r=\frac{\mathrm{d} \phi}{57.3}
$$

and $d$ is the distance from the center of the earth to the geostationary orbit.

Substituting (15) into (14) results in

$$
\mathrm{f}_{\mathrm{d}}=\frac{261.3 \mathrm{p}_{\mathrm{t}} \mathrm{g}_{\mathrm{t}}}{\mathrm{d}^{2} \phi^{2}}
$$

Figure 49 shows a plot of the power density that can be expected for

$$
\begin{aligned}
& p_{t}=6.85 \times 10^{9} \text { Wate } \\
& d=4.22 \times 10^{7} \mathrm{~m}
\end{aligned}
$$

and three values of $g_{t}$. Accurate estimates for $g_{\text {, at }} 90^{\circ}$ off of boresight (gain in the direction of the geostationary orbit) are not yet avaflable. : Quantities such as aperture phase distortion, manufacturing and assembly tolerances, and other considerations can significantly affect the radiation pattern $90^{\circ}$ off of boresight. The current technology in satellite antennas results in $g_{t}$ values as 1 arge as $-10 \mathrm{dBi}$ ( $\mathrm{dB}$ relative to an isotropic radiator) (CCIR Report 558-1).

However the $-10 \mathrm{dBI}$ gain is applicable at the normal victim operating frequency which for MARISAT is $164 \mathrm{~V} \mathrm{MHz}$. A $-10 \mathrm{dBI}$ antenna gain at $1640 \mathrm{MHz}$ is equivalent to an effective antenna apercure of -35.7 $\mathrm{dBm}^{2}$. The following will assume that the effective victim antenna aperture 90 degrees off boresite is the same at $2450 \mathrm{MHz}$ as it is at $1640 \mathrm{MHz}$.

Given these assumptions, the power coupled into a victim recelver can be calculated as shown in Table 13. The calculations shown in Table 13 are made for separation between SPS and v1ct $1 \mathrm{~m}$ of $0.1^{\circ}$ and $1.0^{\circ}$ and reference bandwidths of $4 \mathrm{kHz}$ and $1 \mathrm{MHz}$. Note that the I/N rat io for the $4 \mathrm{kHz}$ reference bandwidth system after filtering is $22.1 \mathrm{~dB}$ with $0.1^{\circ}$ separation and $2.1 \mathrm{~dB}$ with $1.0^{\circ}$ separation. Again these figures should be less than zero to minimize the potential for interference. These calculations show that a potential for interference exists to satellites separated from 0.1 to 1.0 degrees from an SPS.

\subsubsection{INTELSAT Satellite}

An example of possible interference from SPS to geostationary satellites approximately $180^{\circ}$ away 1 s INTELSAT IV or IVA in orbit over the Indian Ocean at about $61.4^{\circ}$ East longltude (F1gure 50). This satellite receives signals in the $5900-6400 \mathrm{MHz}$ satellite bands and transmits on frequencles in the 3700-4200 MHz band. The SPS and INTELSAT orbit locations are $101.3^{\circ}$ West and $61.4^{\circ}$ East long 1 tude, respectively. The SPS aim point is $34^{\circ}$ North latitude and $101.3^{\circ}$. East long itude which corresponds to a point near Lubbock, Texas. The geometry and power flux density irvolved in this case have been 


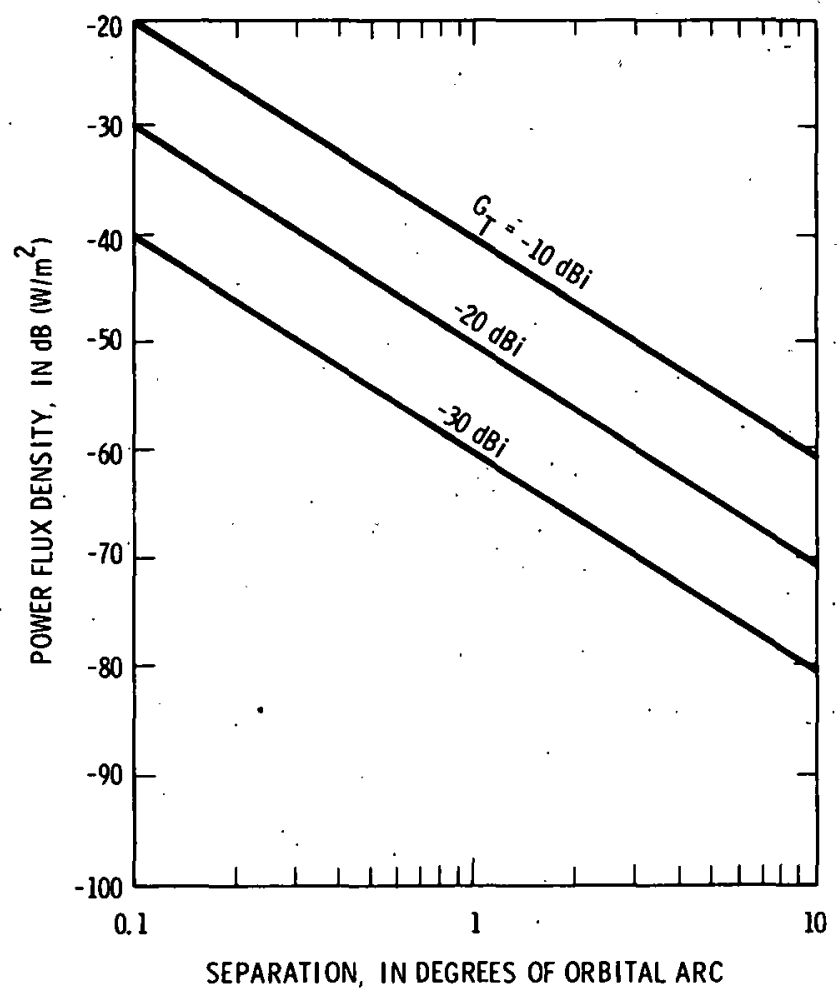

Figure 49. Power Flux Density Along GEO Orbital Arc from a Single SPS . Satellite for Different Values of Transmitting Antenna Gain, $\mathrm{G}_{\mathrm{T}}$, at $90^{\circ}$ to Boresight.

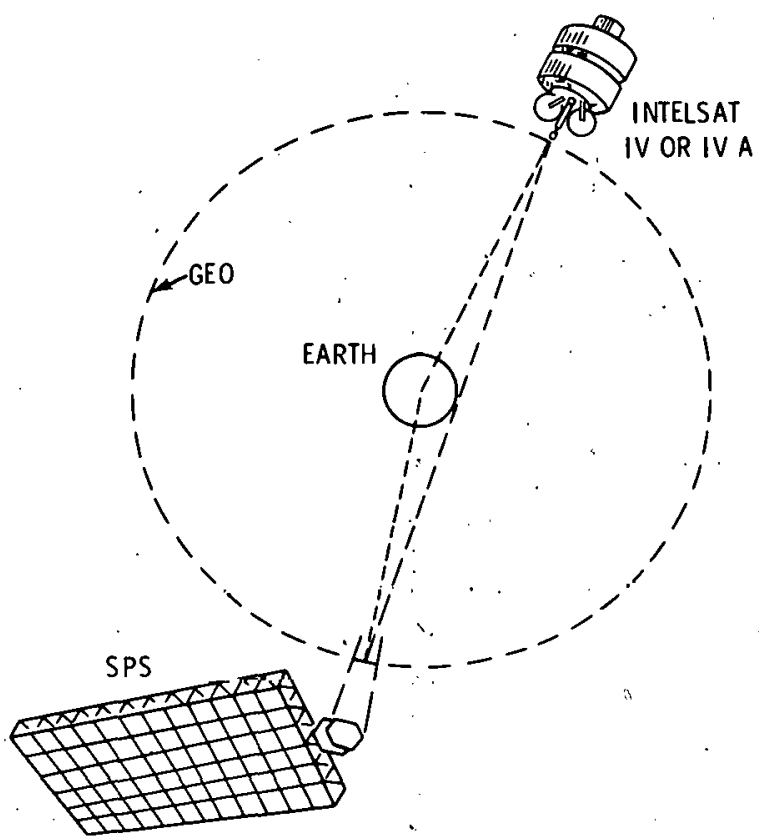

Figure 50. Geometry for Coupling of SPS to INTELSAT at approximately $180^{\circ}$ Separation. 
TABLE 13. Estimates of the Power Coupled into a 1640-MHz Satellite Transponder Separated $0.1^{\circ}$ and $1.0^{\circ}$ from SPS

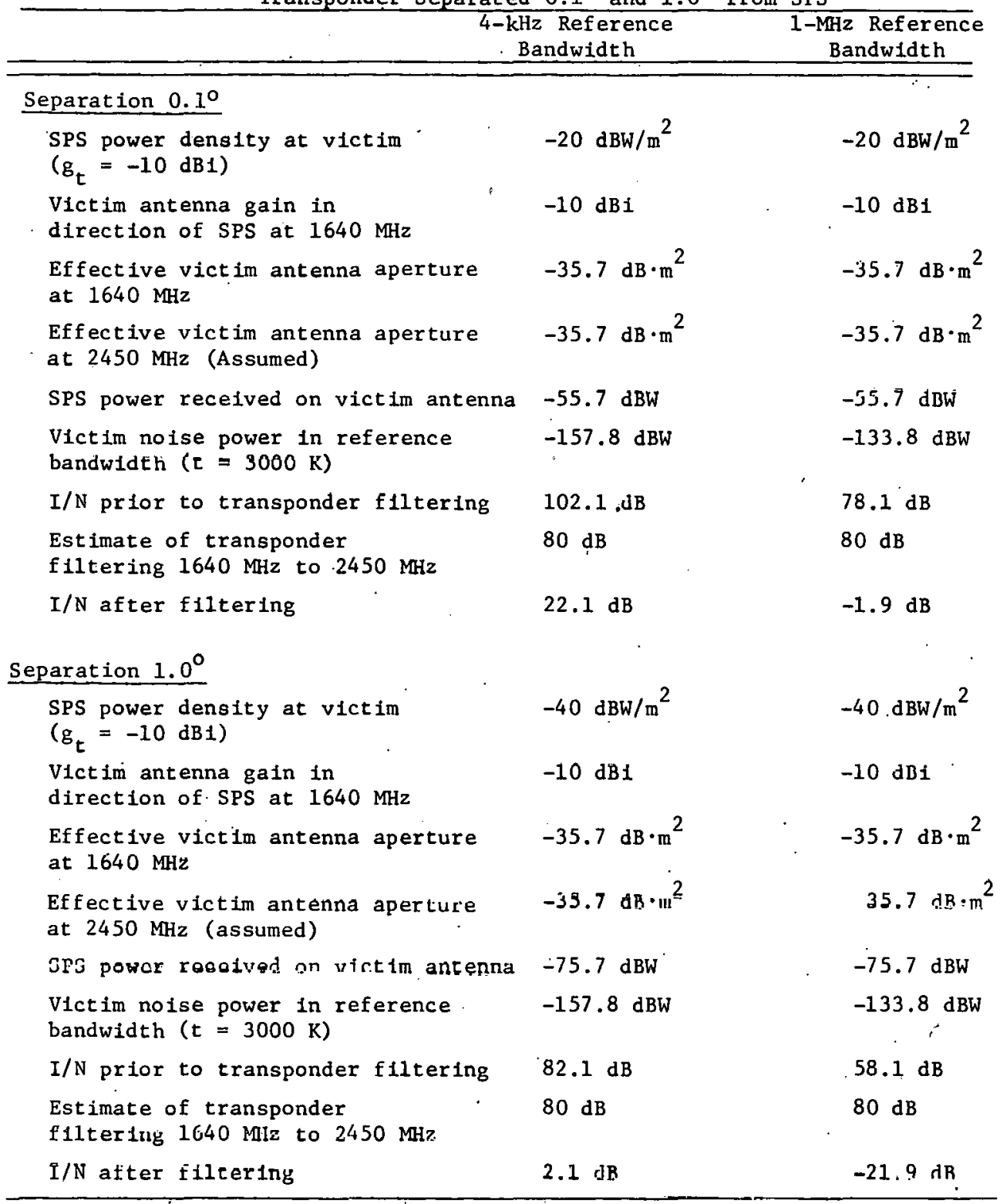

examined by ott et al. (a report entitled "Antenna patterns for the solar power satellice" lias been prepared for limited distribution as a National Telecommunications and Information Agency Technical Memorandum). This satellite recelves vi frequencios in the $5900-6400 \mathrm{MHz}$ satellite hand and transmits on frepuencies in the $3700-4200 \mathrm{MHz}$ band. These calculations estimate the SPS transmit antenna gain to be $-20 \mathrm{dBi}$ for these conditions. Using the $-20 \mathrm{dBi}$ estimallun the powcr flux density at INTELSAT can be computed using (14) with

$$
\begin{aligned}
& \mathrm{g}_{t}=-20 \mathrm{dBi} \\
& \mathrm{p}_{t}=6.85 \times 10^{9} \text { Watts } \\
& \mathrm{r}=81.3 \times 10^{3} \mathrm{~km} .
\end{aligned}
$$

which results in a power flux density of $-91.2 \mathrm{dBW} / \mathrm{m}^{2}$. 
A signal level of $-91.2 \mathrm{dBW} / \mathrm{m}^{2}$ is significantly less than the saturation power flux densities of an INTELSAT transponder which is approximately $-67 \mathrm{dBW} / \mathrm{m}^{2}$ (Bargellin1, 1972). Th1s means that the interference prior to filtering is $29.2 \mathrm{~dB}$ weaker than the victim signal at the surface of the antenna. Estimates of the interfering SPS signal levels that would be recelved by the INTELSAT are 1isted in Table 14. Many factors are unknown in these calculations, such as the response of the clrcularly polarized, global beam INTELSAT antenna to the linear polarized, off boresight, SPS harmonics. The response of an antenna to frequencles other than those normally used is seldom known. The assumption used here is that the INTELSAT antenna aperture is $1.1 \times 10^{-3} \mathrm{~m}$ which corresponds to approximately 0 dB gain at $2450 \mathrm{MHz}$ and $10 \mathrm{~dB}$ at $7350 \mathrm{MHz}$.

TABLE 14. Estimate of SPS Signal Levels at an INTELSAT Satelite Spaced $180^{\circ}$ in Geosynchronous Orbit from SPS

\begin{tabular}{llc}
\hline & $\begin{array}{c}\text { SPS Fundamental } \\
2450 \mathrm{MHz}\end{array}$ & \begin{tabular}{c} 
SPS $\begin{array}{c}3 \mathrm{~d} \text { Harmonic } \\
7350 \mathrm{MHz}\end{array}$ \\
\hline $\begin{array}{l}\text { SPS power density at } \\
\text { INTELSAT }\end{array}$
\end{tabular} \\
$\begin{array}{l}\text { INTELSAT reference bandwidth } \\
\text { INTELSAT noise power in } \\
\text { reference bandwidth (N) }\end{array}$ & $-91 \mathrm{dBHz} / \mathrm{m}^{2}$ & $-169 \mathrm{dBW} / \mathrm{m}^{2}$ \\
$\begin{array}{l}\text { Est Imate of INTELSAT } \\
\text { antenna aperature to }\end{array}$ & $1.1 \times 10^{-3} \mathrm{~m}^{2}=-29 \mathrm{~dB} \cdot \mathrm{m}^{2}$ & $4 \mathrm{kHz}$ \\
$\begin{array}{l}\text { SPS signal (10.25 } \\
\text { off INTELSAT boresite) }\end{array}$ & & $-158 \mathrm{dBW} / 4 \mathrm{kHz}$ \\
SPS received signal 1eve1 (I) & $-120 \mathrm{dBW}$ & $1.1 \times 10^{-3} \mathrm{~m}^{2}=-29 \mathrm{~dB} \cdot \mathrm{m}^{2}$ \\
I/N prior to filtering & $38 \mathrm{~dB}$ & $-198 \mathrm{dBW}$ \\
\hline
\end{tabular}

The $7350 \mathrm{MHz}$ 3d harmonic from SPS is the signal closest in frequency to the 5900-6400 MHz INTELSAT receive frequencies. However, the $\mathrm{I} / \mathrm{N}$ ratio prior to filtering is only $-40 \mathrm{~dB}$ which would not cause significant interference. Thus, this signal is not expected to be a significant interferor. The same can be said for the fundamental. The magnitude of the $\mathrm{I} / \mathrm{N}$ ratio for the fundamental is $38 \mathrm{~dB} \mathrm{pr}$ ior to filtering. This ratio is not considered to be significant because of the large frequency difference between the interference and the victim receive frequencies. Additional filtering in the transponder and attenuation due to waveguides, etc., should reduce this ratio to a value well below $z$ ero.

\subsubsection{TDRSS Satellite}

Another example of potential interference along the geosynchronous orbit is that between SPS and the Tracking and Data Relay Satellite System (TDRSS) (Poza, 1977). This system of relay satellites and earth terminals supplies communications support for various space research misstons. One of the functions of TDRSS, and the subject of the following analysis, is to supply communtcations relays for space shuttle missions (Batson, 1977).

The relay satellites can support both wideband and narrowband communications at $S$ and $K$ band frequencies. The TDRSS communications frequencies closest to SPS is the $S$ band link with uplink frequencles of 2287.5 and $2217.5 \mathrm{MHz}$. Downlink assigniments from TDRSS are at 2042 and $2106 \mathrm{MHz}$, and use spread spectrum signaling techniques, with a $11.232 \mathrm{Mchlps} / \mathrm{s}$ signaling rate, to prevent interference to ground-based terminals. The uplink to TDRS, however, does not require spread spectrum signaling. It is this narrowband mode that is the subject of discussion here.

A typical transmission rate in the low data rate mode is $96 \mathrm{kbps}$. This information stream is encoded with a $1 / 3$ rate, constraint length 7 , convolutional code. The resulting 288 Kbps coded waveform is transmitted with phase shift keying of the carrier. Typical signal levels for a TDRSS-to-space shuttle communication relay are given in Table 15 along with estimates of SPS interference levels that would exist with $\sim 1^{\circ}$ separation between SPS and TDRSS. The reference bandwidth for TDRSS has been assumed to be $228 \mathrm{kHz}$. The interference to system noise ratio after filtering is estimated to be $I / \mathrm{N}=-12.1 \mathrm{~dB}$. Although an $I / N$ rat lo less than $-10 \mathrm{~dB}$ normally does not indicate interference, the marg in indicated is minimal considering the unknowns involved. 


\section{Victim}

Space Shuttle EIRP

Path loss, shuttle to TDRSS

( $R=22786 \mathrm{nmi}, \mathrm{f}=2287.5 \mathrm{MHz}$ )

Pointing and polarization losses

TDRSS receive antenna gain

Receive signal level

TDRSS noise temp

Boltzman's constant

TDRSS nolse density

Information bandwidth, $96 \mathrm{Kbps}$ mode

rt bandwidth, 228 kbpe PSK mode

TDRSS nolse power in $r f$ bandwidth

\section{Interference}

SPS transm1t power, $6.5 \mathrm{GW}$

SPS antenna gain $90^{\circ}$ off boresight

Path loss, SPS to TDRSS, (700 KM, $1^{\circ}$ separation, $\left.2450 \mathrm{MHz}\right)$

TDRSS antenna gain to SPS signal $90^{\circ}$ off boresight

SPS Interference power at Input to TDRSS recelver

Recelver diplexer filtering attenuation to SPS signal

SPS interference power after filtering

Summary

Signal to interference ratio at input to

receiver diplexer prior to filtering $(-141.9+79.1)$

Signal to interference ratio after

filtering in TDRSS recelver $(-141.9+159.1)$

Interference to system noise ratio prior

to f11tering $(-79.1+147)$

Interference to system noise rat 1o after

filtering in TDRSS diplexer. $(-159.1+147)$
$15.2 \mathrm{dBW}$

$-192.1 \mathrm{~dB}$

$-1.0 \mathrm{~dB}$

$36.0 \mathrm{~dB}$

$-141.9 \mathrm{dBW}$

$27.7 \mathrm{dBK}$

$-228.6 \mathrm{dBW} / \mathrm{K} \cdot \mathrm{Hz}$.

$-200.9 \mathrm{dBW} / \mathrm{Hz}$

49.8. $\mathrm{dB} \cdot \mathrm{Hz}$

$53.5 \mathrm{~dB} \cdot \mathrm{ll} \mathrm{x}$

$-147 \mathrm{dBW}$

$98 \mathrm{dBW}$

$-10 \mathrm{~dB} 1$

$-157.1 \mathrm{~dB}$

$-10 \mathrm{~dB} 1$

$-79.1 \mathrm{dBW}$

$-80 \mathrm{~dB}$

$-159.1 \mathrm{dBW}$

$-62.8 \mathrm{~dB}$

$17.2 \mathrm{~dB}$

$67.9 \mathrm{~dB}$

$-12 . i \mathrm{~dB}$

\subsection{SATELLITES IN LOW EARTH ORBIT}

Another major concern of the EMC program was the effect on satelliles lin low earth orbit which might pass through an SPS power beam. The large powers involved represent 1llumination levels as high as 319 volts per meter for satellites such as the proposed space.telescope at an orbit altitude of 10,900 miles. Operational effects for LEO satellites depend on orbits, equipment complement, equipment usage, and vehicle physical configuration. Existing and planned LEO systems include remote sensing, navigation and position fixing, and communtcations functions. On-board sensors sensitive to SPS Interference include electro-optical devices, active and passive microwave systems, and particle detectors.

The susceptibility of various operational and planned LEO salellites has been examined during the cource of the SPS EMC evaluation program. Functional degradation for the electronic systems on LANDSAT, GPS, and the SPACE TELESCOPE have been studied in relation to the amplitude of the SPS illuminat ton components. Analysis and tests include the modes of coupling to on-board devices and subsystems, and performance effects in relation to satellite missions. 
The susceptibility evaluations for LANDSAT, GPS, and SPACE TELESCOPE Indicate the character of functional degradation for data sensors, communications, attitude/stabilization, and processing or control systems for power beam encountered periods. Penetration through antenna and physical apertures, and modes of coupling to internal devices and modules are examined to support sensor and circuit module tests for degradation measurement and mitigation technique specification.

\subsubsection{LANDSAT Satellite}

The LANDSAT satellite program is intended to develop and demonstrate a capability for global monitoring support to Earth Resources Management. Launch of LANDSAT-D is scheduled in the third quarter of 1981. A subsequent launching is anticipated during 1982-83 by the Space Transportation System. An advanced system, LANDSAT-H, is also being planned.

The LANDSAT-D (Figure 51) will provide imagery from a sun synchronous circular orbit altitude of $705.3 \mathrm{~km}$ with a 98.2" Inclination. Imagery is derfved from a Multispectral Scanner (MSS) and Thermal Mapper (TM) on the satellite. Scanner and mapper image data and system status are transmitted to CONUS and foreign control stations directly and through TDRSS (Figure 52).

A power density-time plot for the case of orbit coincidence with the SPS main beam is presented in Figure 53. This situation will occur frequently because of the 6 to 8 orbit tracks/day over conus.

SPS energy coupling into LANDSAT systems might affect the communications, sensor, power bus, and attitude control functions. Coupling would occur through the communications antennas, attitude sensor optical apertures and the optical apertures and thermal louvres of the MSS and TM (Figure 54). Energy coupling through the solar panels to the power busses is not a problem because of the filtering and regulation provided. Exposed area and scanner locations on the satellite indicate that the optical aperture is the principal coupling mode for these sensors.

The LANDSAT star tracker provides error data to the attitude control software. Star tracker noise and angle error ranges in relation to microwave illumination levels are indicated in Figure 55 . Attitude error would accumulate over a period of about 4 to 5 seconds within the SPS beam.

Because of the locations of the TM and MSS on the satellite, the sensor responses will be sensitive to SPS orbit position. Sensor performance was evaluated for the peak and average SPS power density magnitudes indicated in Figure 53. The satellite will be subjected to microwave field intensities greater than $100 \mathrm{~V} / \mathrm{m}$ for about 1 second, intensities greater than $10 \mathrm{~V} / \mathrm{m}$ for 3.2 seconds, and intensities greater than $1 \mathrm{~V} / \mathrm{m}$ for about 13 seconds at LANDSAT velocity. Coupling of this energy into the TM and MSS systems may occur through the thermal control louvers or directly through the optical aperture.

The TM was tested using normal test procedures with no simulated SPS 1llumination. Bar targets were scanned, and recorded impulse response to a $0.2^{\circ} \mathrm{C}$ resolution was measured. This gave the normal imaging performance of the system. Identical tests were then conducted using the bar targets, recording impulse response, with the addition of a microwave signal illuminating the optical aperture. The microwave signal level was varied in steps from $1 \mathrm{~mW} / \mathrm{cm}^{2}$ unt11 complete malfunction occurred at $16 \mathrm{~mW} / \mathrm{cm}^{2}$. The microwave illumination was then aimed directly into the thermal control louvers with the louvers open to the position which gave maximum coupling. The bar target tests were conducted again at various levels of illumination. A preliminary data set indicates an increase in video channel noise of $8 \%$, and a decrease in modulation transfer function of $18 \%$ to $20 \%$, which affects the spatial imaging capability by approximately $20 \%$.

The satellite-earth station uplinks use an S band channel (direct and through TDRSS at $2106.4 \mathrm{MHz}$ with wideband modulation modes through the TDRSS). Other satellite receiver channels include a 1377.5-MHz track signal from TDRSS, and the 1227.6-MHz and 1575.4-MHz transmissions from GPS. For the direct earth-station to satellite S band link (2 Kbps - NRZ/PM), a bit error rate (BER) increase of $70 \%$ to $85 \%$ would occur for SPS main-beam exposure period (approximately 16 seconds). For the wideband TDRSS channel, the BER would increase $20 \%$ to $40 \%$, the higher range caused by nonlinear responses in the first conversion and amplifier stages of the receiver during exposure to SPS power densities of $\geq 8 \mathrm{~mW} / \mathrm{cm}^{2}$.

For perhaps one to three SPS satellites maximally separated over CONUS, the LANDSAT mission profile could be modified to eliminate command/control transmission during the specific orbit time slots corresponding to SPS illumination. This is obviously not a satisfactory mode of operation, but could be a temporary solution for an operational satellite while functional modifications are incorporated into future vehicles. These modifications should eliminate the BER effects for the narrowband and wideband transmissions to the satellite, thus removing all mission dependencies between LANDSAT and SPS operations. 


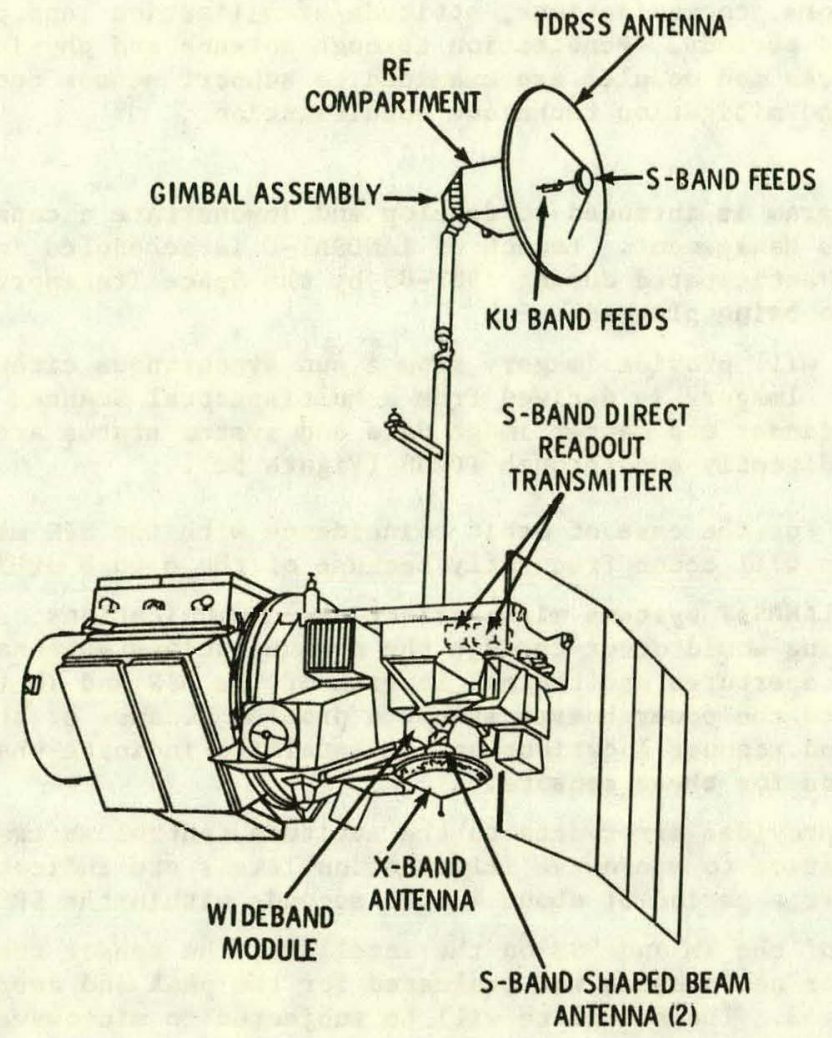

Figure 51. LANDSAT-D Configuration.

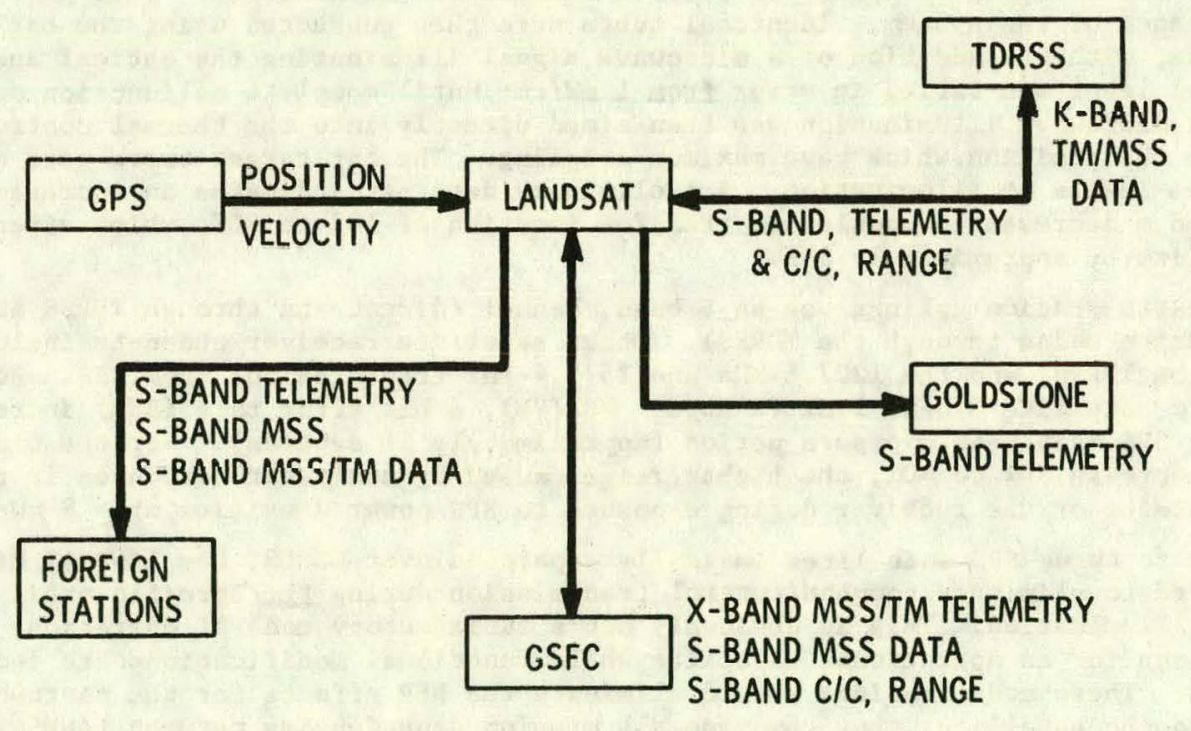

F1gure 52. LANDSAT Communication Links. 


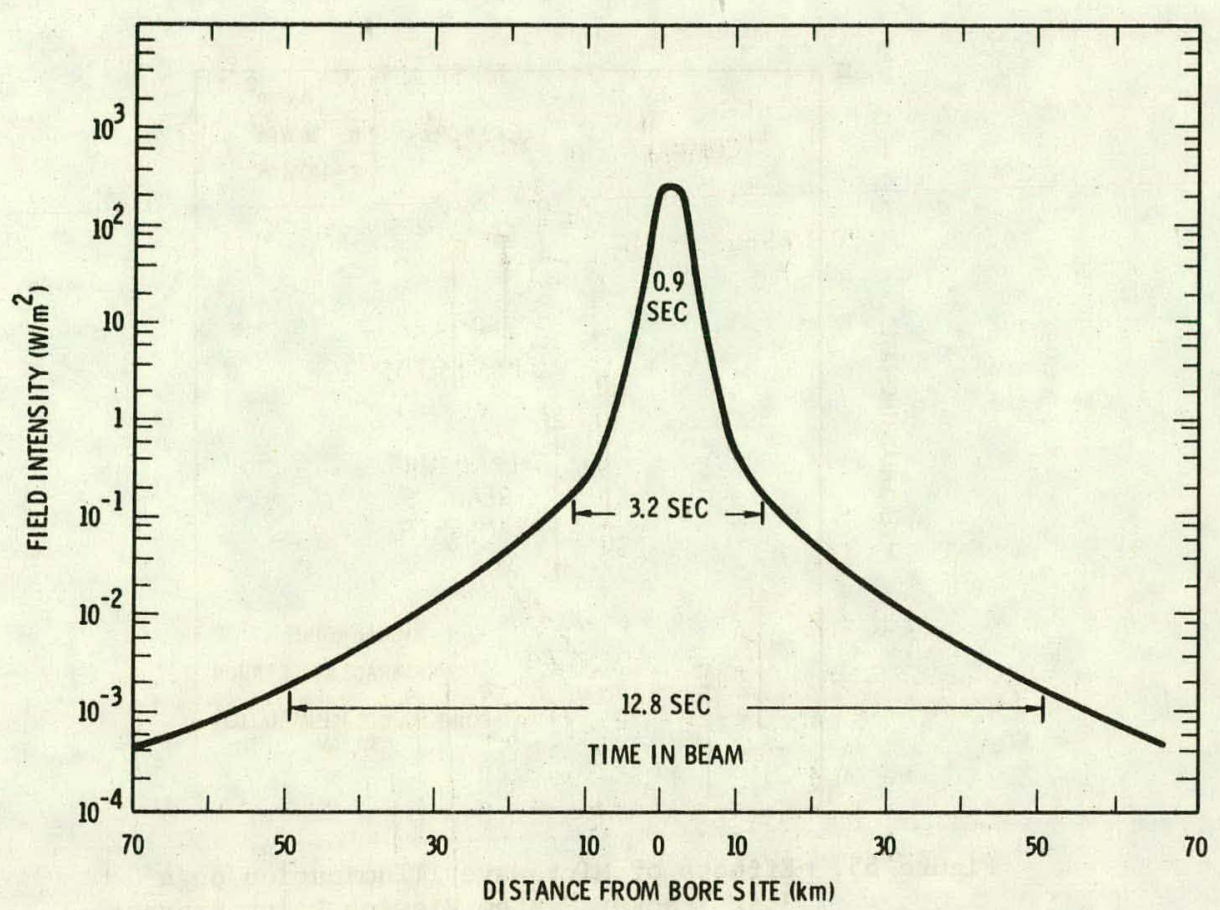

Figure 53. Microwave Field Intensity Encountered by LANDSAT during Transit of SPS Power Beam.

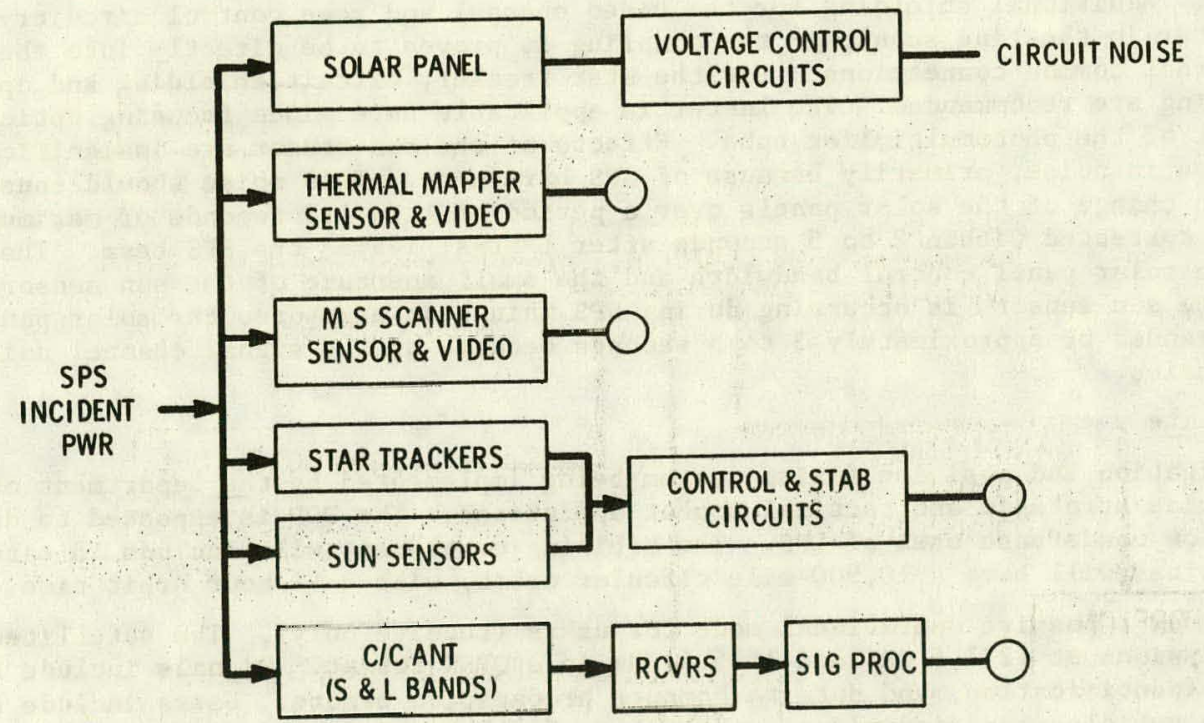

Figure 54. Block Diagram for Evaluation of SPS EMC Effects on LANDSAT. Circles identify evaluation points. 


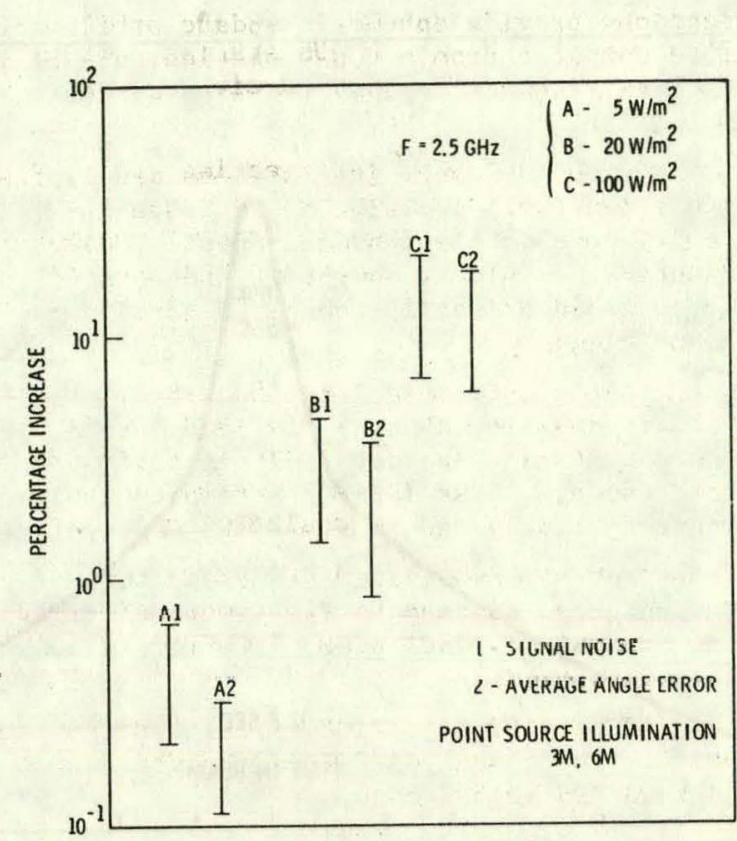

Figure 55. Effects of Microwave Illumination on a Star Tracker System Viewing Point Sources Simulating 3rd and $6 \mathrm{th}$ Magnitude Stars.

Mitigation techniques of possible use for receivers include rejection filters and antenna modifications. The former are preferred because of the relative simplicity, and the elimination of antenna control command and steering software additions. This filter should have a bandwidth of about $10 \mathrm{MHz}$, and an out-of-band insertion loss of less than $2 \mathrm{~dB}$.

Mitigation techniques for the MSS and TM include circuit filters, noise extraction (spectral densitycorrelation models) in the data analysis process, and extended shielding for the detectors and collocated video amplifiers. Additional shielding for the video channel and scan control circuitry is recommended to eliminate jitter in the line scans, if the coupling is proven to be directly into these circuits and not through internal common connections. For the star tracker, circuit shielding and optical aperture wire mesh shielding are recommended. The latter is applicable here since focusing optical components are used in front of the photomultiplier tube. Effects of the sun sensor are insignificant; approximately $2 \%$ increase in noise, primarily because of SPS harmonics. Th1s nolse should cause less than $2^{\circ}$ to $5^{\circ}$ orientation change of the solar panels over a perlod of 1 to 1.3 seconds of maximum SPS beam exposure, and be corrected within 2 to 5 seconds after LANDSAT leaves the SPS beam. The error magnitude is limited by the solar panel control bandwidth and the small aperture of the sun sensors. Where sun acquisition by the sun sensors is occurring during SPS main beam exposure, the solar panel transient time would be extended by approximately 3 to 5 seconds because of the signal channel noise and related angular uncer lainties.

\subsubsection{GPS Satellite}

The GPS is a navigation and position fixing system being implemented by the Department of Defense (DoD) to support worldwide strategic and tactical combat operations. The DOD is expected to decide within 1 to 2 years to allow nondefense uses of GPS. The orbiting complement will include 18 satellites by 1982. The satellites will have a 10,900-mile circular orbit, with a 12-hour orbit time.

This system provides a passive operational mode for users (receive only). The satellites provide two frequency transmissions at $1227.6 \mathrm{GHz}$ and $1575.4 \mathrm{GHz}$ in a QPSK format. Signals include time correlation, ephemeris, identification, and data to compute propagation errors. Users include satellites, aircraft, surface vehicles, and individuals through man pack recelver and display unfts. A position measurement accuracy of \pm 10 to \pm 30 meters is expected for the system; the vartance depends on the severity of local multipath conditions and signal thresholds, and recelver velocily lin the case of low altitude military aircraft. 
Earth-to-satellite communications provide ephemeris update orbiting clock corrections and command/ control data to the satellite computer from a CONUS station, directly and through TDRSS relay. The uplink communications use $\mathrm{S}$ band. Confcal spiral receiver antennas are located on the space and earth pointing surfaces of the satellite.

The GPS power density variations for SPS beam intersection are plotted In Figure 56. Power coupling modes into the GPS satellite (Figure 57) are similar to those for LANDSAT. The GPS vehicle has the additional mode of direct entry through the thermal control louvers that control the temperature of the principal electronic functions -- clock, computer, and command/control receiver and decoder components. This direct penetration energy would primarily couple to electronic functions through cables and interface circuits (impedances $\mathrm{z}_{1}$ through $\mathrm{z}_{4}$ ).

Maximum and average SPS power levels reflected into the satellite electronics are $25 \mathrm{~W}$ and $2.8 \mathrm{~W}$, respectively, considering power densities about $1 \mathrm{~W} / \mathrm{m}^{2}$ and louver openings of $10^{\circ}$, $30^{\circ}$, and $45^{\circ}$. Induced jitter in the internal clock and message decoder logic is estimated to be in the $10 \%$ to $65 \%$ range for SPS power in the $10-W$ to $25-W$ range. These initial estimates would need to be validated in future tests of modular logic components configured to represent GPS systems.

The $S$ band communications receiver and associated processor would experience an increase in BER in the range of 50 to $1000 \mathrm{with}$ the antennas exposed to SPS power densities of $100 \mathrm{~W} / \mathrm{m}^{2}$ to $1000 \mathrm{~W} / \mathrm{m}^{2}$. The probability of losing signal because of mixer stage intermodulation products, in-channel noise, and gain compression lock is also important.

Mitigation techniques that would need to be validated for the GPS communications receivers are 1dentical to those indicated for LANDSAT. Functional differences would result from the increased SPS maximum power density and the broad-band. GPS signal mode.

Sun sensor control of solar panel orientation will be affected only in the same manner as discussed for LANDSAT. The short exposure times and the low control bandwidth 11mit the possible roll of the solar panels due to signal noise. The statement regarding sun acquisition when exposed to SPS illumination is also applicable to GPS.

The earth sensors on GPS are effectively shielded from SPS exposure by the satellite structure for all possible SPS - GPS geometric relationships over the western hemisphere. For geometries where GPS is over European or Asian areas but has a line-of-sight with an SPS side lobe, those power densities are at least $10^{3}$ to $10^{4}$ below the threshold for satellite pointing upset.

The GPS transmitters will not be affected by SPS penetration at the levels indicated. Power and driver amplifier circuitry, and the physical configuration, indicate no possibility of Induced PM $j$ itter on the transmitted signal attributable to coupling into transmitter circultry. Transmitter antennas are shielded from direct SPS power exposure by the body of the GPS. The $50 \Omega$ power amplifier impedance, the wideband output tuned filters, and the output-input coupling of the power and driver stages indicate a net coupling of -40 to $-65 \mathrm{~dB}$ for the SPS fundamental frequency, and values of -70 to $-80 \mathrm{~dB}$ for the SPS second harmonic.

\subsubsection{Space Telescope}

In 1977, the space telescope project was approved by the United States Congress. The space telescope has major advantages over ground-based telescopes in three important areas. 1) The first and most significant is an order of magnitude improvement in angular resolution, 2) twenty-four hour per day observing time, and 3) the telescope being beyond the Earth atmosphere allows photometric data collection over a much wider wavelength range - ultraviolet, infrared, and submillimeter wavebands as well as the visual spectrum.

The Space Telescope orbit is circular at a $500 \mathrm{~km}$ altitude and $28.8^{\circ}$ inclination. A cross-sectional view of the satellite observatory is shown in Figure 58. The telescope consists of the primary and secondary mirrors, the metering structure for maintaining the relative positions of the mirrors, the internal light baffling system and the fine guidance sensors. Communications with the satellite will be via the TDRSS. The scientifte instruments on board are as follows:

Wide Field/Planetary Camera - the camera contains eight charge coupled device (CCD) detectors, each consisting of $800 \times 800$ elements.

Faint Object 3 pecliugraph - uses digicon detectors, each of which consists of a linear array of 512 independent diode elements.

Faint Object Camera - the design uses a three-stage image intensifier with an intensified silicon target television camera tube. 


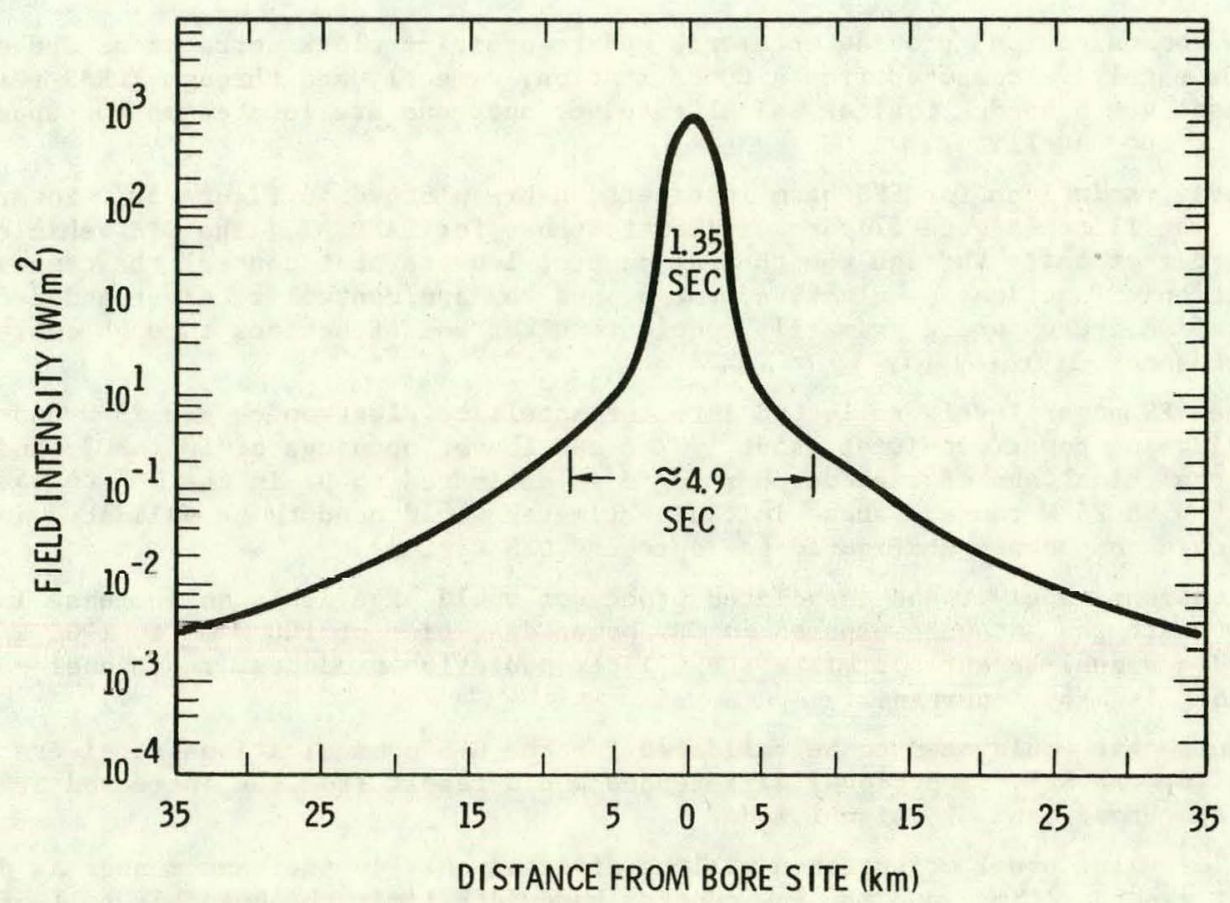

Figure 56. Microwave Field Intensity Encountered by GPS during Transit of SPS Power Beam.

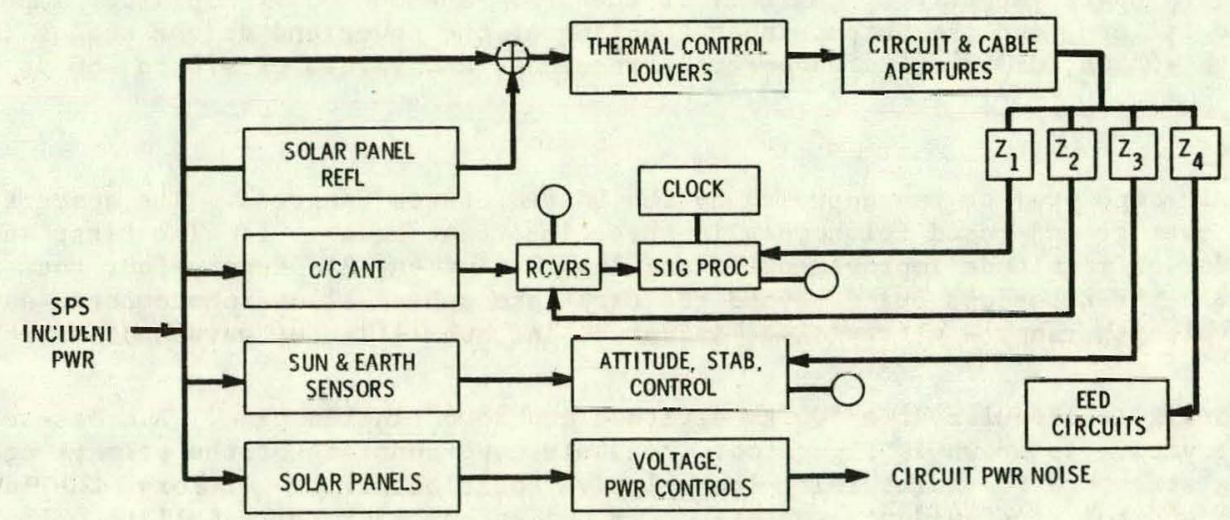

Figure 57. Block Diagram for Evaluation of SPS EMC Effects on GPS. Circles identify evaluation points. 


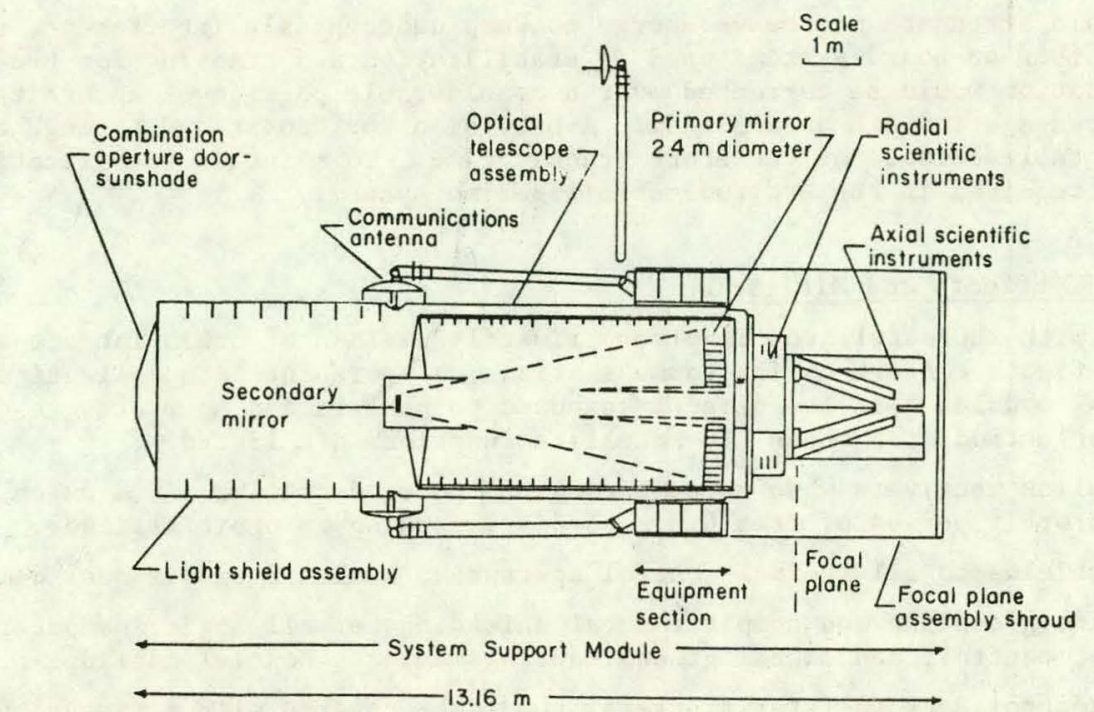

Figure 58. Cross-Sectional View of the Satellite Observatory

High Resolution Spectrograph - the detector is a digicon device consisting of a linear array of 512 diode elements.

High Speed Photometer/Polarimeter - the device consists of a number of image dissectors, their associated electronics and a focal plane aperture mask and filter plate.

Fine Guidance System - uses three independent sensors and detectors located in annular segments around the field of view in the focal plane. This system provides great astrometric potential. These three high-resolution sensors provide data for star field maps to support future stellar experiment planning. These sensors must acquire stars at $M=13$ with an accuracy of $7 \times 10^{3}$ arc seconds.

Coupling of electromagnetic energy into the satellite instrumentation will occur mainly through the telescope's 2.4 meter optical aperture. The SPS peak field intensity would be approximately $28 \mathrm{mw} / \mathrm{cm}^{2}$. This would be equivalent to about $1 \mathrm{kw}$ of microwave power at the telescope aperture. About $40 \%$ of the energy would be coupled through the baffled area to the primary mirror. Some $20 \%$ of this energy would then be reflected through the mirror system into the detector area. There would be about $60 \%$ penetration into the detector areas which would be equivalent to 55 watts of $2.45 \mathrm{GHz}$ energy directly into the instrumentation area.

The impact of SPS radiations on the scientific instruments would be to increase detector channel noise, reduce spatial resolution, and reduce dynamic range. For the satellite guidance system and astronomy missions there would be increased detector channel noise and reduced spatial resolution which would increase attitude instabilities for the few seconds the space telescope is in the SPS beam.

Figure 37 previously shown on page 36 shows a CCD array as used in the widefield camera being illuminated with a normal source signal and the associated resolution given in lines per minute. One line is the normal response of such an array. The other shows the degradation in resolution in the presence of a $2.5 \mathrm{GHz}, 2 \mathrm{mw} / \mathrm{cm}^{2}$ rf field. Here it can be seen that it takes a higher source illumination for a given resolution in the presence of the microwave field, particularly below $10^{-5} \mathrm{~mW} / \mathrm{cm}^{2}$.

CCD matrices, digicon devices, image intensifiers, and image dissectors will experience degraded capabilities in the presence of SPS energy as the satellite observatory intersects the main power beam and major side lobes. The apertures in front of the detectors afford very limited protection since the axial length will be less than $\lambda / 2$ for the SPS fundamental or primary harmonirs.

Mirigation techniques would include wire mesh shielding for image dissectors, digicon devices, and CCD arrays, where focusing optics are employed. For submillimeter, infrared, or ultraviolet detectors, the wire mesh would cause unacceptable distortion and large data errors. Increasing the axial length of the apertures for the instrument detectors to $6 \mathrm{~cm}$ will provide $40-60 \mathrm{~dB}$ microwave attenuation. Uplink communications through TDRSS should not be accomplished during beam intersection. Crystal lenses in 
the optical link would attenuate microwave energy to keep unacceptable interference from the fine guidance system or other on-board systems used in stabilization and tracking for the telescope, Upset in attitude stabilization would be corrected over a considerable portion of an orbit to stabilize the total system after passage through an SPS beam. A provision for "coasting" through the power beam should also be acceptable because of the short transit time. To maintain specification accuracy, a rate memory mode will be required in the attitude stabilization system.

\subsubsection{Summary of LEO Effects and Mitigation}

The SPS interaction with LEO satellites involves primarily periods of orbit intercept with the SPS power beam. Performance effects concern uplink communications, sensors for data collection and attitude control, and internal modules that are directly exposed to penetration apertures (e.g., thermal control louvres). Mitigation methods for these LEO satellite functions are listed.

1. Silence uplink receivers when encountering SPS power densities $>0.2 \mathrm{mw} / \mathrm{cm}^{2}$. This will involve an orhit period of from $0.5 \mathrm{~s}$ to $3 \mathrm{~s}$ depending on orbit altitude.

2. Add mesh shields to all thermal control apertures; mesh < $2 \mathrm{~cm}$ diagonal dimension.

3. Single-point grounding and complete metal shleldlug fur all logic, compriter, and clock components. All signal, control, and signal gruuul calling must uce coavial rahling.

4. Attitude control sensors (star trackers) should be covered with a wire mesh (d $<2 \mathrm{~cm}$ ) if focusing optics are employed. Mesh is placed at defocused axial positions, and AWG 26 to 32 copper wire grounded to the satellite structure should be used.

5. Attitude sensors not using focusing optics should use crystal mirrors or a metal cylindrical collimator having an axial length $\geq 6.5 \mathrm{~cm}$. These methods will provide $220-30 \mathrm{~dB}$ suppression.

6. Earth sensors (visual and IR optical staring or scanning devices) should use a metal collimator with axial length $\geq 6.5 \mathrm{~cm}$, and complete shielding around video amplifiers and control circuits coupling from the sensor elements.

7. Where the recommended data sensor shielding must be compromised in axial dimension, image enhancement software will be required in data reduction to remove periodic noise components and to restore higher spatial frequencies.

\subsection{OTHER POTENTIAL INTERFERENCE CONSIDERATIONS FOR SATELLITE COMMUNICAIIONS SYSTEMS}

Co-channel interference levels below $-185 \mathrm{~dB}\left(\mathrm{~W} / \mathrm{m}^{2} \cdot 4 \mathrm{kHz}\right)$ will be needed to protect earth terminals with antenna apertures of 1 square meter or more, see Figure 45. These figures apply to narrowband systems such as single channel voice systems and FM-FDM voice systems wilh a 4 kIIz reference bandwidth. Wideband satellite earth terminals with a 1-MHz reference bandwidth can withstand higher interference levels of up to $-161 \mathrm{dBW} / \mathrm{m}^{2} \cdot \mathrm{MHz}$, see Figure 46 . Earth terminals whose operating frequency is significantly separated from the SPS power transmission frequency can withstand interference levels substantially higher than those quoted above because of filtering in the receiver. Estimates of the maximum amount of filtering available in satellite receivers is $-130 \mathrm{~dB}$. Laboratory testing needs to be conducted to define more precisely the maximum filtering available in satellite receivers.

Calculations of the potential interference between SPS and NAVSTAR GPS navigation receivers showed that SPS does not represent an interference threat to the 1575.42-MHz navigation signal. The combined rf and IF filtering of the navigation receivers should be sufficient to prevent interference even in an SPS power flux density of $-10 \mathrm{dBW} / \mathrm{m}^{2}\left(0.01 \mathrm{~mW} / \mathrm{cm}^{2}\right)$. A similar conclusion was also reached in a study of interference to MARISAT earth terminals in an SPS microwave field of $-40 \mathrm{dBW} / \mathrm{m}^{2}\left(1 \times 10^{-5} \mathrm{~mW} / \mathrm{cm}^{2}\right)$. However, a potential interterence prublem does exist with MARTSAT terminals in a $\mathrm{field}$ of $-10 \mathrm{dBW} / \mathrm{m}^{2}$.

Interference problems are also possible between SPS and other satellites closely spaced in geosynchronous orbit. This study estimates that a power flux density as high as $-20 \mathrm{dBW} / \mathrm{m}^{2}$ can be expected at victim satellites within $0.1^{\circ}$ of separation from SPS. This figure is based on an SPS antenna gain in the direction of the geosynchronous orbit of $-10 \mathrm{dBi}$. Signal levels of this magnitude can be sufficient to cauce interference to satellite systems with reference bandwidths of $4 \mathrm{kHz}$. It is estimated that separations of more than $1.0^{\circ}$ may be required to prevent interference lu other oatellites in gansynchronous orbit. 


\title{
9.5. FUTURE SATELLITE SYSTEMS
}

A number of resource monitoring satellites are currently in the concept definition phase. These conceptual systems are:

\author{
1. Earth Watch \\ Orb1t altitude approximately $6000 \mathrm{m1}$, \\ mapping and microwave monitor. \\ 2. Microsat \\ Passive $L$ band radiometer. \\ 3. Radar Holographer \\ Bistatic radar (GEO 1lluminator with LEO collector): \\ 4. GEOSAR \\ GEO synthet1c aperture radar. \\ 5. E1lipsometer \\ Bistatic radar for molsture measurement. \\ 6. LANDSAT-H \\ MSS scanner and synthct1c array radar.
}

Most satellites passing through an SPS beam will experience problems similar to those of LANDSAT and GPS. Satellites with optical apertures w11l probably experlence more problems than those without that coupling mode. In-depth analysis of these satellites would be necessary if the SPS concept is pursued.

\subsection{CONCLUSIONS AND RECOMMENDATIONS}

The evaluation of the SPS operation effects on other GEO and LEO satellites Indicates the character of EM functional interactions, lncluding modes of penetration Into satellite recelvers, sensors, and circuits, and the resultant functional degradation in data collection and processing.

The GEO communications satellites should be separated from an sPS by about $1.0^{\circ}$ at orbit altitude to - assure acceptable uplink performance, where SPS Interference effects include coupling of SPS fundamental. and harmonics from spacetenna sidelobes, and reflective multipath from the sps structure. This separation will allow an $S / I>15 \mathrm{~dB}$ for the adjacent communication links.

Future satellites using array antennas can employ nulling techniques for SPS harmonic components that are within communications bands. This method can provide about 20-30 dB suppression from unmodulated interferors.

Satellite-satellite communications modes with an SPS between communications satellites cannot be satisfactorily accomplished without a frequency translator-repeater operating on the SPS vehicle because of reflection multipath interference. Without the SPS repeater, fade depths might restrict link utility for digital or medium bandwidth analog data transmission.

Multiple use communications platforms and multipleispacetenna-SPS platform configurations represent a viable technical option for elimination of the orbit slot contention problems for a 60 sps deployment.

\subsection{EFFECTS ON ASTRONOMY AND RELATED RESEARCH}

The SPS Reference System (DOE/ER-0023) was used to Identify and evaluate significant potential effects on astronomy and related research areas. Some effects are due to specific and active properties of the system. Others arise from general and passive aspects of any system of large satellites. A fractionally small portion of the microwave power not collected by the rectenna would probably interfere with current observations in radio astronomy and could concelvably damage recelving apparatus. Thermal emisstions at radto frequencles from the large warm satellites could also have an effect on radio astronomy. The diffuse reflection of sunlight from the large satellites in geosynchronous orbit would affect optical astronomy and aeronomy by increasing the brightness of the night sky. The brightness of the night sky may also be increased by operations in low earth orbit (LEO) and by specular reflectlon from the large satellites. 
The assessment of the impact on astronomy has two natural divisions: optical effects and radio effects This division is consistent with an astronomical tradition of dividing the profession according to the portion of the electromagnetic spectrum that is observed. From another viewpoint, the division expresses the separate effects of the passive and active properties of the satellite system. In particular, the major optical effects caused by SPS would be functions of the system's structures in orbit and would continue even if the system were turned off. Radio astronomy, however, would be particularly affected by the active portion of the system-the intended microwave transmission of energy from space to earth. Both optical and radio astronomy impacts are primarily a result of unintentional side effects. The optical effects would occur because the SPS solar blankets would reflect some of the 11ght that strikes them. The radio effects would occur because a small portion of the transmitted energy would not be confined to the narrow beam from the orbiting antenna to the earth rectenna, or to the assigned portion of the radio spectrum.

This summary of effects is freely drawn from a workshop on the potential 1mpact of the conceptual Satel1ite Power System on Astronomy (report: CONF-7950143) attended by recognized working scientists and held In May 1979.

\subsection{RADIO ASTRONOMY AND DEEP SPACE RESEARCH}

The SPS concept which proposes the transmission of power to earth via microwaves has a number of potentially damaging consequences for radio astronomy and space research. Production of harmonic radiation and generation of nolselike radiation throughout the spectrum could result in harmful interference. This interference might be produced by SPS satellites in normal operation and in potentially more damaging quantitles by various fallure modes.

The SPS is unique in the large quantities. of radio frequency radiation that will be generated, especlally at the fundamental frequency. Radlo observatorles have been carefully situated at remote 81 tes to protect against such adjacent channel interference effects from earth-based transmitters, but location cannot protect against such effects from transmitters in synchronous orbits. The field strengths in grating side lobes are of partlcular concern, and for a large number of sps ground-receiving stations, it is not clear that grating side lobes will m1ss active radio observatories, or that observatory operation within a side lobe will be practical.

Radto astronomy and space research are recognized radio services as defined in the Radio Regulations of the International Telecomunication Union; with recognized frequency bands that are protected by allocation in the treaty documents. Definitions of harmful interference to these services have been developed by the International Radio Consultat1ve Committee (CCIR). CCIR Report 224-4 describes these criterla for radio astronomy, and CCIR Reports 365-3 and 685 give the criterla for the space research service. The harmful spectral flux densities, specified in $\mathrm{dB}\left(\mathrm{W} / \mathrm{m}^{2}-\mathrm{Hz}\right)$, have been established as reasonable and measurable quantities, and an SPS would have to conform to those specifications in order to avoid harmful interference to those services.

In addition to the specific bands allocated to the Radio Astronomy Service, passive radio astronomy research is conducted at many other frequencles throughout the spectrum. Many of the frequencles of interest are spectral lines (often Doppler shifted from their real frequencles). A 11st of such spectral lines 1s included in CCIR Report 223. To achleve reasonable interference protection at frequencies outside the bands allocated to radio astronomy, radio observatorles have been located in remote areas where man-made interference levels are low. To formalize such protection, the FCC established in 1958 a National Radio Quiet Zone (NRQ2) surrounding the National Rad1o Astronomy Observatọy In Green Bank, West V1rginla, and the nearby Naval Rad1o Research Laboratory In Sugar Grove, West Virgin1a. Within this quiet zone, FCC 11censing procedures are Intendèd to allow only transmitters that produce power fluxes at the observatories of less than $10^{-17} \mathrm{~W} / \mathrm{m}^{2}$. A few broadcasting stat lons remote from, the NRQZ do exceed these 1 imits, producing power fluxes at the observatories on the order of $10^{-12} \mathrm{~W} / \mathrm{m}^{2}$. 0 ther observatories and the Deep Space Network Station at.Goldstone, California, have less formal arrangements to minimize local sources of Interference, generally based on the requirement that spurtous radiation in the protected bands not exceed the levels given In CCIR Report 224-4 (or CCIR Report 685 in the case. of the Deep Space Network).

The strongest anticlpated SPS harmonic, the second at $4.9 \mathrm{GHz}$, does not fall into a currently allocated band of these services, but does fall well within the principal operating band of the Very Large Array (VLA), a major national radio astronomy facility near Socorro, New Mexico, and at the shortest usable wavelengths of the Arecibo telescope, the worlds' largest radio/radar telescope. These fac1lities could be sertously compromised.

The potential for SPS interference with rad 10 "astronomy and deep space research depends crucially upon the notse and harmonic generation properties of all components of the system. At present, the properties of the klystrons in the Reference System must be estimated by extrapolation. If prototype SPS 
transmitters and antennas are developed, laboratory tests could be made of radlated power in the range from approximately $1000 \mathrm{MHz}$ up to the frequency where radiation in the SPS main beam is no more than the amount equivalent to the satellite's passive thermal radiation as seen from the surface of the earth. Thls test result would permit calculations bf the Impact of SPS on radio astronomy and deep space research.

The interference potentlal of the SPS Reference System would significantly increase if the off-axis signals were time-varying on the same time scales as are used for astronomical observations, as it can then mimic the expected behavior of the observations. As currently defined, the Reference System has such an intrinsle time-variability. In the Reference System, all 60 satellites transmit at 2450 MHz. However, It is not possible to phase lock the satellites in such a way that the off-axis radiation from different satellites will remaln phase-constant for all ground-based observers. Each satellite pair, considered as a transmitting interferometer, will have an off-axis fringe pattern. Unavoldable stationkeeping motion will cause this fringe pattern to sweep across the United States in a complex and partlally unpredictable pattern.

One potentlal solution is to offset the frequencles of different satellites by small amounts, to introduce lobe rotation and thus reduce the averaging time needed to reduce the interference. A frequency assignment plan for the SPS satellites is required to assure no unacceptable intermodulation effects.

Generation of harmonics and intermodulation products in nonlinear elements in the SPS and its environment could produce spurious emissions in the radio frequency spectrum. Such effects occur frequently where many antennas transmitting on different frequencles are assembled in a small area. They are the result of the interaction of currents of different frequencies in rectifying junctions in metal structures, hence the name "rusty bolt effect." Normally; Intermodulation products attenuate rapidly with distance.

The extremely high field strength in the main beam of the SPS, nearly $300 \mathrm{~V} / \mathrm{m}$ at the earth's surface, makes it probable that nonlinear conduction will occur in any rectenna structure containing corroded joints or fasteners or other nonlinear elements. Even if it were possible to eliminate all electrically nonlinear joints in the vicinity of the rectenna, the diodes in the array would serve as modulators, producing the same effect unless adequate filtering were provided. Other signals of much lower strength, such as those from television or radar transmitters some distance away, can be expected to interact with the SPS fundamental frequency and its harmonics. It is conceivable that these modulation products may be of sultable frequencles and strengths to be transmitted over great distances by reflection from the lonosphere or from alrcraft or spacecraft.

Illumination of other spacecraft or aircraft by the SPS beam may result in simflar effects. These vehicles carry antennas connected to nonlinear recelving and transmitting circuits. Especially in the transmitting circuit, the SPS frequency and the other transmitting frequency, or their harmonics, may $\mathrm{mix}$ in ways to produce out-of-band radiation. Nonlinear effects from metal structures on the vehicle may also be expected.

The side lobe radiation flux from each pqwer satellite could range as high as $2 \times 10^{-3}$ w/m withln a few hundred $\mathrm{km}$ of the rectenna, $10^{-1} \mathrm{~W} / \mathrm{m}^{2}$ at the grating lobes, and $10^{-5} \mathrm{~W} / \mathrm{m}^{2}$ at varlous peaks out to distances of $400 \mathrm{~km}$ from the rectenna (DOE/ER-0023, Figures 19 and 22). For comparison, the flux near radio and TV broadcast stations in metropolitgn areas (e.g., in Los Angeles at a distance of 20 $\mathrm{km}$ from Mt. Wilson) might be of the order $10^{-9} \mathrm{~W} / \mathrm{m}^{2}$. A system with 60 satellites serving the entire country would raise the power flux to this value $\left(10^{-3} \mathrm{~W} / \mathrm{m}^{2}\right)$ at side lobe peaks scattered over the whole country, since the mean spacing between rectenna sites would then be $\sim 300 \mathrm{~km}$. Thus, in a sense, construction of the SPS would make the radio environment of much of the continental United States as unsuitable for sensitive radio observations as the most densely populated areas are now.

In addition to the satellite signal, fundamental and harmonic power and wideband nolse would be reradiated by the rectennas. This radiation may be reflected by aircraft and by unusual meteorological conditions to distances of the order of $100 \mathrm{~km}$ from the rectenna site. The severity of the direct radlation problem. will depend on local topography.

Observations made with arrays of recelvers used as interferometers may, In some circumstances, be less sensitive to SPS interference than those made with a single receiver. Calculations have been made to estimate the effects of fringe-frequency averaging and decorrelation which reduce the sensitivity of the VLA to interference. The magnitude of the effects for other synthesis arrays depends on parameters of the particular array. The fringe-frequency averaging depends on the size of the synthesized fleld of view and hence on the configuration and observing frequency. The most compact VLA configuration, for which the interference reduction is least effective, will be used as an example in considering the tolerable interference levels. For this case the reduction is approximately $10 \mathrm{~dB}$ for the $18-$ to $21-\mathrm{cm}$ band and $17 \mathrm{~dB}$ for $1.3 \mathrm{~cm}$. These figures refer to declinat lons south of $+70^{\circ}$, and the fringefrequency averaging becomes less effective toward the pole. 
The decorrelation effect depends mainly on the antenna configuration and the bandwidth, and again the most compact configuration w111 be considered. The interference reduction is approximately $14 \mathrm{~dB}$ for a 25-MHz bandwidth and $17 \mathrm{~dB}$ for a 50-MHz bandw1dth. These flgures apply to a source of interference at the declination of the satell1te, $-5.5^{\circ}$, and for an observing declination north of $+20^{\circ}$. the observing declination approaches that of the satellite, the interference reduction becomes much less effective.

Under certain circumstances the above effects should allow the VhA to operate with no decrease in performance in the presence of interference recelved in the far sidelobes of the antennas, for which the gain is equivalent to that of an 1sotropic radiator. With that condition, and for declinations from $+20^{\circ}$ to $+75^{\circ}$, levels of interference about $20 \mathrm{~dB}$ to $30 \mathrm{~dB}$ higher than the ccIR levels should be tolerable. However as the declination of the satellite is approached, this margin falls to about $13 \mathrm{~dB}$.

Since the line of satellites is essentially constant in declination, at $-5.5^{\circ}$ as viewed from the VLA site, there will be a zone of declinations centered on $-5.5^{\circ}$ in which the array cannot operate without recelving interference above a tolerable level. To avoid such interference, the range of hour angle tracking would have to be reduced by something more than the $60^{\circ}$ longitude range of the satellites, and satisfactory mapping of celestial objects in this zone would not be possible.

\subsection{OPTICAL ASTRONOMY}

The primary effect of the SPS on optical astronomy would be through the predicted increases in brightness of the night sky. The assessment of this effect focused on diffuse reflections from the satellites. other concerns, such as the effects of specular reflections and possible 1mpacts on infrared and space astronomy, are not treated in detall, primarily because of surface characteristic uncertainties, as in the case of airglow from the SPS-heated tonosphere. They can be completely characterized if specific SPS designs are developed. For example, specific effects of specular reflections from the antenna depend heavily on rectenna siting and antenna properties.

The actual method of conducting astronomical research is the root of any effect of the proposed SPS on astronomy, and on optical astronomy in particular. Optical astronomy ls characterized by its preoccupation with the detection of photons. A photon of visible light represents about $4 \times 10^{-12}$ ergs of energy, which means that if a 100-watt light bulb emitted 100 watts of visible photons, it would emit $10^{20}$ of them per second. Detectors used in optical astronomy are sensitive enough to detect single photons. In many cases, astronomical detectors are photon counters.

An Important problem encountered in photon counting is that the answer arrived at includes an uncertainty corresponding to the square root of the total number of photons counted. Therefore, the fractional error In the number of photons detected $181 / \sqrt{\mathrm{N}}$ where $\mathrm{N}$ is the total number of photons detected. If an astronomer counts 100 photons, the uncertainty 1s $10 \%$, 1f 10,000 , the uncertainty $181 \%$.

Unfortunately, the detection of photons from astronomical objects 1s complicated hy the fact that the sky 18 a source of photons as well. In the case of an 1dealized astronomical. nhservatinn, nne ran 1 magtne looking at an astronomical object, with a typical optical detection system and trying to make an observatIon w1th $1 \%$ accuracy. Because the detector cannot avold looking at both the sky and the object, 1 t collects and counts the photons from both. However, when the object is very much brighter than the sky, the photons from the sky make a negligible contribution to the total signal, and we get $1 \%$ accuracy just as soon as we have detected 10,000 photons from the source. In such a case, the brightness of the source determines how long the observation will take. If, however, the number of photons recelved from the sky Is comparable to or greater than the number from the object under study, then the brightness of a nearby portion of sky must be determined and subtracted from the observation of the object. However, sky photons can only be measured at best to an accuracy of $1 / \sqrt{\mathrm{N}}$ just as photons are from the object. For example, If the sky is nine times brighter than the object and our detector counts 10,000 photons from the sky and object together, which gave us $1 \%$ accuracy before, our accuracy for measurement of the object would only be 10\%. In this case, the observation 1s said to be "sky 11mited"-In order to get a $1 \%$ measurement of our source, the detector must have detected $1,000,000$ photons. Th1s value represents 100,000 photons from the source or ten times as many as were required to get a $1 \%$ measurement without the sky. Therefore, even $1 f$ the sources in our two examples were the same brightness, the addition of the bright sky would Increase by a factor of ten the amount of observing time required for the same accuracy measurement.

Natural and man-made sources of sky brightness already' have a significant Impact on the conduct of optical astronomy. The largest natural contribution to the diffuse night sky brightness comes from the moon. The moon has such a profound effect on the sky that observatories routinely divide their observing schedule Into "dark" (no moon) and "bright" (moon up) time. Dark time is in much greater demand than bright time on large telescopes.

At present, the primary man-made source of sky brightness 18 outdoor light from cities and towns. Astronomers have attempted to combat this light pollution in a number of ways--the most obvious, building 
telescopes in remote locations well away from city lights. For example, the detailed site surveys that precede construction of a major observatory always include assessments of the sky brightness. In some cases, urban areas have grown up adjacent to observatories. At some of these observatories, observations are limited to the kinds of objects observed during "bright" observing time at darker sites as is the case at Mt. Wilson Observatory where the light pollution from Los Angeles and nearby cities makes the sky very bright. At other observatories, observatory staffs have attempted to convince local public officials that it is possible to control light pollution and minimize the effects of outdoor lighting on astronomy. Tucson, Arizona, and Richland, Washington, among others, have very strong light abatement ordinances specifically tailored to preserve dark skies.

Objects of astronomical observations fall into two categories: point sources and extended sources. For point sources, every attempt usually is made to make the amount of sky being observed as small as possible. Although this is limited by the turbulence of the atmosphere, a small aperture does represent a practical method of reducing the effect of sky brightness for objects that appear as point sources, such as stars.

However, this strategy is not usable for extended objects, such as galaxies. In order to reduce the amount of sky being observed, one must correspondingly reduce the amount of the object to be studied. The case of galaxies is an important one since the average surface brightness of a galaxy (the number of photons emitted per unit area) is considerably less than the average brightness of the dark night sky. Galaxies are brighter toward their nuclei; therefore, the net effect of increasing the sky brightness is to reduce the amount of a galaxy that can be observed. This effect is qualitatively illustrated in Figure 59. The consequences to research of not being able to observe the outer regions of galaxies are noted after the following section.

An observing program is the set of observations that astronomers will make in order to address a particular astronomical problem. The organization of typical observing programs is important. The increase in diffuse sky brightness as a result of SPS is a function of position on the sky, which implies that in particular regions of the sky it will not be possible to observe particular kinds of objects.

Observing programs consist of "surveys" and "type studies". Most observing programs include elements of both kinds of studies. A survey entails the measurement of a few parameters for a large number of objects. An example is the National Geographic-Palomar Sky Survey. This survey, conducted in the 1950s, consists of photographs taken through two different colored filters of almost the entire sky visible from Mt. Palomar. A type study is the detailed study of a single object that is either unique or thought to be representative of a class of objects. Generally, type examples are usually the nearest members of the class.

When planning the details of an astronomical observing program--specifically, what objects are to be observed--several other factors must be considered. The most important is the fact that the atmosphere is not completely transparent, so that the flux of photons from an object is attenuated as it passes through the atmosphere. The amount of attenuation is exponentially related to the amount of the atmosphere the radiation passes through, which is measured in airmasses. An airmass is the ratio of the amount of air toward the object to the amount of air toward the zenith, the point straight above the observer. In order to maximize the number of photons observed, observations must be planned to minimize the average airmass through which the object is observed. In practical terms, this usually means that an object will be observed during the time that the object is within $30^{\circ}$ of the meridian, an imaginary line on the sky on which astronomical objects are at their minimum airmasses. Objects are in this band for four hours every day. Many astronomers have concluded that four hours is a practical upper limit for a single observation. Finally, because objects more than $60^{\circ}$ from the zenith must be observed through more than two airmasses, objects that never come closer than $60^{\circ}$ to the zenith are usually not included in an observing program.

\subsubsection{Major Research Areas}

Current areas of active research that would be negatively affected by the SPS program are listed below. These are important research areas, but no effort at completeness is intended.

\subsubsection{Cosmology and Extragalactic Astronomy (Studies of Objects Beyond the Milky Way)}

Because distances to extragalactic objects are so great, most galaxies, although as luminous as several billion stars, are as difficult to discern and study as the faintest stars visible in our own galaxy.

- The Size of the Universe. Measurements of the size of the universe depend on our ability not only to observe the most distant (and faint) objects but also to develop techniques for distance measurement. The identification of distant objects is extremely marginal because of their faintness and is complicated by the presence of a bright sky background "against" which they must be viewed from the ground. Even small increases in sky brightness can render these objects undetectable.

- Curvature of the Universe.

- Formation Era of Galaxies.

- Open or Closed Universe. 

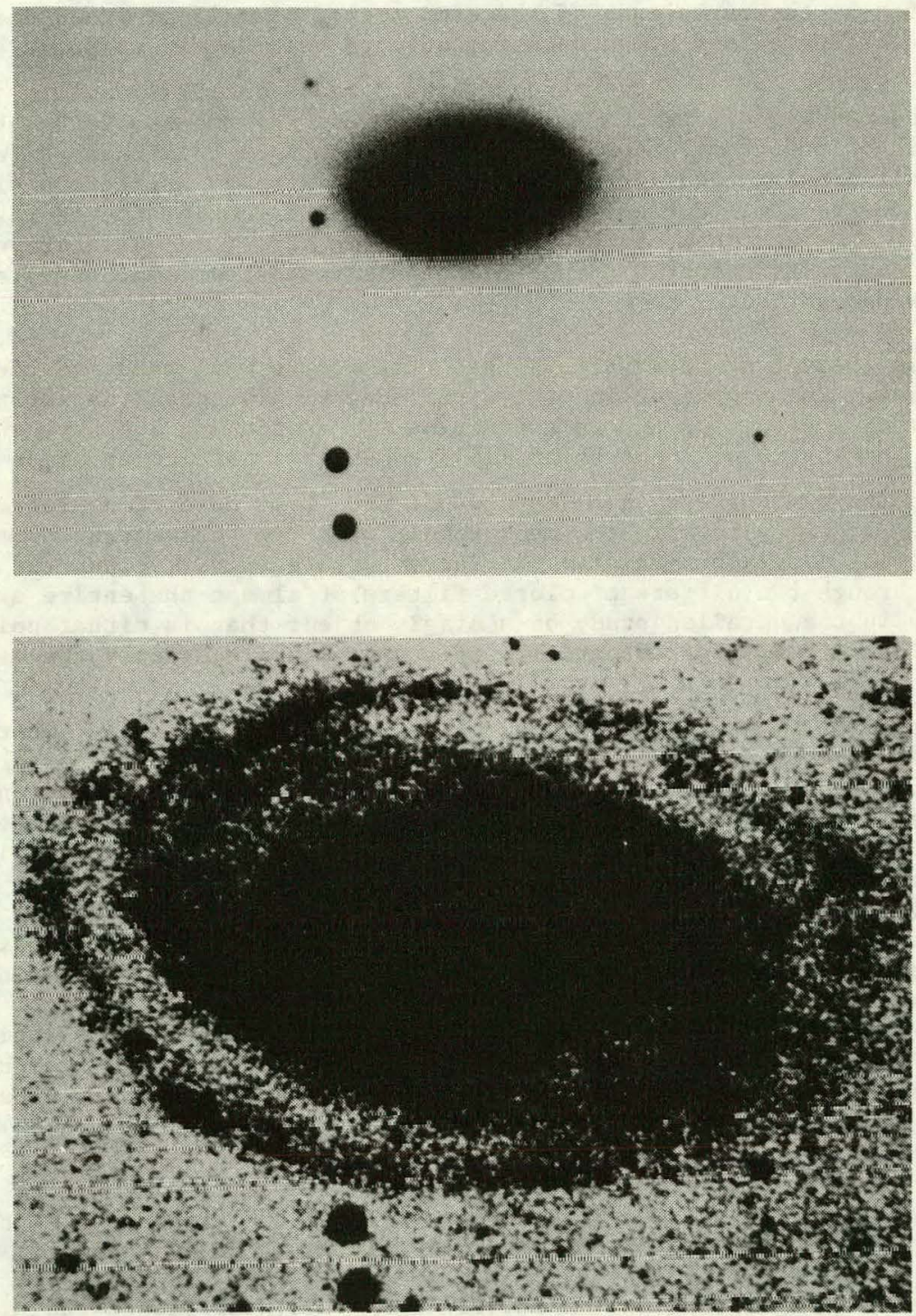

FIGURE 59. Photograph taken at Prime-Focus of the Cerro Tololo Inter-American Observatory 4-m Telescope of the Galaxy NGC 1079 (40-min exposure IIIaj plate and GG385 filter). Photograph A shows conventional print contrast: B shows the contrast stretched to go between dark and light over a narrow brightness range just above sky background using the Interactive Picture Processing System of Kitt Peak National Obscrvatory. The difference between the two pictures shows the loss of outer detail seen in B that would occur with a doubling of the background sky brightness. 
- Active Galaxies and Quasars.

- Faint Regions of Nearby Galaxies.

\subsubsection{The Milky Way}

Our galaxy is one of the most interesting, yet enigmatic, of astronomical objects. We look to our solar neighborhood to understand how stars are born, live their lives, and die, and to understand how our galaxy is structured. The nuclei of many galaxies harbor unusual and, as yet, not understood energetic processes. What about our own? Do other stars have planets? To complicate observations, large clouds of dust hide $90 \%$ of the galaxy from view to observers using optical and ultraviolet techniques. The effective size of the visible galaxy would be severely diminished by even small increases in the night sky levels.

- Diffuse Galactic Light. "Hot tunnels" carved through the galaxy by supernova blast waves appear to permeate the galaxy. Many studies are underway to understand the physical conditions (e.g., temperatures of a million degrees) through optical and ultraviolet observations, but the 1ight levels from these regions are very, very low (they were only recently discovered).

- Faint Nebulae.

- Stellar Winds and Mass Loss.

- Structure of the Galaxy.

\subsubsection{Solar System}

There are some interests in the solar system for which a bright background would severely impede groundbased research. For example, comets and their tails, asteroids, and other "minor" constituents of the solar system are generally faint. The plane of the ecliptic is fairly closely aligned with the equatorial plane of the earth and the satellites, and the faint objects found preferentially in the ecliptic plane, such as minor bodies, will be difficult to observe near the satellites. Although comets do not have ecliptic orbits, they and their tails are generally in their most favorable aspects as they near the ecliptic. Similarly, the zodiacal light is also confined to the ecliptic plane and, likewise, will be difficult to observe near the satellites.

\subsubsection{Effects of SPS on Optical Observations}

The single most important point to keep in mind when considering the effects of SPS on optical astronomy and aeronomy is that the major effect, the increase of sky brightness, stems from the passive properties of the system. As such, this effect is inherent in any space-based solar power collection scheme. For the Reference System, the solar blanket intercepts a large quantity of solar radiation. The most important portion of the collected energy which has an effect on astronomy is the light reflected from the front surface of the blanket. This reflected radiation constitutes approximately $7 \%$ to $15 \%$ of the visible radiation incident on the solar blanket and is made up of both diffuse and specular reflection, as described in the workshop report. The diffuse reflection is responsible for the most persistent and troublesome effects on astronomical and aeronomical observations. The magnitude of the effects is determined by the apparent brightness of the satellites and the properties of the atmosphere. In turn, the brightness of the satellites is determined by their size and reflectivity. The Reference System satellites would be exceeded in brightness by only the sun and the moon.

Even though the actual brightness distribution around an individual power satellite will depend strongly on physical conditions, several properties of the brightness distribution of the entire system are relatively independent of local physical conditions. The area of increased brightness is sharply peaked. In Figure 60, the predicted increase in the sky brightness along the meridian at midnight for Kitt Peak National Observatory has been plotted for a 60-satellite system. While the intensity scale shown in the figure is for a satellite brightness equal to that of Venus, the shape of the profile is independent of satellite brightness and variations in local meteorological conditions (the profile having two parts, the core and the wings). The sharply peaked core region represents the portion of the sky in which the scattered radiation from the one or two nearest satellites dominates the brightness distribution. In the wings, a11 of the satellites make a modest contribution to the sky brightness. The transition between core and wings is determined primarily by the sepalation between the satellites, which for the Reference System is $1^{\circ}$.

Figure 60 also shows the thresholds for a noticeable effect, hindrance and contamination as defined after the following section. The width of the affected zones is the region between the intersection of the brightness profile and the various thresholds. Both the effect of changing satellite brightness and the varying meteorological conditions can be thought of as moving the brightness distribution profile up or down with respect to the threshold values. For example, with either satellites brighter than assumed (4\% albedo) or less favorable weather conditions, Llie profile is mnved upward, thereby substantially increasing the amount of the sky in the different zones. 


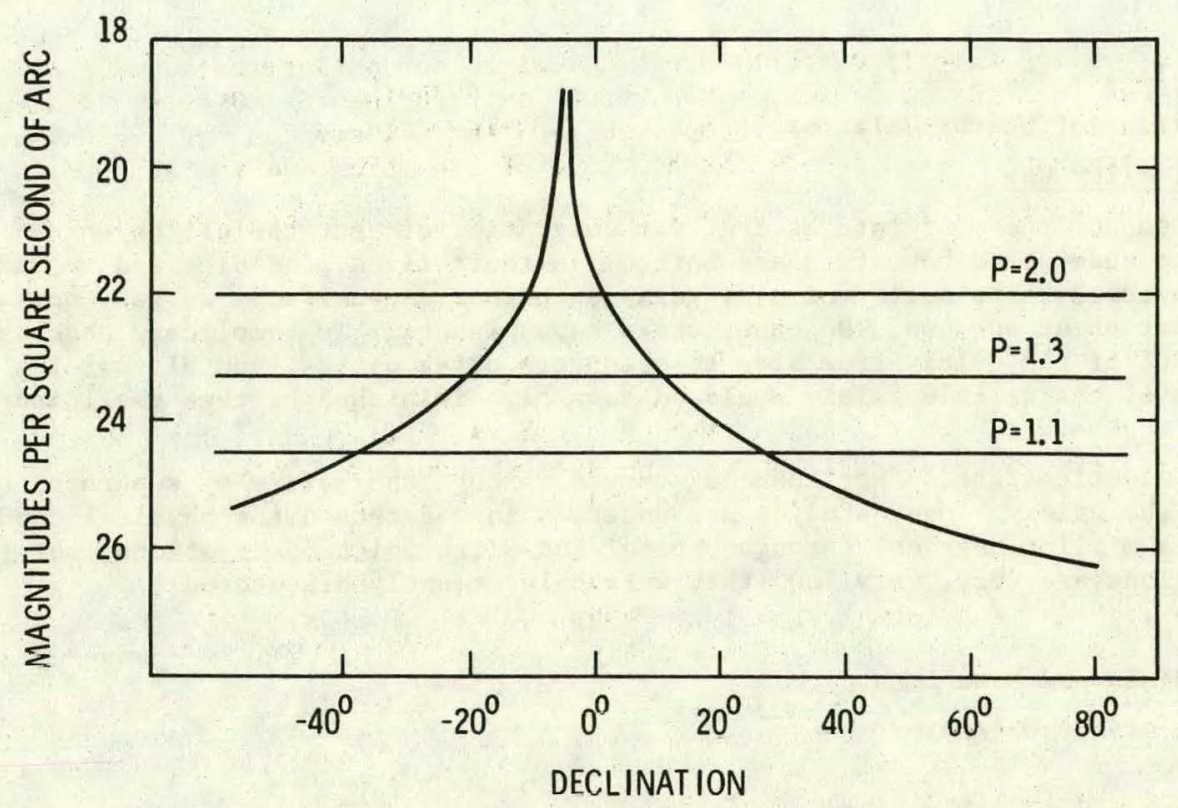

FTCURE 60. The SPS Brightness Profile. This flgure shows the predicted brightness of the sky as a result of a 60-satellite SPS system along the meridian at local midnight for Kitt Peak National Observatory at the vernal equinox. The calculation of this profile is based on an assumed $4 \%$ diffuse albedo. The brightness levels, $P$, corresponding to the three impact thresholds described in the text, are also shown.

Unfortunately, the total area at the contaminated zone is not directly proportional to satellite brightness. Because the brightness profile is so sharply peaked, even relatively large reductions (by factors of 2 or 3 ) in the brightness of the individual satellites would not greatly reduce the size of the contaminated zone. Alternatively, the relatively broad wings of the intensity profile mean that corresponding increases in the apparent magnitudes of the satellites will result in quite large increases in the size of the contaminated zone.

Objects in low earth orbit (LEO), even though smaller than the large SPS structures to be placed in geostationary orbit (GEO), can have similar optical effects. An object with a surface area of $1 \mathrm{~km}$ in an 800-km-high orbit has the same apparent size as a $55-\mathrm{km}^{2}$ SPS solar blanket. Their relative brightness will then be determined by geometry and albedo. One difference is that the LEO objert is only illumiuted through the portion of its orbit that is not in the earth's shadow.

Another difference between GEO and LEO objects poses a particular problem for astronomical observations. Since the power satellites themselves are located in GEO, their position in the sky is fixed. As a result, if their apparent luminosity can be reduced, then the parallactic effect between the northern and southern hemisphere observatories would allow astronomical observations to be planned in a fashion that would minimize but not remove the effect of the SPS on observing programs.

An object in LEO is not geostationary, and it will appear to move across the sky as it travels in its orbit around the earth. Therefore, if the LEO structures are large and reflective, they would appear as bright planet-like objects moving relatively rapidly across the sky. Workshop attendees pointed out that observations made with the 48-in. Schmidt telescope located on Mt. Palomar are routinely affected by existing satellites. The photographs made with this telescope cover a relatively large area of the sky, about the size of the bowl of the Big Dipper $\left(6^{\circ} \times 6^{\circ}\right)$, and are usually made with exposure times of about one hour. Since there are a large number of objects now in orhit around the earth, it is nul unusual for a picture taken with this telescope to show the trails of satellites. Because current satellites are small, they are not very bright and the trails are primarily a nuisance. As LEO satellites get larger and brighter, it will be necessary to schedule observations to avoid them.

Because there are natural sources of diffuse sky brightness (sunlight reflected by dust in the solar system and aurora and airglow in the earth's upper atmosphere), any effect of the SPS should be compared to those sources of radiation. The parameter $p$ is the factor by which the flux of radiation from the night sky is increased over its natural value. In general, the workshop attendees felt uncomfortable associating particular values of $p$ with specific effects on optical astronomy. However, in the following paragraphs we suggest that $p>1.1$ results in a noticeable effect, that $1.3<p<2.0$ creates a serious hindrance to optical astronomy, and that regions of the sky with $p>2$ are contaminated zones within which faint-object astronomy is no longer a reasonable endeavor. 
The required observing time is directly proportional to our pollution factor p. When working on faint sources, increase in light pollution is equivalent to reducing the aperture of a telescope by a factor of $1 / \sqrt{\mathrm{p}}$. For the largest American telescope, the 200-in. telescope at Mt. Palomar, the effect of doubling the sky brightness would be to reduce the aperture of the telescope to $140 \mathrm{in}$.

The threshold values for effects on optical astronomy described above were arrived at in the following fashion:

- Noticeable effect $(p=1.1-1.3)$ - Although some members of the astronomical community would find any additional source of diffuse sky brightness unacceptable, we believe $p=1.1$ as a result of SPS to be the threshold for a demonstrable impact on optical astronomy. This figure is the usual value quoted for the onset of "light pollution" for the purposes of light abatement ordinances with cities near observatories. The value represents a $10 \%$ increase in the night sky brightness and is equal to about $1 / 2$ of the natural variation of the airglow over the 11-year solar cycle. As a further point of reference, at Kitt Peak National Observatory, the lights of Tucson, Arizona, result in $p=1.07$ at the zenith.

- Severe hindrance $(p=1.3-2.0)$ - This level of light pollution will obviously have a demonstrable effect on optical astronomy. The lower range $(p=1.3)$ means that observations will take $30 \%$ longer to reach the same level of statistical accuracy; $p=2.0$ corresponds to the doubling of observing time.

- Contamination ( $p>2.0)$ - At this level of light pollution, compensating for increased sky brightness with increased observing time is no longer possible. Figure 59 illustrates the loss of information for observations of galaxies that would result from $\mathrm{p}>2.0$.

The relationships among SPS-induced increases in sky brightness, typical astronomical observing programs, and thresholds for specific impacts on optical astronomy are summarized in Figure 61 . The diagrams in this figure show the outer contours of three light pollution zones described in the preceding section as they would appear at midnight from the Kitt Peak National Observatory. This observatory was chosen as representative of the observatories located on the major continental masses of the Western Hemisphere.

Diagram 61A shows the computer contours for $4 \%$ satellite albedo. Diagram $61 \mathrm{~B}$ shows the contours if the apparent brightness of the individual satellites were increased by a factor of two. The vertical axis in each of these diagrams is declination, the astronomical equivalent of latitude. As the earth rotates, astronomical objects will appear to rise at the left of these diagrams and move to the right at constant declination. Because the power satellites are in geostationary orbit, the brightness contours will remain fixed in this coordinate system, and astronomical objects at the same declinations will appear to move through these zones of light pollution. These diagrams (Figure 61) illustrate how extremely sensitive the specific impacts on astronomy are to the detailed properties of the proposed system.

The primary effect of the SPS on optical astronomy is to contaminate a large region of the sky to the extent that the study of astronomical objects currently at the limit of detection would be impossible within that zone. The size of the region is extremely sensitive to the properties of the SPS and the meteorological conditions at specific observatories. The impact is greatest for those observatories at longitudes nearest the center of the satellite array. For the Reference System, the instruments most affected are those on the North and South American Continents. The kinds of observations most affected are those currently limited by sky background.

The practical consequences for research programs are as follows:

- For those programs involving the study of randomly distributed objects, such as intrinsically faint stars and, in some respects, faint galaxies, the number of objects that can be studied will be reduced by an amount proportional to the fraction of the sky covered by the contaminated zones, estimated between $3 \%$ and $10 \%$. Further, these observations will be severely hindered in a region that may cover as much as a third of the sky.

- Surveys designed to ascertain the cosmic distribution of objects may become subject to systematic errors stemming from the inability to study the whole sky.

- Specific regions of the sky may be excluded from observation. Various parts of the sky provide a better opportunity to study particular classes of objects. The region most affected by the Reference System is the ecliptic plane. The galactic poles and the Virgo cluster of galaxies are at the edge of the zones most noticeably affected. These two areas of the sky are extremely important to extragalactic astronomy; and a substantial increase in SPS brightness above that assumed would render these areas unusable for many important kinds of observations.

- Several important kinds of observations of type examples of classes of objects could be lost to astronomy. These objects, as noted earlier, are usually the nearest members of the class and are generally the subject of extensive observation and extremely detailed analysis, which is essential to the identification of the physical processes that control the structure of the source. Examples 

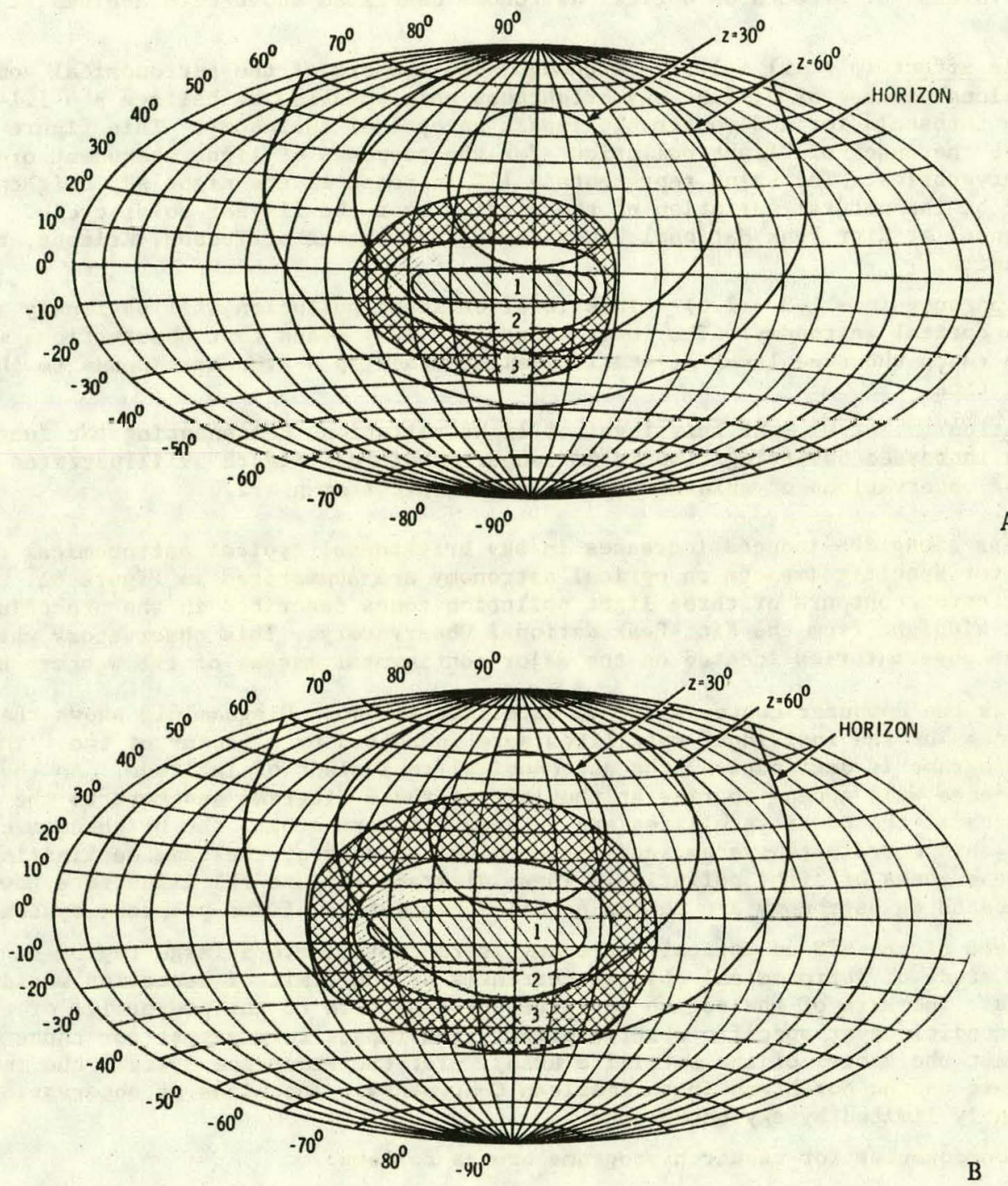

FIGURE 61. (A, B) Distribution of Predicted Increases in Diffuse Night Sky Brightness as a Result of a 60-Satellite System. A and B show the distribution of brightness as sun at midnight, the ulglil of Llie vernal equinox, from Kiec Peak National Ubservatory. A shows the case for 4\% albedo which led to an apparent visilal magnitude of $-4,3$ (as bright as Venus) for the individual satellites. The brightness distributions in $B$ are the result of increasing the brightness of the satellites by a factor of two. The map is an equal area projection and the area enclosed with the horizon line is all of the sky that is visible at a given time from the respective observatories. The separate regions correspond to the impact threshold zones described in the text: 1) contaminated zone; 2) severe hindrance; 3) noticeable effect. Contours showing the fraction of the sky more than $30^{\circ}$ above the horizon $\left(z=60^{\circ}\right)$ and $60^{\circ}$ above the horizon $\left(z=30^{\circ}\right)$ are also shown for reference. 
of specific objects that will fall within the contaminated zone include a) the Orion Nebula, a major testbed for theories of star formation; b) $3 \mathrm{C} 273$ and $3 \mathrm{C} 120$, two of the brightest quasistellar radio sources (Quesars); and c) NGC 1068, one of the brightest and closest galaxies that has an active nucleus.

\subsection{AERONOMY}

The proposed SPS w111 have two effects on aeronomy. The first is analogous but not identical to the effect on optical astronomy; the 1llumination of the night sky by the diffuse reflection from the SPS solar arrays w111 interfere with aeronomical observations. The second effect creates an aeronomical phenomenon through the interaction of the microwave beam with the ionosphere. Significant increases of light are anticipated in this region of interaction. The region's vertical and lateral extent is 1 imited by lonospheric electron concentration and by beamwidth. The range of its view from the ground 1s roughly onlv several hundred kilometers.

While it is concelvable that special studies of processes might take advantage of the uniquely localized parameters within the beam, the masking effect of the artificlal excitation would vitiate most studies of the natural upper atmospheric environment using these standard emfssions within a ground radius of 300 to $1000 \mathrm{~km}$, depending on helght and type of research.

A more pervasive consideration 18 the permanent and general illumination by a belt of sunlit satellites, whose finite reflectivity-produced light estimated as brighter than perhaps 0.1 of a full moon. This light is not only seen close to the sources via small angle scattering but also is distributed more or less over the sky seen from a ground station, depending on the prevalence of fine haze. In optical studies of the upper atmosphere itself, much research rests on ground-based spectrophotometric measurements of the faint light emissions, which yield information on the energy delivered within the sun's outer environment of particles, waves, and radiation. How the solar wind energizes the earth's magnetosphere is traced by the pattern of auroras formed by incident electrons, and the chemistry of upper atmospheric processes is shown by the airglow.

Th1s science depends on measurement of falnt-sky light, accurately discriminated as to wavelength, intensity, and varlations with time and space. Intensities of auroras, which cover a wide range, often approach those of the alrglow while maintaining much information content. Especially at midlatitudes, the subvisual stable auroral red arcs and the diffuse auroras require very sensitive spectral measurement and are unique Indicators of the. plasmapause region of the magnetosphere. Much future study will center on relatively weak emissions extending from the near-ultraviolet to the near-infrared. Many measurements press detection sensitivity to the 11mits of background 1ight. High-resolution studies of Doppler shifts in thermospheric winds are at the limit of photon statistics. The airglow continuum is already compromised by natural backgrounds, and the artificial 1ight would directly overwhelm it in any but the best conditions. Weak band emissions from minor atmospheric components would find obvious competition from scattering. Numerical estimates of the impact are difficult because of variable requirements of different experimental tasks, ranges of thin haze cover, and varlous contributions from aerosol and Rayleigh scattering. Effects would translate into reduced hours and poor intensity discrimination, and in some cases an end to many desired aeronomical studies.

\subsection{MITIGATION}

Mitigating strategies focus on potentially inexpensive modification in astronomy and aeronomy apparatus, SPS design features, and possible redeployment of affected observations. Due to the nature of astronomy apparatus and the broad way in which SPS may affect astronomy, the modification of existing astronomy equipment is not a promising mitigation technique. This is because of two fundamentai conditions: astronomy observations are currently limited by interfering radiation and the satellites are located in geosynchronous orbit.

Larger telescopes should be considered for optlcal astronomy since increases in the brightness of the night sky are equivalent to a proportional decrease in the effective aperture of a telescope. However, a portion of the night sky would be lost even with new telescopes having twice the effective aperture because of the predicted increases in sky brightness. It is possible to design and build filters that will protect radio astronomy equipment from damage. Input filtering will reduce the sensitivity of the radiometers by introducing $108 s$ in the signal path and by the thermal radiation from the filter elements. Input filtering may also increase the system nolse temperature by $25 \%$ or more, even if the $f 11$ ter is cooled to the physical temperature of a cooled parametric ampliffer ( $20 \mathrm{~K})$. Finally, the use of input filters, of course, cannot remove interference at the signal frequency.

Effects on astronomy and aeronomy depend on both broad properties of the SPS concept and unspecified details of the system's design. Important SPS design features for optical astronomy include a reduction in the albedo of the satellites and in the solid angle subtended by the satellites as seen from the earth. The most important parameter in determining the apparent brightness of the satellites Is its albedo, which is the ratio of the radiation reflected from an object to the total incident radiation. Active baffling might be a way of lowering the albedo. 
At the side lobe levels given in the Reference System, Report (DOE/ER-0023), separation between rectennas and radio astronomy observatories will be important. Separation of several hundred $\mathrm{km}$ or more is probably required. Interference to radio astronomy observations is still probable and all the ways in which the SPS system could create radio frequency. interference will not be known until SPS hardware has been designed and tested.

The redeployment of affected observations into space is the most promising area for the mitigation of impacts on astronomy. The major difficulty foreseen for space-based radio astronomy is expense. Once costing algorithms are avallable for space transportation and for supporting personnel in space, they should be used to estimate the cost of moving astronomy and maintaining it in space. The cost of moving all radio astronomy facilities into space will be an important worst-case value. The Workshop attendees believed that this cost would be prohibitively large.

Space telescopes have several advantages. At optical frequencles, space telescopes will produce a smaller image size and allow higher resolution studies 'of extended objects. In addition, the background light within a stellar image would be reduced several orders of magnitude compared to what can be obtained on the ground. Other advantages are that it can work in the ultraviolet and infrared where ground-based observations are currently limited by atmospheric emission and absorption.

Two points must be noted with regard to any proposal that space astronomy might serve as a substitute for lost capability of ground-based optical telescopes. First it is important to remember that astronomy is an observational science rather than an experimental science. It has not always been obvious what the critical observations are or what the best instrument-to-pursue them will be. As a result, the of astronomical facilities has been an important source ofy vitality in research. While astronomy, in space is important and desirable, creating a relatively small number of space factlities as a replacement of impalred ground-based factlities would not preserve this vitality. Second, ground-based observations have historically been used to complement studies made from space. A reduction in ground-based capabilities would compromise the overall scope of research

For aeronomy, space-based observation may be unable to replace lost capability in current grọund-based observations. The brightness of the earth's surface prohibits downward looking observations of faint but important atmospheric emissions.

\subsection{CONCLUSIONS AND RECOMMENDATIONS}

The EMC evaluation has addressed the range of performance effects on electronic equipment and systems, and tested techniques to modify most of these systems to allow operation in the appropriate SPS environments. This evaluation included communications, radar, computers, and sensor systems; applications including common carrier and industrial/transportation/milittary command/control communications, military and transportation radars, scanning and storing sensors used for a wide range of military and resource management operations, medical electronics, and special research support services. Terrestrial, aircraft, and satellite-systems in the cited functional categories were evaluated.

Mitigation techniques were tested for most affected systems, with the goal to allow normal modes of operation within the SPS environment. For terrestrial, alfcraft, and LEO space systems this involves SPS fundamental frequency 1 llumination levels of $1-5 \mathrm{mw} / \mathrm{cm}^{2}, 23 \mathrm{mw} / \mathrm{cm}^{2}$, and $20-100 \mathrm{mw} / \mathrm{cm}^{2} \mathrm{respectively.}$ The ranges for LEO systems concern, the differences in orbit altitude (e.g., LANDSAT at $\sim 120 \mathrm{~m} 1 \mathrm{les}$ and GPS at $\sim 11000$ miles altitudes). Successful mitigation methods have been identified for many electronic systems. Radio astronomy receivers represent the most severé constraints in separation distances from rectenna sites, and complexity of functional mitigation techniques.

\subsection{Conclusions}

The conclusions of this EMC program are summarized in the following listing.

1. Most communications, radar. sensor, and computer devices and systems would be unacceptably degraded in performance when located within $20-50 \mathrm{~km}$ of a rectenna site. Mitigation techniques, primarily shielding and signal channel filtering modifications, would allow normal performance for terrestrial system operation with SPS power densities expected at a rectenna exclusion boundary.

2. Separation constraints would be required between rectenna sites and facilities having critical safety criteria, or where mitigation of interference would compromise the performance and operational capability. Nuclear power and research facilities are examples of the former; military operations and test and evaluation facilities are in the latter category (reference Section 6). 
3. Aircraft communications and navigation equipment would be degraded to an unacceptable performance level by exposure to SPS power densities, Including beam center and edge power densities. Effective mitigation includes shielding and filtering, and minor antenna pattern modifications to reduce sensitivity to the vertical SPS power beam.

4. A monitor and control procedure is required for rectenna structure intermodulation emissions, to locate sources and effect repair so as not to cause interference in the HF-UHF spectral regions to terrestrial and afrcraft systems.

5. Sateliftes in LEO can be exposed to power densities in the $20-100 \mathrm{mw} / \mathrm{cm}^{2}$ range depending on orbital altitude. No practical procedures can be identified to assure no LEO orbit will pass through an SPS beam particularly with a full SPS deployment. Shielding and filtering methods can remove effects on sensors and computer/control circuitry, thus eliminating attitude and system command/control impact. Uplink receivers will require desensitization when passing through an SPS power beam to prevent large transient data error blocks from being passed to on-board computers and controllers. This action can readily be provided by a separate recelver channel for $2.45 \mathrm{GHz}$.

Earth viewing sensors should be protected by additional telescope shlelds to prevent SPS power coupling by reflection from LEO satellite components (e.g., solar panels, parabola antennas).

6. Satellites in GEO, if sufficiently separated from the solar power satellite, would not be expected to be affected. This would be true even for satellites in a GEO position opposite (separated by $180^{\circ}$ ) the power satellite. The allowable spacing between a solar power satellite and other satellites in GEO would probably not be less than $1^{\circ}$, but this is based on approximate analyses that will require refinement as the SPS technology develops.

7. Scattered sunlight from SPS would, unless reduced substantlally below levels expected from the Reference System ( $4 \%$ diffuse albedo), have a harmful effect on optical astronomy and other scientific observations requiring dark night skies.

Thermal microwave emissions from SPS photovoltaic arrays may have some effect on satelitte communications, radio astronomy and deep space research. Extent of the impact depends on the level of such emissions and SPS location.

Radio astronomy receivers represent the most complex area for interference mitigation because of the sensitivity and wide spectrum of observations. These facilities probably could not operate within a distance of $150 \mathrm{~km}$ from a rectenna site. Signal channel filtering is not generally acceptable because of the increased receiver noise temperature.

\subsection{RECOMMENDATIONS}

If the SPS concept is to be pursued further, the following ef forts are recommended either to provide data needed for a more complete and firmly based EMC Assessment or to examine ways to mitigate antic1pated problems. As part of any future design program, obtain data and include interference analyses and mitigation evaluation of the SPS which are important to EMC concerns:

a. Determine the levels of spurious emissions from the MPTS. This will require construction and testing of important representative components and subsystems such as spacetenna and rectenna modules, control components, and power amplifier systems.

b. Evaluate the potential for electromagnetic emissions from other components of the SPS, e.g., generation of intermodulation components in rectenna and satellite structures or electronic systems, or radiation from control electronics.

c. Refine estimates of reflected 1ight, both diffuse and specular components, from all space components of the SPS including LEO construction facilities.

d. Testing of susceptibility of electronic equipment to. SPS microwave flelds and of mitigation techniques.

e. Test the effects of strong out-of-band signals on sensitive recelving systems as used in satellite communication and radio astronomy, and mitigation techniques. 
f. Include effects of the atmosphere on the SPS microwave power beam to assure electromagnetic compatibility.

g. Any SPS design and development program should continue to emphasize minimization of emission characteristics for harmonics and spurious components, and optical reflections and thermal emisstons. 


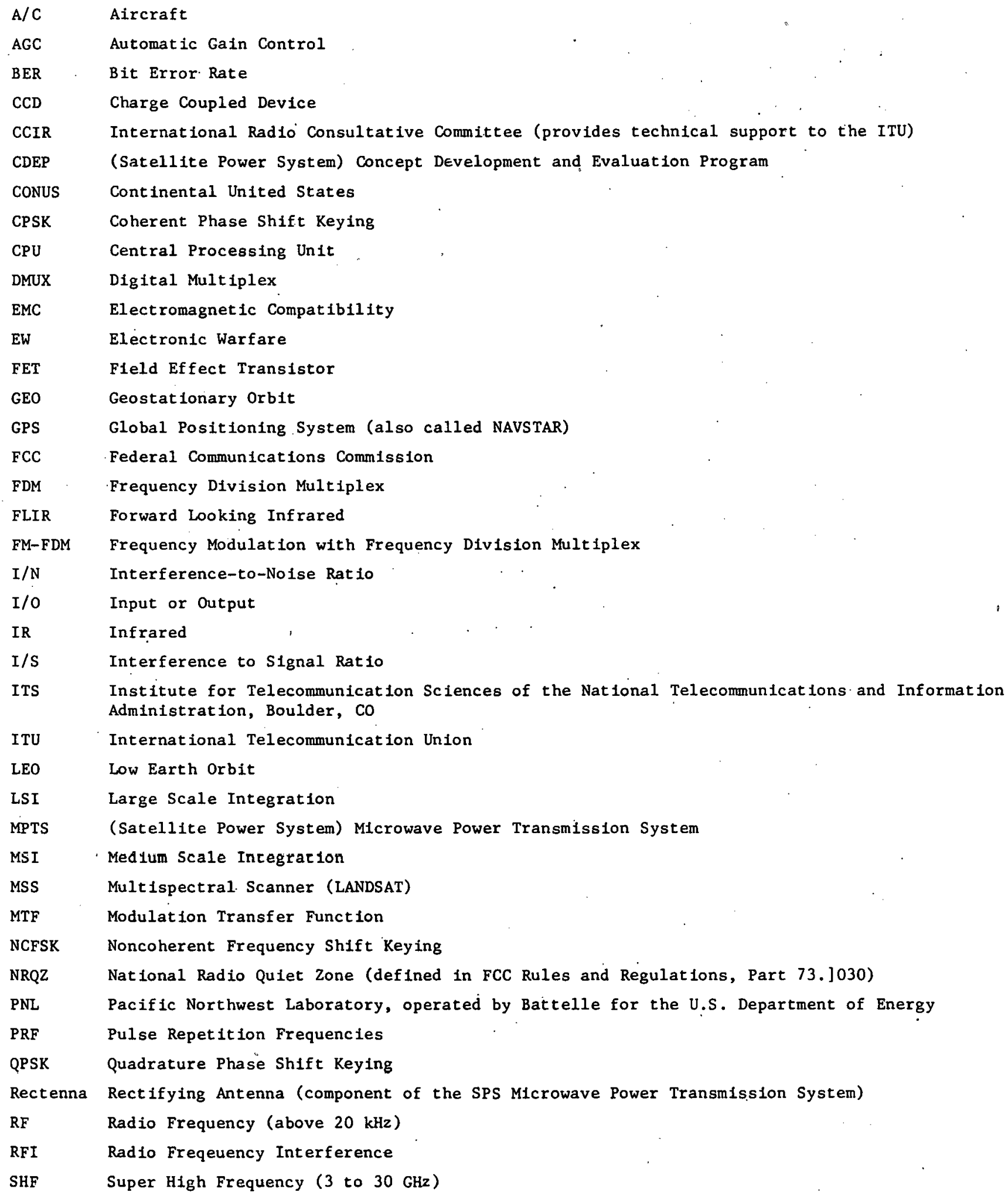




$\begin{array}{ll}\text { S/I } & \text { Signal to Interference Ratio } \\ \text { S/N } & \text { Signal to Noise Ratio } \\ \text { SPS } & \text { Satellite Power System } \\ \text { TDMA } & \text { Time-division, Multiple-access } \\ \text { TDRSS } & \text { Tracking and Data Relay System Satellite. (NASA) } \\ \text { TM } & \text { Thermatic (or Thermal) Mapper (LANDSAT) }\end{array}$


1

REFERENCES

Arndt, G. D. and L. Leopold, "Environmental Considerations for the Microwave Beam from a Solar Power Satellite," 13th Intersoclety Energy Conversion Engineering Conference, San Diego, CA (August 1978), reprinted in Append1x E of CONF-7905143 (1980).

Bargellin1, P. L., "The Intelsat IV Communicat1on System;" COMSAT Technical Review, Vol 2, No. 2, pp 437-572. (1972).

Batson, B. H., S. W. Novosad, and T. W. Sheehan, "Space Shuttle Ut1lization of TDRSS Services," IEEE NTC'77, Conference Record, Vo1 1, pp 09:4-1, 09:4-5 (1977).

Blackburn, J. B. Jr. (1980), Eligible Areas for REctenna Siting", Rice University.

Boeing D180-26019-1, "Population Exposure Estimates for a Mult1-Solar Power Satellite Configuration," Boeing Aerospace Company, Seattle, WA. 30 May 1980.

Bonney, C. H., P. L. Rustan, Jr., and G. Ford, "Evaluation of Effects of the Microwave Oven ( 915 and $2450 \mathrm{MHz}$ ) and Radar (2810 and $3050 \mathrm{MHz}$ ) Electromagnet1c Radiation on Non-Competitive Cardiac Pacemakers," IEEE Trans. on Biomedical Englneering, Vol BME-20, No. 5, 19.

CCIR Recommendation 365-3, "Frequencles, Bandwidths and Protection Criteria for Manned and Unmanned Deep-Space Research," International Rad1o Consulțative Comm1ttee, XIVth Plenary Assembly, Vo1 II, Kyoto, Japan, pp 144-146 (1978) (reprinted in Append1x B of CoNF-7905143).

CCIR Report 223-4, "Line Frequencles, Arising from Natural Phenomena, of Interest to Radioastronomy and Related Sciences," International Radio Consultative Committee, XIVth Plenary Assembly, Vol II, Kyoto, Japan, pp 365-386 (1978) (reprinted in Append1x A of CoNF-7905143).

CCIR Report 224-4, "Characteristics of the Radioastronomy Service, and Interference Protection Criteria," International Radio Consultative Committee, XIVth Plenary Assembly, Vol II, Kyoto, Japan, pp 387-400 (1978) (reprinted in Append1x A of CONF-7905143).

CCIR Report 387-3, "Protection of Terrestrial Line-of-Sight Rad1o-Relay Systems against Interference due to Emissions from Space Stations in the Fixed Satellite Service in Shared Frequency Bands between 1 and $23 \mathrm{GHz}$," International Radio Consultative Committee, XIVth Plenary Assembly, Vo1 IX, Kyoto, Japan (1978).

CCIR Report 391-3, "Radiation Diagrams of Antennae for Earth Stations in the Fixed Satellite Service for Use in Interference Studies and for the Determination of a Design Objective," International Radio Consultative Committee, XIVth Plenary Assembly, Vol IV, Kyoto, Japan (1978).

CCIR Report 558-1, "Satel11te Antenna Patterns in the Fixed Satel11te Serv1ce," International Radio Consultative Committee, XIVth Plenary Assembly, Vol IV, Kyoto, Japan, pp 243-262 (1978).

CCIR Report 685. "Protection Criterła and Sharing Considerations Relating to Deep-Space Research," International Rad1o Consultat1ve Committee, XIVth Plenary Assembly, Vol II, Kyoto; Japan, pp 158-166 (1978) (reprinted in Appendix B of CONF-7905143).

CCIR Report 713, "The Radiation of Spurious Emissions from Earth Stations and Space Stations of the Fixed Satellite Service," International Radio Consultative Committee, XIVth Plenary Assembly, Vol IV, Kyoto, Japan, pp 307-313 (1978).

CCIR Report 719, "Attenuation of Atmospheric Gases," International Radio Consultative Committee, XIVth Plenary Assembly, Vo1 V, Kyotu, Japan (1978).

CONF-7905143, see "Workshop on Satell1te Power Systems (SPS) Effects on Optical and Radio Astronomy."

Denney, H. W., B. M. Jenkins, and J. C. Toler, "Behavior of Card1ac Pacemakers 1n Pulsed Fields," Paper given at the IEEE International Symposium on Electromagnet ic Compatibility, Seattle, WA (August 1977).

- Ditton, V. R., "Coupling to Aerospace Cables at Microwave Frequencies," IEEE EMC Symposium, San Antonio, TX, pp 4BIcl-6 (1975). 
DOE/ER-0023, see "Reference System Report."

Environmental Assessments: the results of the Environmental Assessment of the SPS CDEP. w111 be summarized in six reports, an integrated Environmental Assessment report:

ENVIRONMENTAL ASSESSMENT for the SATELLITE POWER SYSTEM - CONCEPT DEVELOPMENT and EVALUATION PROGRAM.

and five individual task reports:

ENVIRONMENTAL ASSESSMENT for the SATELLITE POWER SYSTEM - CONCEPT DEVELOPMENT and EVALUATION PROGRAM - MICROWAVE HEALTH and ECOLOGICAL EFFECTS.

ENVIRONMENTAL ASSESSMENT for the SATELLITE POWER SYSTEM - CONCEPT DEVELOPMENT and EVALUATION PROGRAM - NON MICROWAVE HEALTH and ECOLOGICAL EFFECTS .

ENVIRONMENTAL ASSESSMENT for the SATELLITE POWER SYSTEM - CONCEPT DEVELOPMENT and EVALUATION PROGRAM - ATMOSPHERIC EFFECTS.

ENVIRONMENTAL ASSESSMENT for the SATELLITE POWER SYSTEM - CONCEPT DEVELOPMENT and EVALUATION PROGRAM - EFFECTS OF IONOSPHERIC HEATING ON TELECOMMUNICATIONS.

I

ENVIRCNMENTAL $\Lambda$ SSESSMENT for the SATELLITE POWER SYSTEM - CONCEPT DEVELOPMENT and EVALUATION PROGRAM - ELECTROMAGNETIC SYSTEMS COMPATIBILITY (this report).

Federal Communications Commission Rules and Regulations, Vo1 III, Section 73.1030, "Nat1onal Radio Quiet Zone Specifications," (1976, regularly updated).

Grant; W. B, E. L. Morrison, and E. J. Dutton (1980), "Electromagnetic Compatibility Analysis for a Satellite Power System Recelving S1te in the Mojave Desert", Prepared for: U.S. Department of Energy, Satellite Power System Project Office, Washington, D. C. 20545.

Huhta, J. C., and J. G. Webster, "60-Hz Interference In Electro-Cardiography," IEEE Trans. on Biomedical Engineering, Vol BME-20, No. 2 (1973).

International Telecommunication Union Radio Regulations, published by the General Secretariat of the ITU, Geneva (Edition of 1976).

Jacobs, Ernest (1963), Fresnel Region Power Transfer, Electromagnetic Theory and Antennas, ed. E. C. Jordan, (The MacMillan Co., New York), pp 1051-1075.

Jenkins, B. M., and J. A. Woody, "Cardlac Pacemaker Responses to Power Frequency Signals," Paper given at the IEEE EMC Symposium, Atlanta, GA (1978).

Lassiter, Edward M., and Col. Bradford Parkinson, U.S.A.F., "The Operational Status of NAVSTAR/GPS," Journal of Navigation, No. 1, pp 35-41 (1977).

Liebe, H. J. (1980), "Fleld Maxima Inside Habitable Structures Exposed to 2.45 GHz Plane Wave Radiation", U.S. Department of Commerce, National Telecommunications and Information Administration, NTIA Report 80-49, October.

Milliken, R. J., and C. J. Zeller, "Principle of Operation of NAVSTAR and System Characteristics," Navigation Journal of the Institute of Navigation, Vol 25, No. 2, Pp 75-105 (1978).

Mitchell, J..C., and W. D. Hurt, "The Blological Significance of Radio Frequency Radiation Emissions on Cardiac Pacemaker Performance," Symposium on Blological Effects of Electromagnetic Waves, at the USNC/URSI Meering ae Boulder, Cú. Vol Ti, HEW (FDA) 77-8011 (Úctober 20-23, 1975).

Ott, R. H., and H. B. Janes, "A Comparison of Ralnfall Attenuation Models," to be published as an NTIA Technical Memorandum.

Ott, R. H., E. L. Morrison, and W. B. Grant, "Antenna Patterns for the Solar Power Satellite," NTIA-TM-79-5, U. S. Department of Commerce, National Telecommunications and Information Administration, (January 1979).

Poza, H. B., "TDRSS Telecommunlcations Payload: An Overvlew," IEEE NTC'77 Conference Record, Vol 1, pp $19: 1-1,19: 1-7$ (1977). 
"Reference System Report," Satellite Power System Concept Development and Evaluation Program, DOE and NASA, DOE/ER-0023 (October 1978).

Roe, James M., "Microwave Interference Effects in Integrated Circuits," IEEE EMC Symposium, San Antonio, TX, pp 4AIb1-6 (1975).

Skoln1k, Merrill I., Radar Handbook (McGraw-H111 Book Company, New York) pp 29-4, 29-7 (1970).

Thompson, A. R., "The Effects of the Proposed Satellite Power System on the VLA," In CONF-7905143, p 135 (1980).

Wells, P. I., "The Attenuation of UHF Rad1o S1gnals by Houses," IEEE Trans. VT-26 (4), Pp 358-362 (1977).

"Workshop on Satell1te Power Systems (SPS) Effects on Optical and Radio Astronomy," Satell1te Power System Concept Development and Evaluation Program, DOE and NASA, CONF-7905143, Edited by P. A. Ekstrom and G. M. Stokes (April 1980).

$\therefore$ U.S. GOVERNMENT PRINTING OFFICE: $1981-341-060: 396$ 
United States

Department of Energy

Washington, D.C. 20585
THIRD - CLASSMAII POSTAGE \& FEES PAID U.S. DEPT. OF ENERGY

PERMIT NO. G 20

THIRD CLASS M?

Official Business

Penalty for Private Use, $\$ 300$ 